\title{
A Critical Analysis of Apprenticeship Programs in British Columbia
}

\author{
by \\ Gregory Matte \\ A thesis submitted to the Faculty of Graduate and Postdoctoral Affairs \\ in partial fulfillment of the requirements for the degree of \\ Doctor of Philosophy \\ in \\ Public Policy \\ Carleton University \\ Ottawa, Ontario \\ (C) 2020 \\ Gregory Matte
}




\section{Abstract}

This study examines issues surrounding apprenticeships in the construction industry in British Columbia (BC) during the period of 1993 to 2004, particularly the state of the social settlement amongst its primary stakeholders, namely the government, unionized and non-unionized employment associations and postsecondary colleges. It provides a conceptual framework to research apprenticeships as a skills ecosystem, and to explain why successive provincial governments were motivated to impose significant legislative changes on the vocational education and training system. The findings not only examine the motivation, but also the resulting outcomes, using the different political ideologies as a basis to explain how contrasting stakeholder perspectives shaped both. Based on a combination of structure and agency, the primary stakeholders operated within the confines of institutional structures, extant logics and the limitations of their own perspectives and objectives.

This thesis examines how the relationships between apprenticeships, the labour market and the post-secondary education system are coordinated, governed, influenced and shaped in $\mathrm{BC}$, as well as how these same relationships have evolved, including the impact of such changes on apprenticeship programs as a skills ecosystem. The period of 1993 to 2004 was specifically chosen as it was a period of bold political reforms pertaining to trades training within the province by two ideologically opposed political parties. The research design applies a case study 
methodology, comparing the differences between these two governments, as well as process tracing, within the theoretical framework of historical institutionalism.

The findings demonstrate that apprenticeships are a unique skills training ecosystem that typify an employment logic, but are nestled within a broader vocational education system that is typified by an education logic. The exogenous market forces of Canada's liberal market economy, as well as the predominant education logic typified by BC's post-secondary education system, were found to contribute to the stakeholder tensions and resulting pressures on apprenticeships as a unique skills ecosystem.

These pressures contributed to a weakening of collaboration amongst the primary stakeholders during the research period, rather than convergence towards supporting different government legislative initiatives. The findings demonstrate the influence of the provincial government in affecting (for better or worse) outcomes on post-secondary programs involving multiple stakeholders and multiple institutions, thereby highlighting the need for strategic government leadership that rises above partisan interests. While both the New Democratic Party (NDP) and Liberal governments stated an interest in improving apprenticeships, particularly achieving higher completion rates, they allowed partisan interests to undermine these objectives at the expense of the apprentices themselves. 


\section{Acknowledgements}

It is with tremendous humility that I conclude this thesis and the accompanying doctoral studies that have pre-occupied me for over a decade on a part-time basis. This accomplishment in many ways is a tribute to my father, Roland Gerald Matte, who was gifted a brilliant mind and incredible inquisitiveness, but whose circumstances (as the oldest of 16 children) was denied a formal education beyond Grade 8. His auto-didactic spirit of continuous learning and the value of knowledge provided a meaningful basis for the time, effort and sacrifice that my own $\mathrm{PhD}$ efforts required. I would be remiss not to attribute this achievement to my mother, Marlene Glenora Richards (née Morse) who provided the same love, encouragement and pride in my doctoral studies that she provided me throughout my academic "upbringing".

To my children, Natasha Karin Nicole Matte and Joshua Nicholas Kristian Matte, I dedicate this monumental effort to you as my determination to provide you leadership by example, and to demonstrate that there are no insurmountable goals in life, nor any age limitation to achieving both self-actualization as well as a meaningful contribution to mankind. To my former wife Lori Wickert, I express my appreciation for her many helpful tips and continuous support in this endeavour. To my partner Sandra Lynn Heggie, I express my tremendous appreciation for her incredible patience, understanding, support and motivation to complete my thesis. 
Finally, I would be remiss not to thank my committee (Professor Leslie Pal and Professor José Galdo) and my co-advisors (Professor Calum Carmichael and Professor Leesa Wheelahan) for their commitment, support and guidance throughout my thesis efforts over the past four years. Finally, a very special thank-you to Professor Wheelahan for her belief in me, her unfailing support throughout my academic apprenticeship and for welcoming me into her international community of scholars whose academic interests are focused on vocational education and training. 


\section{Table of Contents}

Abstract

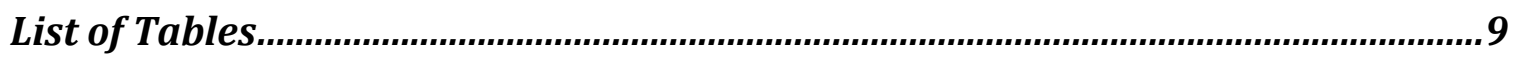

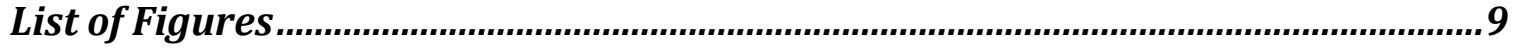

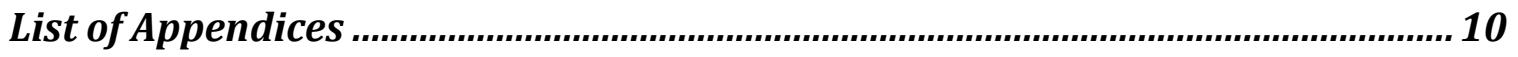

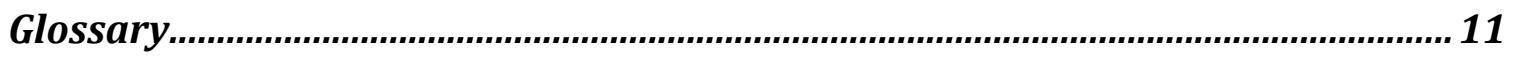

Chapter 1: Introduction ...................................................................................... 12

Background to the Selection of the Research Case Study............................................... 16

Focus of the Research ............................................................................................... 22

Research Questions.......................................................................................................... 24

Chapter 2: Vocational Education Training in British Columbia............................26

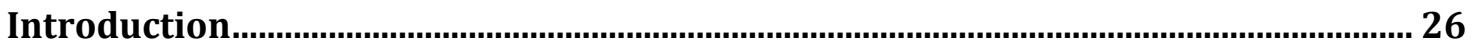

Origins of Apprenticeships.............................................................................. 27

Origins of Apprenticeships and Trades Training in BC.......................................................................30

Institutionalization of VET within the Post-secondary Education System ............................................36

Divergence - Apprenticeship Skills Ecosystem within the Broader VET System ...............................40

Attempts to Rectify Bureaucratic Overlap between Ministries............................................................42

Examining Apprenticeships as a Unique Form of VET ………...................................... 46

The Apprenticeship Process for Earning the Certificate of Qualification .................................................50

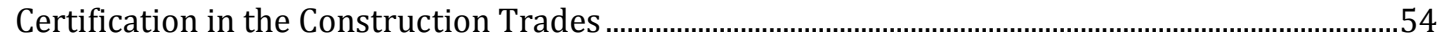

Primary Stakeholders in Apprenticeships in BC.....................................................................................58

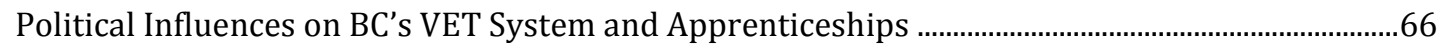

Summary ........................................................................................................................... 72

Chapter 3 - Problematizing and Conceptualizing the Apprenticeship Skills

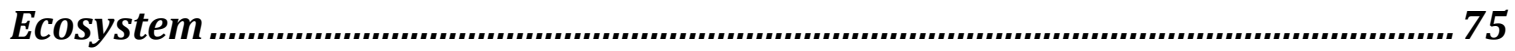

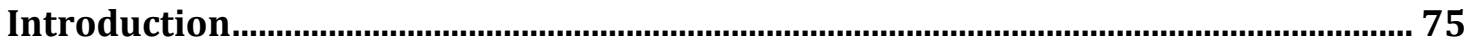

Developing a Conceptual Framework ………………….................................................. 76

Conceptualizing Apprenticeships as a Skills Ecosystem............................................... 78

Problematizing the Situation for a Theoretical Analysis ................................................ 81

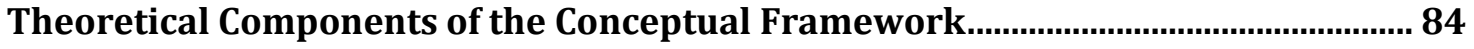

Historical Institutionalism ........................................................................................................................8

Varieties of Capitalism.............................................................................................................................................89

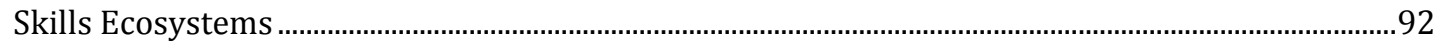

The tension between the Education and Employment Logic.......................................................................96

The Tension between the Intrinsic and Institutional Logic ...................................................................98

The Conceptual Framework - Integrating the Theories and Models........................... 99 


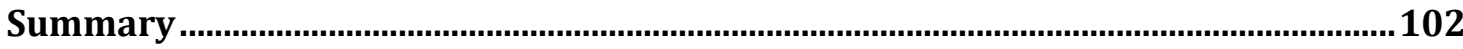

Chapter 4: Research Design and Methodology .............................................104

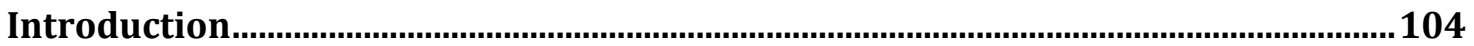

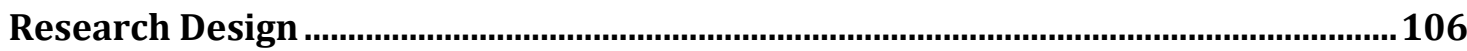

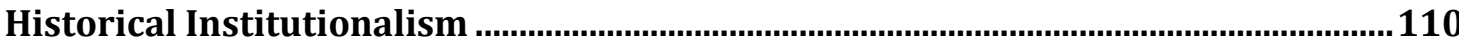

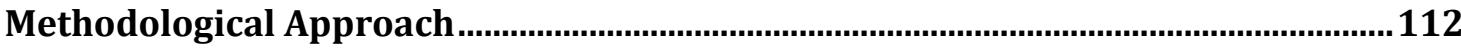

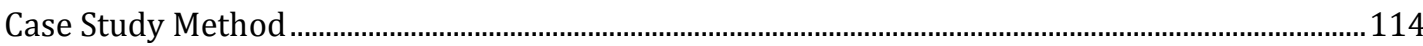

Process Tracing Method ............................................................................................................................

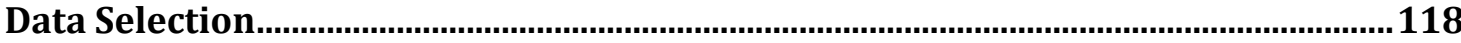

Interviewee Selection Framework

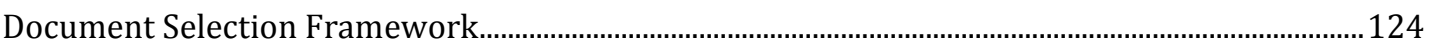

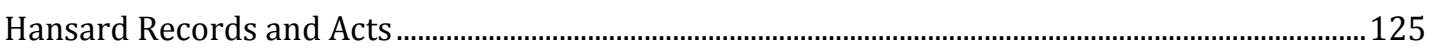

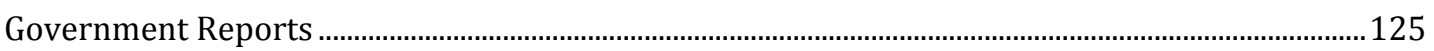

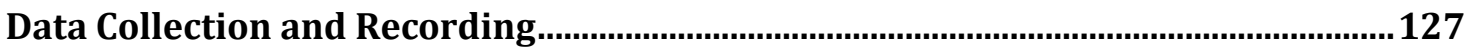

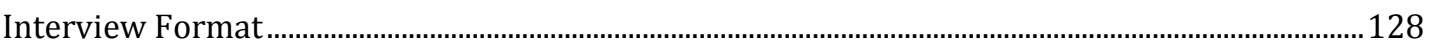

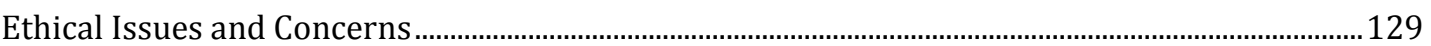

Data Organization, Coding and Interpretation .........................................................130

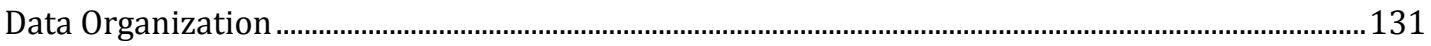

Inductive Organization - Principal Themes.........................................................................................132

Data Coding Process ………………………………………...................................................................135

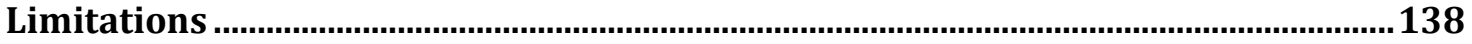

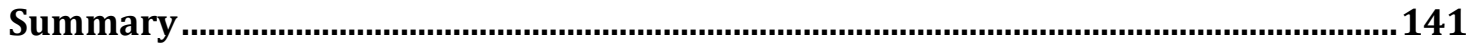

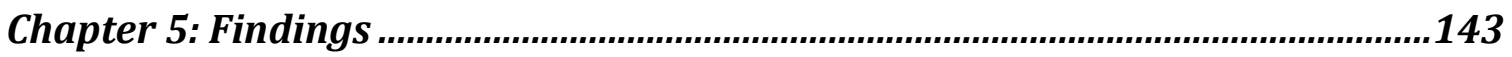

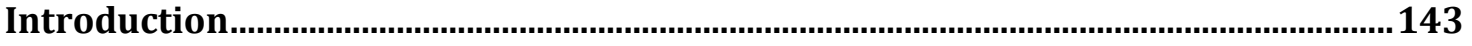

Two Different Governments - Two Different Approaches....................................................................144

Overview of BC's Economy $(1993$ - 2004) ...................................................................................... 145

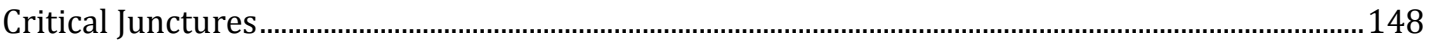

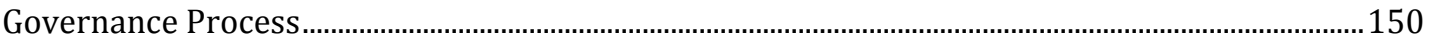

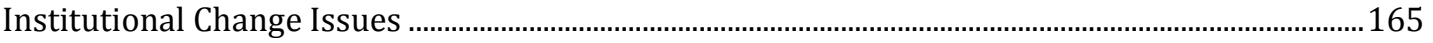

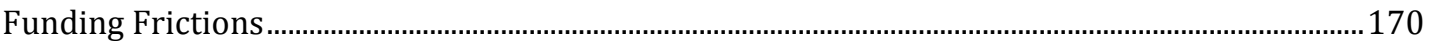

Training, Certification and Regulatory Implications..............................................................................178

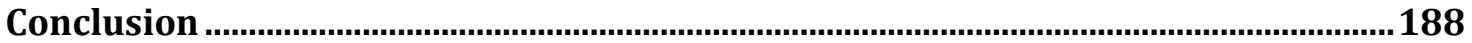

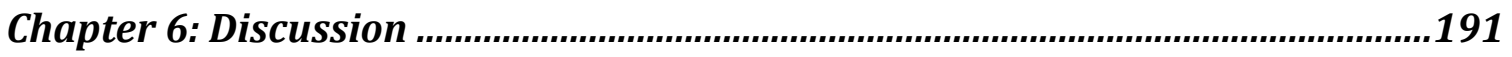

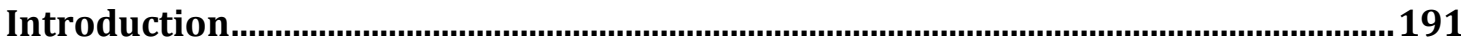

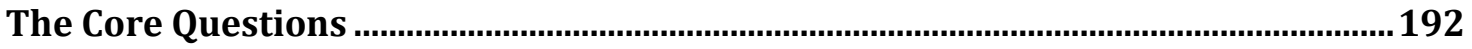

Historical Context - A Basis for Interpreting the Elements of Change ......................192

Discussion of the Findings in Answering the Core Research Questions ................... 193

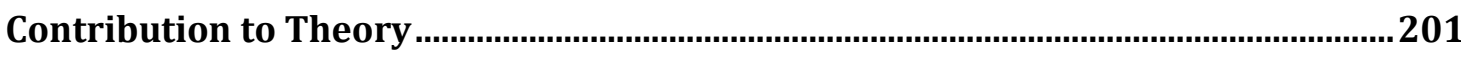

Evaluation of the Conceptual Framework …....................................................................202 


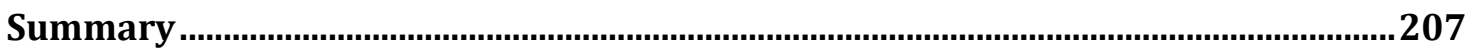

Chapter 7: Conclusions and Recommendations .................................................210

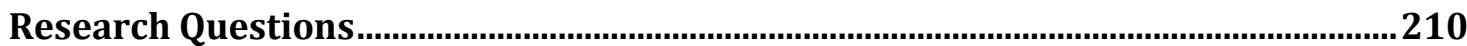

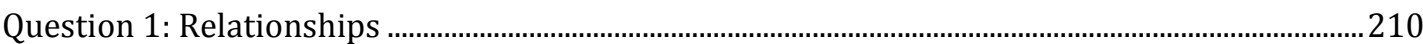

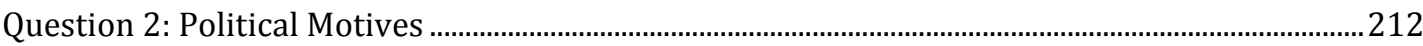

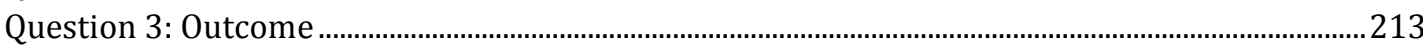

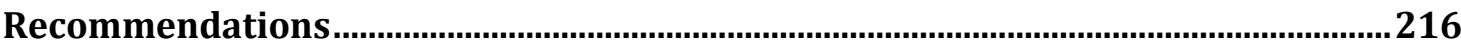

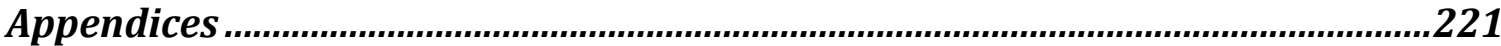

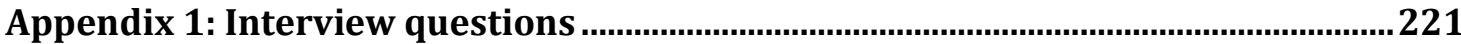

Appendix 2: Colour-coded spreadsheet integrating themes with analysis ...............224

Appendix 3: Chronology of key legislative initiatives in BC (up to 2004) .................227

Appendix 4: Former Premiers of BC (1986 - 2011) ...................................................... 231

Appendix 5: Ministers of post-secondary education in BC (1986 - 2010).................232

Appendix 6: Ministers of labour / employment in BC (1986 - 2010) ........................... 233

Appendix 7: Apprenticeship Outcomes on the BC Economy .........................................234

Appendix 8: The Value of Coordination Mechanisms - Examining the Joint Apprenticeship Training Committee (JATC) Model ........................................................ 247

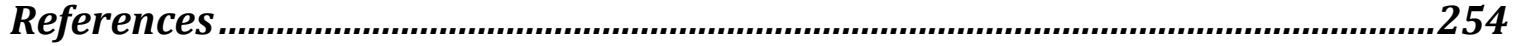




\section{List of Tables}

Table 1: Distribution of employer sponsors in BC (circa 1995) ...................................... 44

Table 2: Apprenticeship registration in BC ........................................................................ 50

Table 3: Framework for selection of interviewees ..........................................................123

Table 4: Overview of documents selected ........................................................................126

Table 5: Comparison of BC's NDP and Liberal governments (1993 - 2004) ..............145

Table 6: Legislative critical junctures (1993 - 2004)......................................................150

Table 7: Funding allocations for VET and apprenticeships in BC .................................177

Table 8: Projected differences between ITAC and the new ITA ...................................185

\section{List of Figures}

Figure 1: Percentage of apprentices in compulsory trades, by trade group ................ 57

Figure 2: Key trades training stakeholders ……………………………………………... 60

Figure 3: Visual depiction of conceptual framework ......................................................101

Figure 4: Distribution of BC construction companies by size .......................................238

Figure 5: New apprentice registrations versus employment (BC construction)......241

Figure 6: Apprenticeship completion rates (2000 - 2003 and 2004 - 2014) .............243

Figure 7: Comparison of completion rates ……………………………………….....251 


\section{List of Appendices}

Appendix 1: Interview questions.........................................................................221

Appendix 2: Colour-coded spreadsheet integrating themes with analysis...............223

Appendix 3: Chronology of key legislative initiatives in BC (up to 2004)...............226

Appendix 4: Former Premiers of BC $(1986$ - 2011) ...............................................230

Appendix 5: Ministers of post-secondary education in BC $(1986$ - 2010) ...............231

Appendix 6: Ministers of labour / employment in BC $(1986$ - 2010).......................232

Appendix 7: Apprenticeship Outcomes on the BC Economy ....................................233

Appendix 8: The Value of Coordination Mechanisms - Examining the Joint

Apprenticeship Training Committee (JATC) Model.........................................................246 


\section{Glossary}

BCBTC: British Columbia Building Trades Council

CBT: $\quad$ Competency Based Training

CCDA: $\quad$ Canadian Council of Directors of Apprenticeships

CE0: $\quad$ Chief Executive Officer

CME: $\quad$ Coordinated Market Economy

CQ: $\quad$ Certificate of Qualification

ELTT: $\quad$ Entry Level Trades Training

HI: $\quad$ Historical institutionalism

ICBA: Independent Contractors and Businesses Association

ITA: Industry Training Authority

ITAC: Industry Training and Apprenticeship Commission

ITO: Industry Training Organization

JATC: Joint Apprenticeship Training Committee

LME: $\quad$ Liberal Market Economy

NDP: $\quad$ New Democratic Party

PAB: $\quad$ Provincial Apprenticeship Board

PSE: $\quad$ Post-Secondary Education

RAIS: $\quad$ Registered Apprenticeship Information System

TDA: $\quad$ Training Delivery Agency

VET: $\quad$ Vocational Education and Training

VoC: $\quad$ Varieties of Capitalism 


\section{Chapter 1: Introduction}

The objective of this thesis is to explain the underlying puzzle behind this research, namely the desire to understand the evolution of the apprenticeship programs within the broader vocational system in British Columbia (BC) during the period of 1993 to 2004, and to explain why successive provincial governments intervened in apprenticeships in $\mathrm{BC}$ during this period.

The approach to explaining this puzzle includes an examination of the state of the social settlement and the lack of consensus amongst its primary stakeholders, including the outcomes that resulted from a series of legislative initiatives that transpired during this timeframe in which the New Democratic Party (NDP) held power from November 1991 to June 2001, and the Liberals from June 2001 until July 2017. The underlying drivers for this research is to understand and explain the evolution of the apprenticeship programs within the broader vocational system in BC. Fundamental questions relating to this lack of consensus require a deeper analysis as to whether the apprenticeship system in $\mathrm{BC}$ is conceptualized as a production system designed to meet near-term labour requirements, an alternative form of post-secondary education to that of university or college studies, designed to prepare individuals for a career in the trades sector of the broader work force, or a blend of both divided in overall purpose. 
The decades preceding the research period, along with the case study opportunity to examine the results of different government ideologies, raises several interrelated questions that beg a solution. Such a solution could explain the logic shaping the relationship between vocational education and training (VET) system, the labour market and the provincial government.

Overall during the research period, the apprenticeship system itself was subject to the influence of four principal stakeholders: the provincial government; VET training providers through provincially certified Training Delivery Agencies (TDAs); and unions and employer associations. More specifically, the provincial government was frequently represented by two different ministries ${ }^{1}$ and their active representation in the Industry Training and Apprenticeship Commission (ITAC) and later the Industry Training Authority (ITA), both of which provided governance and administration over apprenticeship programs. While there were a number of TDAs during the research period, including private training institutions accredited for apprenticeship training and public colleges, the primary actor was the British Columbia Institute of Technology (BCIT) given its size, the scope of VET provided, and its political influence as a major employer in the heavily populated lower mainland.

\footnotetext{
1 The Ministry of Labour and the Ministry of Advanced Education, Skills and Training (which had a variety of names over the years, but during the research period, it represented the post-secondary school system).
} 
The remaining two primary stakeholders were ideologically opposed in their view of apprenticeships and in terms of how they viewed the government's role. While the unionized sector was composed of many different organizations, the focus for this research was the British Columbia Building Trades Council (BCBTC) which was closely aligned with the NDP in terms of their political views and mutual support in achieving their respective objectives. From the "open shop" non-unionized sector, the primary organization considered in this study was the Independent Contractors and Businesses Association (ICBA), which was very active in the construction industry in $\mathrm{BC}$, and closely aligned with the Liberal government. For the remainder of this thesis, any further reference to the "primary stakeholders" will refer to the two provincial ministries, the BCIT, the BCBTC and the ICBA.

For the purpose of this study, the term "social settlement" (Wheelahan, 2015) is defined as the degree of collaboration amongst these primary stakeholders in balancing their self-interests in apprenticeships with the overall benefits of the apprenticeship programs for apprentices and BC's economy. The starting point from a research perspective is the opposing ideologies of the two political parties (the NDP and the Liberals) and the provincial governments that they formed during the research period. However, while the opposing ideologies and the legislative reforms that were applied by these two governments were catalysts to changes in apprenticeship programs, they do not adequately explain the underlying factors that were weakening the social settlement. Rather, it appears that there existed longstanding institutional issues pertaining to the role of apprenticeships within BC's 
post-secondary education (PSE) system and the value of the associated qualifications of trades workers. These institutional issues appeared to confound the situation thereby undermining the achievement of positive improvements through legislative initiatives. The resulting tensions this imposed on the social settlement, and the impact this had on the interpretation, implementation and success of the legislative reforms is a central focus of this research.

Within Canada, apprenticeship programs as with all other forms of VET fall under the jurisdiction of provincial governments. Amongst all the jurisdictions in Canada, $\mathrm{BC}$ provided a compelling case study for research due to the level of interest and legislative reform efforts directed towards apprenticeships during the research period, as well as the fact that it involved two successive governments of significantly opposing political ideologies and perspectives on trades training. Of particular interest was the initiative to eliminate compulsory trades, effectively deregulating the labour market for skilled tradespeople in BC. While both governments acknowledged the importance of skilled trades workers to meet industry requirements in $\mathrm{BC}$, their legislative initiatives did not demonstrate a comprehensive explanation of the uniqueness of apprenticeships as a skills ecosystem within the much broader VET system.

This thesis examines the apprenticeship system in $\mathrm{BC}$ on a conceptual basis to identify the underlying problems that manifested in the persistent shortcomings of the system's effectiveness (in terms of apprenticeship completion rates), despite the 
legislative initiatives of two different governments. These shortcomings were typically expressed in terms of the annual production of skilled workers (i.e. apprenticeship completion rates). Disappointment in the apprenticeship system was also expressed as part of a broader narrative relating to shortfalls in meeting the requirements of BC's construction industry (and other skilled trades sectors) in terms of training delivery, skill sets and qualifications. As described in the next section, these same shortcomings continued to manifest themselves in $\mathrm{BC}$ for many years after 2004 suggesting that the underlying problems pertaining to the weakening of the social settlement amongst the primary stakeholders, remain either unrecognized or underestimated.

The remainder of this chapter will address these shortcomings in terms of the research questions pertaining to the underlying factors negatively impacting the social settlement, the intended approach to answer these questions, and how the results of this research will contribute to existing literature pertaining to VET and potential improvements to the apprenticeship system in BC.

\section{Background to the Selection of the Research Case Study}

In 2014, then Premier Christie Clark proclaimed the need to revamp the apprenticeship system in BC in her government's plan entitled B.C.'s Skills for Jobs Blueprint: Re-engineering Education and Training. The impetus for this plan was to ensure the province would be well positioned to respond to the anticipated demand 
for skilled workers in the coming decade, in part due to the potential development of liquid natural gas facilities and other major construction projects in $\mathrm{BC}$ such as pipelines, bridges and other infrastructure upgrades. Another major factor was the inevitable retirement of the remaining baby boomer workers, supervisors and instructors who were still active in the workforce (Clark, 2014).

The Premier's blueprint was the culmination of several related government strategies focusing on job creation, strengthened infrastructure, expanded market access and strong economic growth within the province. A skilled workforce was identified as a core requirement for building an improved skilled trades training system as a key enabling function for advancing these strategies. In June 2013, the Minister of Jobs, Tourism and Skills Training was given the mandate to undertake the review, focusing on the roles and responsibilities of the ITA, the crown agency responsible for the administration of the VET system for skilled trades training in BC. The subsequent report to the Minister, entitled The Industry Training Authority and Trades Training in BC: Recalibrating for High Performance, provided a thorough review of the ITA complete with numerous findings and recommendations (McDonald, 2014).

This report and Premier Clark's subsequent Blueprint plan follow earlier attempts to introduce policy reforms to the VET system over the previous decades in BC, with a focus on improving the system to meet industry requirements. Given that the Liberals had been in power in BC since 2001, it is useful to go back in time to see 
how a different government viewed the training system, and how they sought to reform it. As previously stated the period of 1993 to 2004 is used for this case study as it spans two different governments and multiple legislative initiatives aimed at improving the VET system.

During the period being researched, legislative reforms focused on improving the VET system in general and apprenticeship programs in particular, as well as on regulations surrounding employment practices and certification requirements for the skilled trades. The objectives of these reforms were to meet industry requirements for skilled labour, particularly in the construction industry. However, the impact of these legislative reforms was subject to the institutions engaged in the VET, and the associated challenges of implementing such reforms while continuing to administer programs. Furthermore, the relative influence of the primary stakeholders in apprenticeships was determined by their relationship with the government in power and the structure of the governance mechanisms put into place to oversee the administration of the VET system. The resulting tensions this imposed on the social settlement, and the impact this had on the interpretation, implementation and success of the legislative reforms is a central focus of this research.

Viewed from a conceptual perspective, apprenticeship programs in BC constitute a unique skills ecosystem within a broader VET system, with links to both the education system (supply side of new apprentices) and the labour market (demand 
side for skilled trades workers). As such, apprenticeships can be conceptualized as being part of a system of systems that includes the transition systems (policies, programs, networks and support mechanisms) into and out of apprenticeship programs. Unlike university degrees, college programs and most other forms of VET, apprenticeships are a unique form of skills training in that they require their students (apprentices) to operate within both the PSE system as well as the labour market as they progress towards achieving their trade qualification.

Upon completion of their Journeyperson certificate of qualification (CQ), an apprentice will have accumulated thousands of hours of supervised work experience in addition to various block periods of concentrated VET within an accredited training institution. The dual components of VET and work experience provide graduates of apprenticeship programs with a combination of knowledge, skills and workplace experience that are attractive to employers and valuable to Journeypersons in terms of employability and wages. However, these same dual components require apprentices to switch back and forth between the VET system and supervised work periods under an indentured arrangement with an employer or employer association (such as with the BCBTC) that can lead to significant challenges for the apprentice, especially in the absence of support and coordination mechanisms.

Understanding the components of apprenticeship programs as a skills ecosystem within the broader VET system requires an explanation of the interests of the 
primary stakeholders who actively engage in shaping the apprenticeship system, including its training requirements and occupation certifications. Given the complexities of the system of systems and the dynamics of the social settlement amongst the primary stakeholders, it is useful to conceptualize the system in terms of existing theoretical frameworks and pairs of logic. From a policy-making perspective, these same complexities suggest that any legislative initiatives designed to achieve specific outcomes should take a comprehensive approach to explain the system of systems to mitigate any undesirable unexpected outcomes.

At the highest level, Hall and Soskice's (2001) Varieties of Capitalism (VoC) theoretical typology provides a framework to compare national VET systems while ascribing the associated level of coordination/mediation between the training / education systems and industry in different types of market economies. The VoC typology characterizes countries in Northern Europe as coordinated market economies (CMEs) and Anglophone countries (which include Canada) ${ }^{2}$ as liberal market economies (LMEs). Iannelli and Raffe (2007) provide a theoretical framework to and apply the concepts of employment and education logics to explain how relationships are mediated between the education system and the labour market within CMEs and LMEs. They argue that CMEs tend towards an employment logic, where VET programs are positively supported through well-established connections with the labour market. This support system is built upon strong

\footnotetext{
2 Of course, Canada is Francophone as well as Anglophone, but in this instance I am including Canada in the 'club' of Anglophone liberal market economies.
} 
networks of relationships between social partners (stakeholders) that cooperate in managing and coordinating the system, and in matching graduates to career opportunities in the skilled trades.

By contrast, Iannelli and Raffe (2007) argue that LMEs tend towards an education logic, where VET programs have weak links to the labour market given that the primary focus of the PSE system is to provide students with pathways to achieve generalized academic credentials. Consequently, VET programs within LMEs tend to be seen as less desirable career paths, and left for those who are less academically inclined or capable. Furthermore, within the VoC typology, LMEs demonstrate a preference for less regulation and greater competition in the market (P. A. Hall \& Soskice, 2001) for new graduates of the VET system entering the skilled trades sectors such as construction.

Wheelahan and Moodie (2017) have postulated that while LME countries such as Australia are characterized as being predominantly influenced by an education logic, including between the VET system and the labour market, their apprenticeship system tends more towards an employment logic, thereby setting it apart as a unique subset of the broader VET system. So, tendencies towards an education and employment logic exist in one system in tension with each other, with the former stronger than the latter in those systems. They apply the theories relating to skills ecosystems to make this argument (Buchanan et al., 2001), 
although they do so more in terms of differences within nations between industries and / or between regions.

\section{Focus of the Research}

The framework applied here to conceptualizing the VET system and the stakeholder relationships also serves as a guide to the research design and methods, as well as to the subsequent analysis and interpretation of the findings. The focus of the research is to explain the way in which relationships between apprenticeship programs, the labour market and the PSE system were (are) mediated in BC. Apprenticeships by their very nature are embedded in the labour market because they are based on an employment contract for indentured training, primarily between the employer, the apprentice and provincial agency that formally administers apprenticeships. As highlighted by Cowin (2017) in his research on the evolution of the PSE system in BC, "The apprenticeship component of vocational education has been viewed from a policy perspective [by successive provincial governments] as serving primarily to meet the needs of employers rather than of students." Consequently, the dominant logic is an employment logic tendency. However, apprenticeships are also by definition VET programs, and as such are embedded within the broader PSE system in BC. Given this context, the research examines the apprenticeship system in BC on a conceptual basis, doing so to identify the underlying problems that manifested themselves in the persistent shortcomings of the system's effectiveness, with a focus on seeking to explain the basis for the weakening of the social settlement. 
Skill levels and workplace applications are associated with certifications, which in turn provide a measure of a trades worker's employability and wage levels to employers. Consequently, the skills, knowledge and experience that establish the requirements to achieve a CQ in any given trade become an important point of interest for stakeholders in the apprenticeship system. The points of dispute amongst the stakeholders, particularly between the BCBTC and the ICBA, tend to focus on the scope and depth of the skills being taught, the requirement for certification in a regulatory environment, as well as wages and mobility (including transferability of skills across employment sectors and provincial borders). Changes in the requirements and the role of the CQ reflect broader changes in the nature of the social settlement that underpins the apprenticeship system given the competing interests at play amongst the primary stakeholders.

Finally, changes in the structure and mandate of the governance body that administers the apprenticeship system affects the role of the primary stakeholders in their efforts to guide and influence outcomes. The research explains how the primary stakeholders sought to influence the apprenticeship system to meet their particular interests through the use of the formal governance system, as well as through any informal influence that could be achieved through their relationship with the government. Research in the theoretical literature and grey literature is augmented by my practitioner's experience as the former Executive Director of the Helmets to Hardhats program, a national organization that assists Canadian military 
veterans transition into civilian careers in the construction industry through entries into apprenticeship programs.

As previously mentioned, the scope of this thesis is limited to $\mathrm{BC}$, the period of 1993-2004 and the construction sector. These limits help to make the study more manageable but are also justified on other grounds. Provinces differ in how they legislate and administer their respective VET systems and apprenticeship programs. Selecting only one sidesteps those differences and allows for a more exacting study. The period 1993-2004 captures a particularly dynamic decade of change in BC during which two different governments with fundamentally opposing political ideologies and perspectives on apprenticeships held power and introduced legislative reforms that had significant impacts on the VET system. And finally, the construction sector is the largest employer of skilled trades in BC.

\section{Research Questions}

This thesis examines the conditions - particularly, those affecting the social settlement - that prevented the legislated reforms to BC's VET system from realizing their stated objectives. More specifically, the research seeks to explain the nature of the relationships amongst the primary stakeholders with interests in apprenticeship programs and the associated requirements, training delivery and qualifications. Two sources of qualitative data are used. The first consists of interviews with key stakeholders who were major participants in shaping the apprenticeship program 
during the research period. The second includes a range of documents that together with the interviews form the basis for the analysis.

The three research questions for this thesis are:

1. How were the relationships between apprenticeship programs, the labour market and the post-secondary education system coordinated, governed and shaped in BC, and why did they take the shape they did?

2. What was the impetus for the NDP and Liberal provincial governments imposing significant changes to apprenticeships and the governance structure?

3. What was the outcome of these processes of change on apprenticeships as a skills ecosystem within the broader VET system in BC as a result of the NDP and Liberal legislative changes aimed at improving the system?

The next three chapters cover the context, concepts and research design of this thesis that will underlie its findings and analysis. As the first step in this sequence, Chapter 2 outlines the context of the apprenticeship ecosystem in BC, including a historical review of the evolution of the institutional structures, program challenges and dynamic tensions of the social settlement amongst the primary stakeholders. 


\section{Chapter 2: Vocational Education Training in British Columbia}

\section{Introduction}

This chapter describes the apprenticeship system in British Columbia (BC), first by looking at the origins of apprenticeships, and then by examining the institutionalization of apprenticeships within the broader vocational education and training (VET) system, and the principal changes that have taken place since the mid-1990s. This detailed overview is necessary to provide a "thick description" (Sayer, 1992) of the nature of, and changes to, the apprenticeship system in BC over the period of study, 1993 - 2004. This description includes an explanation of how apprenticeships are uniquely situated as a skills ecosystem within BC's VET system. Items of note include how apprenticeship programs are governed, how training delivery has evolved institutionally, and the role of certificates of qualification (CQ) in terms of the requirements to complete an apprenticeship as well as the value of a CQ in the workforce. These last two aspects of the apprenticeship system are important in terms of the differing perspectives of stakeholders and the impact this has on the social settlement amongst them as influenced by the broader economic circumstances (to be explained later in the thesis). 


\section{Origins of Apprenticeships}

Apprenticeships are generally accepted to have originated in the Middle Ages (although some consider them to have originated during the Roman Empire) as a means for a master craftsperson to secure an assistant as well as to transmit their craft to a successor (Stewart \& Kerr, 2010). Such a master craftsperson was typically a member of a local guild, an association that acted to control the production and sale of the crafts and services within their local region. The first known formalization of contracts between a master craftsperson and an apprentice, as a formalized apprenticeship, originated in medieval England in 1562 under the Statute of Artificers (Laurie, 2013). During that era and upon completion of an apprenticeship, the apprentice became a recognized Journeyman. ${ }^{3}$ While this qualification allowed a Journeyperson to apply their craft independently of a guild to earn money, they would typically work for years before they could seek to join a craft guild, and only then if they were recognized as a master craftsperson. While craft guilds were common in medieval times, they eventually faded with the onset of the Industrial Revolution as they were seen to detract from increasing opportunities for production and the trade of goods and services (Technical Education Matters, 2009).

\footnotetext{
${ }^{3}$ While the term 'Journeyman' is the commonly used term, the gender neutral term of 'Journeyperson' will be used throughout the remainder of the thesis.
} 
The use of apprenticeships in Canada as a mechanism for training skilled workers was introduced by the skilled trades people who immigrated to Canada from Europe in the $18^{\text {th }}$ and $19^{\text {th }}$ centuries (Stewart $\&$ Kerr, 2010). The early foundation for the eventual institutionalization and regulation of apprenticeships (as a subset of VET) at the provincial level was established by the Constitution Act of 1867, an act that established the division of responsibilities between the federal government and the provinces and territories. More specifically, Section 93 of the Act assigned the responsibilities for academic education to the provinces, but did not explicitly address training, which has led on occasion to the federal government weighing in on the delivery of VET by the provinces (Lyons, Randhawa, \& Paulson, 1991). The first major demand for skilled workers in Canada originated in the late $19^{\text {th }}$ century with the undertaking of the building of a national railway. This coincided with the first federal engagement in solving workforce issues of a national interest by using foreign workers rather than by developing policies, programs and institutions to develop skilled trades people domestically.

Apprenticeships in Canada, as a particular mechanism to develop skilled workers within the broader field of VET, transitioned from a largely privately sponsored activity into a publicly funded service, beginning in the early $20^{\text {th }}$ century (Stewart, 2010). An example of this was the recognition of the need for a coordinated, panCanadian effort to develop a vocational training system based on the lessons of World War I and the demand the war effort placed on the production capacities of industries in Canada. This led to the introduction of the Technical Education Act of 
1919 by the federal government as an initiative to address a growing need for a skilled workforce (Lyons et al., 1991; Stewart \& Kerr, 2010). A similar initiative was fuelled by the demands of World War II when the survival of Great Britain and the British Empire became dependent on the manufacturing efforts of Canada and other former colonies to supply war materials and supplies. The federal government passed the Vocational Training Coordination Act in 1942, followed by the Vocational School Assistance Act in 1945, which was meant to directly subsidize provincial funding for secondary school education and to encourage a greater emphasis on VET (Stewart \& Kerr, 2010).

The inadequacy of these early federal initiatives, which were more reactive to world events than proactive in anticipating skilled labour requirements, became evident in the objectives of immigration policies following World War II that sought to attract skilled tradesmen from war-torn European countries, repeating the approach taken by their forefathers to build a national railway (Lyons et al., 1991). In more recent decades, the immigration of skilled workers and labourers has persisted as a recurring approach to addressing shortages of skilled workers in Canada through the Temporary Foreign Workers Program (Ferguson, 2017). This in turn has had the secondary effect of diminishing the prioritization of establishing a resilient and effective VET system in Canada, effectively relying on training in other countries to meet domestic workforce requirements (Lyons et al., 1991). 


\section{Origins of Apprenticeships and Trades Training in BC}

In keeping with other provinces that were part of Canada's Confederation in the late $19^{\text {th }}$ century, BC's public education curriculum was academic in nature, reflecting the preferences of the British aristocracy and the desire by class-conscious Canadians to seek a higher social standing through the adoption of a similar developmental path for their children (B. Cowin, 2012; J. R. Cowin, 2017; Lyons et al., 1991). The early efforts to promote and provide coordinated VET to produce skilled trades people were organized by the working class through the International Union as early as 1908 through correspondence courses (B. Cowin, 2012; Selman, 1995). Such efforts grew in scope, and evolved into the creation of the Vancouver Apprenticeship Council in 1925 through a joint initiative between the unionized BC Building Trades Council (BCBTC) and the General Contractors' Association (Peterson, 1967).

However, VET in general and apprenticeships in particular remained privately sponsored and unregulated until March 23, 1935, when the BC government passed the Apprenticeship Act. This legislative initiative was largely influenced by the lobbying efforts of organized labour and their employer associations (B. Cowin, 2012; Peterson, 1967). This Act was a significant transition towards BC's initial efforts towards the institutionalization of VET and apprenticeships through the establishment of the Provincial Apprenticeship Committee. Up until the creation of the Industry Training and Apprenticeship Commission (ITAC) in July 1997, 
apprenticeships would remain under the direct administration of the government bureaucracy within the Ministry of Labour (B. Cowin, 2012; J. R. Cowin, 2017; Peterson, 1967). This turning point was significant not only in providing public support to VET and apprenticeships, but also for setting the basis for the institutional tensions and inefficiencies that would gradually accumulate as other Ministries would become involved. It would also set the stage for competition that would arise amongst training providers (public and private alike) for the funding subsidies that would follow in due course from both the federal and provincial governments.

With the advent of government involvement, the funding and administration of VET and apprenticeships both at the federal and provincial levels, came a concomitant increase in bureaucratic influence. While such influence, often as a result of legislative initiatives, was designed and presented to the public as a constructive means to achieve positive outcomes that would benefit British Columbians and the $\mathrm{BC}$ economy, such initiatives were typically short-sighted in perspective, and seemed to underestimate or fail to recognize the secondary and tertiary consequences of such actions.

The federal funding that accrued to the provinces and territories under the federal Vocational School Assistance Act of 1945 led to the creation of several new vocational schools in BC including the first provincial vocational school in Nanaimo at the end of World War II as well as the Vancouver Vocational Institute in 1949. Of 
note, these public vocational schools were focused on youth and were administered by the Department of Education. VET and apprenticeships eventually came to be seen as an element of post-secondary education in $\mathrm{BC}$, and they remained within the secondary school domain throughout the 1950s and 1960s, and into the early 1970s. As a result, the public funding and administrative oversight fell under the Department of Education, and any public funding destined for these pursuits flowed into the secondary schools - or "high schools" - that were engaged in providing such vocational programs during this timeframe (Ministry of Education Science and Technology \& Ministry of Labour, 1979).

With the revamping of the Apprenticeship Act through the passing of the Apprenticeship and Tradesmen's Qualification Act in 1955, additional trades were formally recognized. However, beginning in 1957, pre-apprenticeship programs were introduced for the first time in $\mathrm{BC}$ to "meet the needs and anticipated requirements of industry" (Peterson, 1967). In the early days of these preapprenticeship programs, the intent was primarily to ensure a steady supply of young people who would possess the necessary basic skills and education to be accepted into an indentured apprenticeship, and capable of working for employers. As such, the first cadre of 231 pre-apprenticeship graduates in BC in 1958 were all successfully indentured in their respective trades (Ministry of Education Science and Technology \& Ministry of Labour, 1979).

As time progressed such pre-apprenticeship training grew in popularity and 
received an increasing share of funding subsidies compared with the VET programs (levels of training in between periods of employment) offered to apprentices. However, the simple fact that an apprenticeship involves a contractual relationship with a sponsoring employer in the form of an indentureship was, and is, an important distinction that sets it apart from pre-apprenticeship VET. However, it's clear that this important distinction - the coordination with the requirements of the labour market to ensure graduates would successfully enter the workforce - was either ignored or misunderstood resulting in an oversupply of graduates from preapprenticeship programs who were unable to secure employment in their field as well as a divergence between the training requirements of employers and the curriculum designers of the VET providers (Cowin, 2012).

During this same decade, efforts were made to harmonize the certification requirements for a number of trades across provincial and territorial boundaries in part to allow for mobility of workers enabling them to work across the country, but also to address the growing differences in VET curriculum and certification requirement between the provincial and territorial jurisdictions. This led to the creation of national coordination body in 1952 that today is called the Canadian Council of Directors of Apprenticeship (CCDA) (B. Cowin, 2012; Lyons et al., 1991). This also led to the establishment of the Red Seal endorsement, a stamp that was added to a Journeyperson's "ticket" that came with the achievement of their Journeyperson CQ to prove that they had achieved this additional level of qualification. This also led to the growth in the designation of certain trades as Red 
Seal trades, since these same trades had achieved a common level of certification for this endorsement through the joint efforts of the CCDA (Stewart \& Kerr, 2010).

With the post-war economic growth and surge in the manufacturing industry in Canada as well as other primary industries in BC such as mining and forestry, additional funding was allocated to $\mathrm{BC}$ by the federal government and other provinces for the provision of VET through the Technical Vocational Training Assistance Act of 1960 (B. Cowin, 2012). New vocational schools were opened across the province to meet the growing need, as funding was available for both apprenticeship as well as pre-apprenticeship VET (B. Cowin, 2012; Ministry of Education Science and Technology \& Ministry of Labour, 1979). Another catalyst to the rise in federal subsidies for VET was related to the federal government's expenses related to administering the federal Unemployment Insurance Act. Given the costs of supporting unemployment insurance, it was in the government's interest to provide the means to re-train unemployed workers seeking to find new work and new careers so as to get them back into the workforce as soon as possible (Schugurensky, 2004).

However, this additional funding and growth in the provision of VET began to take a life of its own. The funding began to provide for not only tuition costs but also training materials and administration of such programs within schools. In other words, the provincial government was becoming heavily invested in VET (Peterson, 1967). As the provision of pre-apprenticeship training grew, little consideration was 
given to the demand side of the economy for apprenticeship openings. Furthermore, while the secondary schools providing VET were happy to do so, the coordination of the curriculum provided in the pre-apprenticeship programs and what employers actually needed in industry were not aligned (Peterson, 1967).

Institutionally, the VET provided by the secondary school system was under the Ministry of Education, while the administration and oversight of apprenticeships and the associated ties with industry, fell under the Ministry of Labour. Similarly, different funding streams for VET were provided from these two ministries, with the Ministry of Labour providing funding for the apprenticeship system. However, the necessary coordination efforts required to coordinate the funding objectives, requirements and regulation policies of these two Ministries fell victim to the inevitable challenges of maintaining such a degree of coordination, resulting in institutional divergence in objectives, oversight and administration.

Because of this lack of coordination between the supply side of pre-apprenticeship graduates and the demand side of employers for apprentices and skilled workers, it was not uncommon for employers to seek such skilled labour through immigration and other policy instruments rather than to invest in the development of a workforce from within the province (Sinclair, 2017). In more recent times, this was witnessed through the significant use of Temporary Foreign Workers to meet workforce requirements in a variety of industries in $\mathrm{BC}$ and across Canada, and reported by the Auditor General of Canada (Ferguson, 2017). 


\section{Institutionalization of VET within the Post-secondary Education System}

The report by John Macdonald in 1962 entitled Higher Education in British Columbia and a Plan for the Future was an independent report sponsored by the University of British Columbia. This report was rather prescient in foreseeing the need for changes to the post-secondary education (PSE) system in BC. With the post-World War II baby boom, there was a concomitant surge in students advancing through the secondary school system staged to move into the post-secondary system in great numbers. Although the report was focused more on broadening the PSE options including VET through public colleges, the primary strategic concern was to ensure that high school graduates were guided into streams of PSE appropriate for their academic capabilities and their career interests.

Furthermore, Macdonald recognized the need for more advanced VET curricula than could be provided in secondary schools to meet the increasing technical demands of industry and the rising sophistication in technology (Macdonald, 1962). However, no specific mention was made of apprenticeships in his report, which may have reflected a perception that apprenticeships were seen to be more work related than VET related, a perception that continues to perpetuate the institutional inefficiencies between the ministries previously mentioned.

Macdonald also foresaw the need for colleges to complement universities as PSE options. The BC government quickly acted on this proposal through an amendment 
to the existing Public Schools Act in 1963 that provided the funding and authority for the establishment of several new regional colleges (Ministry of Education Science and Technology \& Ministry of Labour, 1979). From a political-economic perspective, it is important to note that BC adopted a PSE model similar to that which was used in California that allowed for the delivery of both academic and technical courses in colleges (J. R. Cowin, 2017; Fisher et al., 2008; Skolnik, 2010). This model provided an additional pathway to prepare students for university while also providing classroom accessible PSE across the geographic regions of BC rather than remaining concentrated in the lower mainland and southern half of Vancouver Island (J. R. Cowin, 2017). In practical terms, BC proactively sought to provide access to PSE to British Columbians throughout the province primarily through a network of new colleges, which in turn served as a transitional pathway for some of its graduates to continue on into university degree programs.

The "California model" adopted in BC served dual purposes (Skolnik, 2010): to provide greater access to PSE across the geographical outreach of the provinces, and to provide a transitional pathway for academically inclined and capable students to enter into university studies, which were limited to a single university in the lower mainland at the time. In other words, BC adopted a synergistic and complementary PSE strategy in which the new colleges served both to provide necessary PSE (including VET), and to provide the University of British Columbia with an intermediary PSE pathway that ensured that applicants to undergraduate programs were better prepared and motivated to succeed than students applying directly out 
of high school. Consequently, the strategy allowed for accreditation of college courses and their provisional "associate degrees" towards university credits, thereby facilitating the transition, reducing the time to graduate and providing a recruitment instrument for attracting new students to the University of British Columbia (Fisher et al., 2008).

However, apprenticeship program support, as a subset of the broader VET system, was a minor piece of the PSE model that the new colleges were being asked to deliver by the province (J. R. Cowin, 2017; Meredith, 2011). This fact, along with the reality that these colleges had to become relatively self-sufficient financially in a liberal market economy (LME) that supports an education logic tendency, could explain why apprenticeships would be a lesser priority. Regardless, as the economy in $\mathrm{BC}$ grew during the 1960s, and various industries in the province increased their demand for skilled trades people, the government eventually responded by committing in the 1971 provincial budget speech, to significant additional funding towards the creation of additional regional colleges to meet this demand, as well to fulfill the larger strategic objectives of the Macdonald report from the previous decade (BC Hansard, 1971, 29th Legislature, 2nd Session).

Despite the commitment to new colleges, during the interim period of the mid to late 1960s, pre-employment training and VET continued to be provided largely through the secondary school system, which was focused on generalized VET rather than the specific requirements of apprenticeships. The demand for the provision of 
generalized VET grew rapidly during the 1960s as identified by the BC Department of Labour's Annual Report for $1966^{4}$ (Peterson, 1967). Similarly, the Ministry noted a 30\% growth in the number of students registered in pre-apprenticeship programs over the period of 1965-1966. All of this training was provided through government owned and publicly funded vocational schools across the province (Peterson, 1967).

Another important development around the same time was the introduction of a compulsory designation for certain trades in BC, commencing in January 1967, such as plumbing, steam-fitting and gas pipe-fitting trades (Peterson, 1967). This 'compulsory' designation allowed for tighter regulations pertaining to the VET curriculum, training standards and work experience for reasons of safety. Consequently, 'compulsory' trades typically require a credential (a trades certificate or license) as a condition of practice to work in regulated areas, whereas voluntary trades do not (Canadian Apprenticeship Forum, 2016b; R. Crocker, 2014).

With the advent of the $\mathrm{BC}$ government's initiative to create a number of new colleges across the province beginning in 1971 came a formal shift of VET from the secondary school system into the PSE system creating tensions due to the subsequent shift of the associated, and quite significant, public funding for VET (B. Cowin, 2012). This also coincided with the growth of "pre-employment" training by the colleges as an alternative to pre-apprenticeship training. The subtle distinction between pre-apprenticeship training and contractual indentured apprenticeships

4 The report mentions $110 \%$ growth in registered apprentices over a period of three years (1964-1966). 
which originated in 1960 when the Department of Education began funding this initiative, would lead to a gradual divergence between the two training models.

This divergence, which was increased as a result of different public funding streams from the education and labour ministries, also led to greater autonomy by colleges in curriculum development for pre-employment training. In other words, the curriculum would be determined largely by the college, under the auspices of the Ministry overseeing PSE), without necessarily maintaining a close coordination with the needs of industry and the Ministry of Labour. This duality of Ministries and divergence in oversight continues to the present, despite efforts along the way to rectify the problem.

\section{Divergence - Apprenticeship Skills Ecosystem within the Broader VET System}

The distinction between pre-apprenticeship programs and pre-employment programs was nicely captured by the definitions provided by the Task Force on PreEmployment and Pre-Apprenticeship Training Programs in British Columbia in its first of two reports that was published in June 1979 (Ministry of Education Science and Technology \& Ministry of Labour, 1979):

The objectives of the pre-apprenticeship programs are:

(1) To provide basic skills and technical knowledge in a designated trade to individuals preparing to enter a specific trade as an apprentice. 
(2) To provide a supply of apprentice candidates having sufficient basic training to meet the needs of industry.

The objectives of the pre-employment programs are:

(1) To provide new entry workers with a sound basis of fundamental technical theory and basic skills in a range of occupations related to business, health, community service, and industry.

(2) To provide the special requirements of the occupation in the areas of attitudes, safety, deportment, work habits, and personal responsibilities.

At that time, formal indentured apprenticeship programs were administered by the Provincial Apprenticeship Board (PAB) under the authority of the Minister of Labour, whereas pre-apprenticeship programs were designed for vocationally inclined apprentice aspirants seeking a vocation. The provincial government made efforts to address the growing divergence between the provision of VET and industry requirement for apprenticeship programs (as a unique form of VET that had an employment logic tendency). In 1977, with the formation of the Commission on Vocational, Technical and Trades Training, the government passed two pieces of legislation that were passed as based on recommendations that were proposed by the Commission: the Apprenticeship and Training Development Act, and the Colleges and Provincial Institutions Act (Goard, 1977). Of note, the strategic objective of the second Act was specifically to provide a coordinated approach between the Ministries through the provision of "...an administrative framework for developing, approving and funding technical and vocational training in British Columbia" (Ministry of Education Science and Technology \& Ministry of Labour, 1979). 


\section{Attempts to Rectify Bureaucratic Overlap between Ministries}

The framework was implemented through the newly created Occupational Training Council (OTC), which came into being in 1978. The objective of the OTC was to act as a coordinating body with the various stakeholders, as well as to cut through the bureaucratic red tape that had been compromising the efficiency and effectiveness of the VET and apprenticeship system in BC. The reports by the Task Force on PreEmployment and Pre-Apprenticeship Training Programs in British Columbia also highlighted the fact that the colleges had greater financial autonomy than secondary schools and were less restricted in how they applied public funding (Goard, 1977). In due course this would become a significant point of contention amongst the primary stakeholders, particularly after the establishment of the Industry Training Authority in 2004.

Another important recommendation made in the Second Report of the Task Force on Pre-Employment and Pre-Apprenticeship Training Programs in British Columbia, identified the crucial requirement to "establish a Labour Market Information Service which will be responsible for the collection, analysis, and distribution of information on labour markets and future manpower requirements" (Minister of Education Science and Technology \& Minister of Labour, 1979).

Yet another sign of growing frustration with the bureaucratic inefficiencies was the Training Access (TRAC) initiative announced by the Ministry of Education in 
December 1982. In essence, bureaucrats between the Ministries of Education and Labour lobbied their own government to overcome the divergent and redundant pre-apprenticeship and pre-employment programs being offered by PSE colleges by abandoning both in favour of a bold new approach. However, this new approach, designed to be a self-paced, competency-based training (CBT) model, was neither well thought through nor developed with VET providers, who, along with employers, were opposed to the TRAC initiative. TRAC was short-lived, and replaced by the more traditional VET delivery system by the colleges in the form of Entry Level Trades Training (ELTT) (B. Cowin, 2012; Ministry of Education, 1982). However, this system also failed to avoid the previous issues stemming from a disconnect between industry requirements and college independence for curriculum development.

As BC's economy fell into a recession in the early 1980s and the availability of indentured apprenticeship positions diminished, a disconnect developed between the supply of ELTT graduates and demand for new apprentices. Along with the divergence in the VET being provided and the evolving industry requirements of employers, yet another Task Force to study the problems was formed. Convened by the Minister of Labour and overseen by the PAB, the task force findings and recommendations once again identified the pre-existing and persistent disconnects, inefficiencies and funding tensions in relation to VET and apprenticeships. Of particular interest was the observation that most employers in $\mathrm{BC}$ was too small to indenture an apprentice and support their training over the 3-5 year span of their 
apprenticeship. Although the report suggested the novel solution of creating cooperatives of small employers who could collectively sponsor an apprentice, similar to the successful Joint Apprenticeship Training Committees (JATCs) ${ }^{5}$ administered by the BC Building Trades Council (BCBTC), it appeared to have fallen on deaf ears and was never implemented (McClelland, 1984).

However, as identified both by the Minister of Labour (1997) report entitled Revitalizing Apprenticeship: A Strategic Framework for BC's Apprenticeship Training System, (see Table 1), small and medium sized companies had supported an increased percentage of registered apprentices between 1980 and 1995. Conversely, the large companies had decreased their support of apprentices by 63 per cent even though the number of such companies only decreased by approximately 17 per cent during the same period.

\section{Table 1: Distribution of employer sponsors in BC (circa 1995)}

\begin{tabular}{|l|c|c|c|}
\hline Employer size & 1980 & 1995 & $\begin{array}{l}\text { \% Increase } \\
\text { (Decrease) }\end{array}$ \\
\hline Small/Med (<100 employees) & 6,444 & 5,910 & \\
\hline Registered Apprentices & 11,901 & 10,965 & $(-8 \%)$ \\
\hline Large (>employees) & 377 & 314 & \\
\hline Registered apprentices & 9,035 & 3,300 & $(-63 \%)$ \\
\hline Total registered Apprentices & 19,215 & 14,625 & \\
\hline
\end{tabular}

Source: Revitalizing Apprenticeship: A Strategic Framework for BC's Apprenticeship Training System (Ministry of Labour, 1997)

\footnotetext{
5 This is a generic name, as these organizations have variations in what they are called across different construction unions, and even between regions.
} 
Another recommendation also came into being, that of allowing for the establishment of private Training Delivery Agencies (TDAs) that would be provincially accredited for the delivery of VET and subsidized by public funds like the colleges (McClelland, 1984). In fact, several of the larger unions, such as IBEW Local 213 in lower mainland BC were able to capitalize on this initiative to develop self-sustaining and highly successful training institutions to support apprenticeships in a variety of trades (Sinclair, 2017).

As this historical review of the evolution of VET and apprenticeship programs in BC approaches the beginning of the period of interest for my thesis, namely the period of 1993-2004, the final initiative of interest was the Task Force on Employment and Training that was commissioned by the Minister of Advanced Education, Training and Technology. The Task Force was convened under the Social Credit (SOCRED) government of Premier Bill Vander Zalm, yet the report was published a few weeks after the New Democratic Party (NDP) government of Mike Harcourt came into power with a strong majority of seats in the fall of 1991. Once again, the purpose of the report and the theme of the recommendations were tied to the persistent problems created by the division of responsibilities for the apprenticeship system in $\mathrm{BC}$ between two different Ministries. However, the recommendations not only emphasized a greater influence for the trade unions but also a greater role for industry in the development of VET requirements and certification standards (Strand, 1991). 


\section{Examining Apprenticeships as a Unique Form of VET}

Tracing the historical evolution of the apprenticeship system in BC provides the basis for an explanation of the institutional tensions which evolved over time and reflects the exogenous impacts of the economy and periodic government interest in workforce development. As highlighted earlier, the institutionalization of apprenticeships in Canada exists at both the national level, primarily through harmonization efforts of the trades through the Red Seal program, and at the provincial / territorial level, where the trade requirements are established. As with education, the responsibility for administering apprenticeships was delegated to the provinces through the Constitution Act of 1867, resulting in 13 different jurisdictions that exist today (Lyons, Randhawa and Paulson, 1991). Each jurisdiction has its own apprenticeship authority that administers its apprenticeship system, and works in consultation with industry sectors to determine the trades in demand as well as the skills required in local labour markets. In BC, the Industry Training Authority (ITA) is the designated crown agency that is mandated to administer apprenticeship programs within the province's broader VET system. The ITA's system to produce skilled tradespeople involves a unique combination of formal education and training with on-job experience under the supervision of one or more qualified tradespeople. McClelland (1984) offers a useful definition:

Apprenticeship is a system of supervised employment through which an individual learns a skilled trade or occupation. The apprentice learns practical skills and technical knowledge. The former are acquired through experiences working with journeymen already 
skilled in the trade; the latter is acquired usually through attendance at technical training classes.

The skilled trades are subdivided into 'voluntary' and 'compulsory' categories (as within the construction sector), and are assigned at the discretion of the provincial authority leading to differences across jurisdictions. Consequently, the skilled trades have become highly diversified across Canada. There over 400 designated trades today, but due to a lack of standardization in establishing 'compulsory' trades, problems for accreditation of trade qualifications across jurisdictions have become an issue (Laporte and Mueller, Canadian Apprenticeship Forum, 2016b; 2010). This lack of standardization in turn creates structural barriers to labour mobility across jurisdictions as certifications awarded in one province may not comply with those from another. This has also led to a persistent lack of reliability in the quality and comparability of data collected across provincial jurisdictions as well as the aggregated national results provided through the Registered Apprenticeship Information System (RAIS). Such unreliability results from a lack of consistent terminology, definitions and standardization in accounting for apprentice progress and results between the provincial jurisdictions.

As mentioned earlier, the Red Seal program which originated in the early 1950s seeks to mitigate this problem through harmonization efforts at the national level. Red Seal trades are those which are identified by the CCDA as having sufficient commonality across jurisdictions, that accreditation can be achieved through successful completion of a written exam by anyone who is already certified in the 
trade (Stewart and Kerr, 2010). Most of the apprenticeship systems across Canada, including $\mathrm{BC}$, have integrated the Red Seal exam into their programs thereby ensuring that graduates in Red Seal trades are awarded this endorsement. In 2012, over 75 per cent of apprentices in Canada were in Red Seal trades (Canadian Apprenticeship Forum, 2016a; CCDA, 2014). However, for those who fail to complete their apprenticeship or who are not in a Red Seal trade, employability remains constrained by the circumstances of weak cross-accreditation between jurisdictions.

In terms of contribution to the skilled labour force, there were approximately 430,000 registered apprentices across Canada in 2010, the number having doubled in the decade prior (Brydon and Dachis, 2013). ${ }^{6}$ However, other than by exception such as in 'compulsory' trades, an individual can work in the trades in Canada without either having undertaken an apprenticeship or having achieved a trades certificate. As such in 2006, registered apprentices represented only about 17 per cent of the total workforce in the trades across Canada. Regardless, the apprenticeship system has become the primary means to achieving a trades certificate in Canada, with over 60 per cent of newly certified Journeypersons coming though this route in recent years (Crocker et al., 2010).

6 The number has remained relatively stable. More recently, the number of registered apprentices in Canada was 417,300 in 2016, with a decrease to 405,699 in 2017 according to Statistics Canada and the Registered Apprenticeship Information System (Statistics Canada, 2019). 
Statistical data provide a broader, if inexact, sense of the apprenticeship system in $\mathrm{BC}$ before, during and after the research period. Table 2 is also provided for illustrative purposes only, bearing in mind that the $\mathrm{BC}$ data, coming from a single jurisdiction, are similarly unreliable due to ongoing changes in their terms, definitions and interpretations, particularly during the transition from the ITAC to the ITA (see Chapter 4). It provides a picture of changes in apprenticeship programs as a PSE pathway to employment by way of the number of apprentices registered in several different trades common to the construction industry. While the number of registrations remained relatively stable throughout most of the research period, the sudden rise in 2004 and subsequently doubling four years later in 2008 relate to the two legislative initiatives for VET introduced by the Liberal government (deregulation of the trades and the creation of the ITA).

The subdivision of the large carpenter trade into sub-trades (such as the Residential Framing Technician and Native Residential Construction Worker), as well as the creation of 28 new apprenticeship-eligible programs following the introduction of the ITA led to a rise in the overall apprenticeship registrations (Prism Economics and Analysis, 2017). 


\section{Table 2: Apprenticeship registration in BC}

\begin{tabular}{|c|c|c|c|c|c|}
\hline Year & $\mathbf{1 9 9 1}$ & $\mathbf{1 9 9 7}$ & $\mathbf{2 0 0 1}$ & $\mathbf{2 0 0 4}$ & $\mathbf{2 0 0 8}$ \\
\hline Primary trades & 19,194 & 20,241 & 22,119 & 25,719 & 53,106 \\
\hline Carpenter & 2,478 & 2,604 & 2,490 & 3,729 & 10,602 \\
\hline Electrician & 2,661 & 3,075 & 3,060 & 4,260 & 8,892 \\
\hline Plumbers $^{7}$ & 1,740 & 2,079 & 1,629 & 2,466 & 5,949 \\
\hline Heavy Equipment $^{8}$ & 852 & 789 & 768 & 894 & 2,001 \\
\hline Heat \& Frost $^{9}$ & 210 & 318 & 411 & 495 & 840 \\
\hline Sheet Metal & 534 & 510 & 543 & 663 & 1,455 \\
\hline
\end{tabular}

Source: Apprenticeship Completion, Certification and Outcomes (Statistics Canada, 2018)

\section{The Apprenticeship Process for Earning the Certificate of Qualification}

As previously highlighted, apprenticeship programs as a skills ecosystem of training follows a unique approach that differs from the broader field of VET, given its ties with employers through indentureships and associated work periods. Compared to other forms of PSE, such as the pursuit of an undergraduate university degree or a college diploma in which a student follows a well-established educational pathway within an academic institution, an apprenticeship is distinct. It requires alternating between a classroom style VET and supervised workplace experience, working through successive levels towards completion.

Although university and college co-op programs and compulsory workplace placements (for example, for practical nurses) could be seen as similar to an

\footnotetext{
7 This category includes sprinkler fitters, pipe fitters and gas fitters in addition to plumbers.

${ }^{8}$ Heavy equipment includes cranes as well as other mobile heavy equipment machines such as bulldozers, backhoes, graders, etc.

${ }^{9}$ Trades that deal with air conditioning, refrigeration, heating as well as insulation.
} 
apprenticeship, the difference is that an apprentice's work experience is a mandatory requirement of an apprenticeship, which is underpinned by a contract of employment. Workplace experience is measured in documented hours of work, with the quantity of hours required for each level typically equating to about a year of continuous employment. Ideally, the working phase also exposes the apprentice to different aspects of the trade, thereby enriching their applied knowledge and competencies of the skills (Canadian Apprenticeship Forum, 2016b). In other words, the underlying fundamentals of an apprenticeship are different from VET based on the emphasis of combining education and training with real world experience on the work site.

The working phase is followed by a period of VET with an accredited vocational training delivery agency (TDA) that can be several weeks to a couple months in duration, usually culminating with a test for successful completion of each level. The designations for the successive levels of completion are identified by years. For example, a third-year apprentice has successfully completed the second level, and is now in the third level, whereas a first-year apprentice has just begun their apprenticeship but has not yet successfully transitioned to the next level. These levels also help contractors to determine the measure of the skill, knowledge and experience an apprentice offers, as well as the appropriate wage level which increases with experience but are less than that of a Journeyperson. 
The duration of a typical apprenticeship in the construction trades is usually two to four years of continuous effort (Cadieux, 2010; Canadian Apprenticeship Forum, 2016b). However, delays in completion are common due to coordination challenges between work and training periods, as well as fluctuations in the economic circumstances on the industry (Gunderson, 2013). It is not uncommon for apprentices to abandon the program to pursue long-term employment at the level of training they have achieved or to move into a completely different vocation (Canadian Apprenticeship Forum, 2004, 2011; C. Laporte, and Richard Mueller, 2010). The culmination point for a structured apprenticeship is the awarding of the Journeyperson CQ, a written exam that can be taken by an apprentice only once the prerequisite periods of VET have been successfully completed and the required hours of supervised work experience achieved. In BC, this final exam is the Red Seal exam for apprentices in designated Red Seal trades, and ensures these new graduates have the opportunity to seek employment across Canada in their trade.

The value of the CQ can be measured in several different ways. In the 'compulsory' trades, it is used to ensure only qualified individuals and supervised apprentices can work in regulated domains, thereby protecting public safety interests. From a public policy perspective, the CQ is essential to the sustainability of the apprenticeship skills ecosystem, as certified Journeypersons become the instructors who provide training in the classroom as well as the supervision in the workplace. From the employer's perspective, the CQ is a measure of a trade worker's level of accomplishment in their trade, as well as the basis for wages. From the trades 
worker's perspective, the CQ provides access to higher wages, increased employability (including in supervision and instructing), and greater interprovincial mobility as provided by the Red Seal endorsement. Finally, within the skilled trades community, the CQ also provides social status (Brockmann, Clarke and Winch, 2011).

In $\mathrm{BC}$, apprentices must be registered with the ITA to formally pursue an apprenticeship for reasons of administration, tracking of progression and certification. The first step for untrained novices entering into the trades is usually several weeks to a few months of pre-apprenticeship training through an accredited TDA such as a community college to provide them with the basics for employability; the critical step is to become indentured by an 'Employer Sponsor'. An 'Employer Sponsor' can either be an individual employer or an organization with an established labour employment relationship with multiple employers, such as a union's JATC model with its affiliated contractors (Gunderson, 2013; ITA, 2016).

Ideally an apprentice has employer support for both the work assignments and time away for their successive levels of VET, either through the same employer or through a coordinated, rotational work assignment system as with the union's joint model. In the union-based JATC model, apprentices are supported by the training center and affiliated union local which arrange successive work assignments after the completion of each training period. Such coordination is possible through the pool of unionized contractors who have committed to the apprenticeship training. 
However, in other cases such as with smaller companies, challenging economic circumstances or in cyclical industries like construction and resource extraction, apprentices are at greater risk of unplanned periods of unemployment (BCFED, 2012; Canadian Apprenticeship Forum, 2012; Sharpe \& Gibson, 2005b; Stewart \& Kerr, 2010). Furthermore, the commitment of an 'Employer Sponsor' is not legally binding as a contract thereby allowing them to drop an apprentice mid-way through an apprenticeship due to a lack of "enforceable obligations on the employer with respect to training" (Meredith, 2011).

As such, the apprentice's pathway to the successful completion an apprenticeship is impacted by labour market conditions. Therefore, mitigation strategies in the training system would be a logical area to seek improvement. Using completion rates as a metric, the McDonald Report (2014) identified the need to focus on support for apprentices and employers alike through improved coordination mechanisms.

\section{Certification in the Construction Trades}

The primary basis for the Journeyperson certification process for trades workers is to satisfy employer requirements within their industry sector. It is central to developing an understanding of the role of the apprenticeship system, the nature of the trades associated with an apprenticeship, and the value of the Journeyperson CQ in terms of wages, employability and social status. The requirements for attainment 
of a Journeyperson CQ is based on the scope and standards of the knowledge, skills, and experience provided through the apprenticeship training system within a given trade, the requirements of which are established by the apprenticeship authority in consultation with its primary stakeholders (ITA, 2016; McDonald, 2014).

As mentioned earlier, the establishment of such requirements can vary widely across provincial jurisdictions in Canada, and this results in divergence amongst stakeholders within what is arguably a weak governance system (Laporte and Mueller, 2010; Lyons, Randhawa and Paulson, 1991). However, according to the Auditor General of BC, poor relationships amongst stakeholders (particularly the BCBTC and the BC Institute of Technology, who had been excluded from governance roles in the ITA) negatively impacted the training system (Doyle, 2008). Economic considerations appear to be the primary catalyst for such divergent perspectives, primarily in terms of remunerations for labour (wages and benefits), while competency in terms of workmanship quality and productivity, as well as workers' social status are additional points of difference (BCFED, 2012; Heinrichs, 2015; Johncox, 2001b). The construction industry is but one of several sectors employing skilled trades workers in cooperation with other sectors including manufacturing, transportation and the service industry.

As previously mentioned the construction trades in Canada, are categorized as either 'compulsory' or 'voluntary'. To recap, the 'compulsory trades' are typically trades that involve work in regulated domains guided by strict public safety 
standards. They are strictly regulated, with respect to the requirements for apprenticeship training, within individual jurisdictions that have them. Only registered apprentices or certified trades workers can be employed in these particular trades (Hurrell, 2010). The more commonly known 'compulsory' construction trades include electrician, steamfitter/pipefitter, boilermaker, plumber, refrigeration and air conditioning technician.

Figure 1 shows some of the more common 'compulsory' trades across Canada relative to the study period, most of which were based in the construction industry. This is included for illustrative purposes only given that provinces do not consistently apply the compulsory status to the same trades. The data is based on the 2007 National Apprenticeship Survey derived from surveys conducted between 2002 and 2004 (Hurrell, 2010). The designation of compulsory trades is determined at the provincial and territorial level, and varies across these jurisdictions. As such, because the hairstylist trade had been designated as compulsory across most provinces and territories, it has a very high percentage of registered apprentices, whereas the boilermaker trade was only designated as compulsory in a few provinces, with the other trades percentage determined accordingly. 


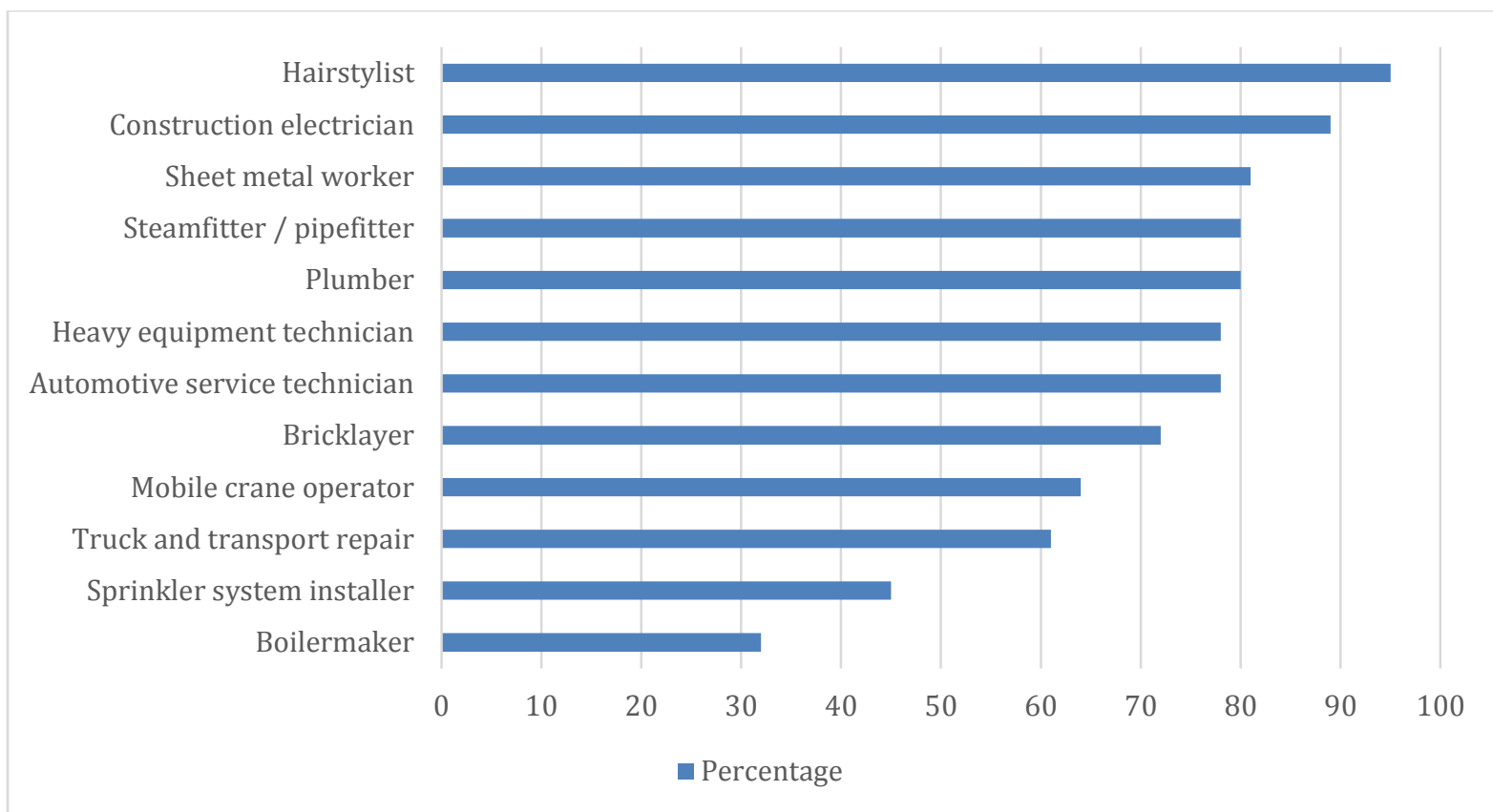

Figure 1: Percentage of apprentices in compulsory trades, by trade group Source: The Impact of Compulsory Certification on Apprenticeship in Canada (Hurrell, 2010)

The 'voluntary' trades are not tied to such industry regulations, and thus are subject to far greater discretion in the determination of the skills, knowledge, and experience required to fulfill the Journeyperson CQ (Johncox, 2001b). In addition to the Journeyperson CQ, certification exists in other forms such as a licence to operate heavy equipment or competency in a more specific skill recognized by an endorsement, permit, or similar documentation (CCDA, 2014).

While the VET system in BC is like those in most other provincial jurisdictions in Canada, the situation in $\mathrm{BC}$ is unique due to the legislation introduced in 2001 and 2003 by the Liberal government, under then premier Gordon Campbell. The Liberal government introduced legislation to eliminate 'compulsory' trades, thereby 
deregulating trades training, and introduced modularized training which enabled apprentices to achieve certification for specific skills sets enroute to completing their Journeyperson CQ (Harris \& Company LLP, 2003). Consequently, competencybased certifications may be earned as a component of an apprenticeship, or separately as a stand-alone training module, thereby devaluing the Journeyperson CQ.

\section{Primary Stakeholders in Apprenticeships in BC}

From a high-level perspective, the broader VET system in BC is structured as a system of systems composed of functional relationships between various institutions and stakeholders. The examination of the VET system (over the fouryear period since the creation of the ITA in 2004) by the Auditor General of BC was significant (Doyle 2008). Not only did this signal a concern with the operations and outputs of the ITA, as well as the accounting for public funds that supported its mandate, but it also provided rare insight into the system from a non-stakeholder perspective. Figure 2 shows various stakeholders involved in apprenticeship programs within the broader system, as well as their functional roles. Together, they provide the core functions of trade requirements, employment, training delivery and governance/administration that guide the intake, development and certification of apprentices. 
Overall as conceived here, the apprenticeship system is subject to the influence of four primary stakeholders as explained in Chapter 1. Once again, they are: the provincial government via the Ministry of Labour and the Ministry of Advanced Education $^{10}$; Skills and Training, the BC Institute of Technology (BCIT); the unionized BCBTC (synonymous with the term 'labour' as used in Figure 2); and the non-unionized Independent Contractors and Businesses Association (ICBA). Although the unionized sector is composed of both trade union locals and employers that operate within a framework of collective agreements with the unions, for the purposes of this thesis they are collectively considered as being part of 'labour'.

The employers are the most influential stakeholders, as they provide the employment opportunities both to indenture new apprentices, as well as to employ them once they complete their CQ. Therefore, they have a pragmatic interest in determining the requirements for skilled ${ }^{11}$ trades workers in the construction industry. However, the two employer stakeholder groups of interest (the BCBTC and the ICBA) are also divided along ideological lines, resulting in divergent views on the knowledge, skills and experience required for the different trades to achieve the CQ. Of note, while the apprentices are cited as stakeholders in Figure 3, their voice and

\footnotetext{
10 The Ministry's name varied over the period of research, as well as during the years prior (see Annex 5), but consistently represented BC's post-secondary education system from the 1970's onwards.

11 The interpretation of the term "skilled" is a controversial aspect of the tensions between the primary stakeholders, as will be explained in subsequent chapters.
} 
influence is minimal compared with the primary stakeholders, as explained in Chapter 5.

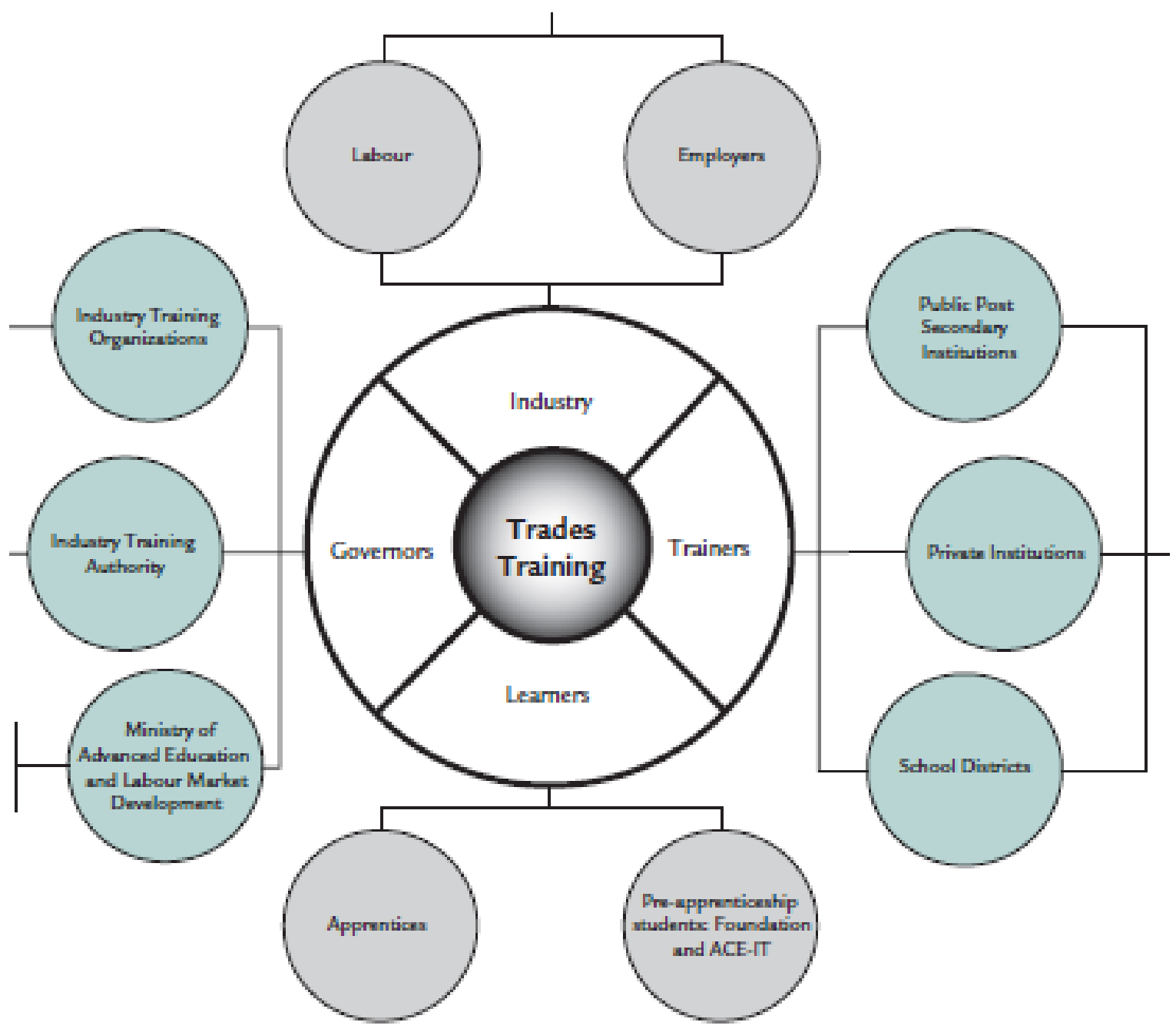

Figure 2: Key trades training stakeholders

Source: A Major Renovation: Trades Training in British Columbia (Doyle, 2008)

While all stakeholders have a shared interest in the apprenticeship system, their objectives are derived from different perspectives. While both the ITAC and ITA (Figure 3) provide a governance framework to oversee the system, the primary stakeholders operate with relative autonomy to pursue their self-interests in the 
context of asymmetrical power relationships with the provincial government, as will be explained in Chapter 5. The result is that apprenticeship programs, as a unique skills ecosystem, reside within a broader VET system that has many seams rather than being seamless, with apprentices facing greater challenges to graduation (completion of their CQ) than their peers in colleges and universities. While some of these seams are structural, such as the alternating periods of formal learning within a training organization, others are systemic, such as the social status of trades workers within the education system, the labour market and society.

Institutionally, apprenticeships are influenced by the competing interests and perspectives of the primary stakeholders. In the case of the provincial government, the apprenticeship system, including the extant transition programs from high school into the trades, is included within the mandates of three separate ministries: the Ministry of Education, the Ministry of Advanced Education, and the Ministry of Jobs, Tourism and Skills Training. ${ }^{12}$ Additional Ministries, such as Finance, may have a specific involvement with the apprenticeship system, but not to the same degree. VET is provided through a combination of public and private training centers operating under a variety of funding models (ITA, 2016; McDonald, 2014). Public TDAs are provided through community colleges while private TDAs are provided through either a company or a union-led coordinated training model.

\footnotetext{
12 The names of these Ministries vary over time.
} 
The apportionment of state subsidies via the ITA is structured differently for the public training centers (McDonald, 2014) than for their private counterparts. This has particular implications for pre-apprenticeship training, which is a key transition program into the trades. Pre-apprenticeship training facilitates entry into apprenticeships, but policy settings can contribute to an oversupply of graduates from these programs given that successful completion of the pre-apprenticeship training in a public TDA does not guarantee becoming indentured by an employee sponsor.

Funding subsidies for public training centers are based on the number of students enrolled in programs. This provides potential for an oversupply of students with pre-apprenticeship training unless provisions are made to ensure an adequate number of employers to indenture them upon completion (Sharpe \& Gibson, 2005b). Furthermore, the principal purpose of community colleges is to provide college diploma programs as the basis for transferring to a technical or applied bachelor degree programs at universities; such programs depend on government funding for students to remain in operation. Their primary objective is the provision of education and training, not the coordination of employment upon graduation. As such, the business plan for community colleges is logically focused on attracting as many tuition dollars as possible and to maximize the state subsidy income based on its funding formula, which reflects the education logic tendency. 
The findings by Meredith (2011) suggest that if the labour market demand is tilted towards a preference for lower cost semi-skilled workers, then such a public subsidy mechanism may actually contribute to lower completion rates as job prospects will become more abundant for apprentices who are mid-way through the apprenticeship system (i.e., second and third year apprentices), than for graduates who achieve the Journeyperson CQ. The lower percentage of completion rates amongst registered apprentices in $\mathrm{BC}$ over the past decade appears to support this explanation, but does not necessarily confirm it. Rather, most of the existing studies portray the existence of multiple factors in addition to the possible effect of the subsidy mechanism.

For the private TDAs the situation is quite different. An apprentice may be hired by a company such as BC Hydro, for example, that has an established program incorporating the training and work experience requirements within its own apprenticeship system (BC Hydro, 2016). The union-run TDAs, which are often a component of their JATC model, are supported by the union and its affiliated contractors. With a pool of unionized employer sponsors committed to apprenticeship training along with a coordination system to oversee the training and rotational employment assignments, apprentices are supported through each level of development through to completion.

Quite often such models include a pre-apprenticeship program that emphasizes careful screening of applicants, mentorship and individual development. Course 
scheduling is usually coordinated with forecast demand for new apprentices. Thus, the JATC model is designed to achieve a balance between intake of new apprentices and demand for newly qualified skilled trades workers. This model, which reflects an employment logic tendency, has produced superior results in Ontario (Gunderson, 2013) as well as in BC by the BC Federation of Labour (2012) which cites a $90 \%$ completion rate for Red Seal apprenticeships, reflective of the value this system applies to the success of each apprentice as well as the high level of support provided to ensure completion.

Finally, as highlighted in the McDonald Report (2014), there are competing ideological views on the knowledge, skills and experience required for various types of certification, particularly the Journeyman CQ, within the key stakeholder groups representing the labour market, namely the unionized and non-unionized sectors. The competing views are based principally on costs, associated with investment in training and labour costs. While the non-union approach is to minimize costs to remain competitive in the market, the union approach is to control access to the labour market to preserve wages and protect their market share of work through qualification requirements (Barbash, 1968; Johncox, 2001b). However the literature has noted that a narrow focus on costs at the expense of skills training can create new problems (Thelen, 2004). The variable and highly subjective nature of the process for determining the scope and standards of apprenticeship training provided by the ITA opens the door for divergence rather than for establishing a mechanism for consensus and convergence on these views. Similarly, opportunities 
for securing labour at lower wages through oversupply of partially trained apprentices, for example, are preferred.

As such, the employer organizations tend towards a narrower view on skills training and qualifications, preferring to minimize investments in training as well as reducing time that apprentices are away from the workplace for VET. The preference in an LME such as in Canada is for the state and/or the individual to pay for the generalized training, with the employer only providing training that is specific to their needs. In those circumstances where the employer contributes to training costs, they seek compensation through suppression of full wages as is possible when hiring more experienced apprentices; although they may be very well trained, their pay remains $20-30 \%$ below the wages of someone with a CQ (Meredith, 2011).

Conversely, the unions tend towards supporting a broader, knowledge-based approach to skills training across the scope of their vocational occupation. This sector values the Journeyperson CQ over specific sub-qualifications that focus on specific skill sets within the occupation. This preference is for several reasons such as mobility, quality and innovation in addressing new challenges, and the ability to contribute to continuation of the VET system as work site supervisors and instructors. Thus, the dynamic tension that exists within these key primary stakeholders in the apprenticeship system can be reduced to differing interpretations of the purpose and pre-requisites of the CQ itself. This persistent 
divergence in the vocational trades has similarities to the tensions highlighted by Brockmann, Clarke and Winch (2011) in the European Union despite efforts to achieve convergence.

\section{Political Influences on BC's VET System and Apprenticeships}

The apprenticeship situation in $\mathrm{BC}$ over the past few decades provides an opportunity to examine the results of different government ideologies as they pertain to the core element of institutional interpretations of trades qualifications and the associated logic shaping the relationship between vocational education and the labour market.

The apprenticeship programs within the VET system in BC have been subject to regulatory reforms since the mid-1990s, driven by very different political ideologies as well as changing economic circumstances. The NDP government under Premiers Mike Harcourt and Glen Clark introduced two separate pieces of legislation between 1994 and 1997: one to regulate sectors of the construction industry, and the other seeking to strengthen the apprenticeship system through stakeholder consultation. This was followed in 2001 by Premier Gordon Campbell's newly-elected Liberal government, which enacted legislation to repeal the NDP's reforms, including the elimination of compulsory trades, the introduction of modularized competencybased training, and an industry-led approach that also reduced the influence of labour unions in some sectors including construction (Sharpe and Gibson, 2005b). 
Both governments also introduced significant organizational change to the crown agency mandated to administer the apprenticeship system (Doyle, 2008; Goedbloed, 2014).

More recently in 2014, one of the cornerstone elements of Premier Christie Clark's Blueprint is to ensure that a revamped apprenticeship system includes an emphasis on attracting youth progressing through secondary school, and to lay the groundwork for a "seamless path right from school through to the workplace" (Clark, 2014). Numerous reports and research studies (Brown, Thomas and Crocker, 2010; Canadian Apprenticeship Forum, 2007; Gunderson, 2013) consistently indicate that most apprentices are several years older than youth who pursue a university or college education. This suggests that a career in the trades is not the first choice for most high school graduates, and that employment in some trades such as construction is not seen as a career per se, thereby rendering trades-based apprenticeships as a less desirable post-secondary option for secondary school graduates (Gunderson, 2013).

Another cornerstone of the Premier's Blueprint is the move towards greater coordination between the production of skilled workers and the demands of the labour force with an emphasis on an industry-led approach to shaping the training system. However, while coordination implies cooperation amongst stakeholders, an industry-led approach risks a power shift that can erode trust and weaken relationships which can create unsustainable outcomes due to a lack of consensus 
(Bosch and Charest, 2008). Furthermore, such a shift would suggest an exploitive view of the apprenticeship system that leans towards production of skilled and semi-skilled labour rather than career development for the apprentices themselves.

The apprenticeship situation in $\mathrm{BC}$ to date reflects a seemingly unresolved debate at the political level about what can be learned from Premier Clark's plan as well as the previous attempts by the former NDP and Liberal governments in $\mathrm{BC}$ to change the apprenticeship system. If the swings in policy were related as much to a lack of a consensus among stakeholders in the apprenticeship system as to differences in political ideologies (exacerbated by the competing logics and structural challenges of the two ministries), then a comprehensive analysis may provide valuable insight into the basis for such divergence.

Under Premier Mike Harcourt, the NDP government adopted a more regulated approach to trades qualifications in line with the unionized sectors' demands (Johncox, 2001b). Conversely, the subsequent Liberal government under Premier Gordon Campbell deregulated the trade qualifications and privatized the system under an industry-led approach that marginalized the labour unions (Bourke, 2013). In both cases, the governance structure and service delivery model of the apprenticeship agency underwent dramatic changes that reflected their opposing political ideologies regarding the welfare state and the market economy. However, given that both governments viewed the skills training system as an instrument of 
the economy, particularly in terms of employment and productivity, their actions were influenced by the economic context within which they governed.

In the period preceding these two legislative changes, the apprenticeship system had been centrally administered by the government through the PAB. In 1994, the Harcourt's NDP government passed the Skills Development and Fair Wages Act which introduced specific regulations into the construction sector in an effort to strengthen the apprenticeship system including the status of Journeyperson qualifications (Mandryk, 2014). This was followed by the passing of The Industry Training and Apprenticeship Act in July 1997, which mandated the reorganization of the administrative agency for the apprenticeship system into the newly named Industry Training and Apprenticeship Commission (ITAC). Central to this reorganization was the introduction of a consultative governance model (that included the state, industry, labour and the training side), including oversight by two different Ministries rather than simply one as before. The system was designed to be more productive in meeting industry requirements while introducing specific apprenticeship programs for every designated trade (BCFED, 2012; Goedbloed, 2014). However, the Board of Directors of 24 members applied a consensus model that proved to be inefficient in reaching decisions (Coalition of BC Businesses, 2001).

The Liberals reversed course from the NDP by repealing legislation in 2001 that deregulated the construction industry while satisfying the demands of the 
employers to allow competitive market forces to determine labour terms and wages. This was followed, in a similar fashion to the NDP government, with the passing of the Industry Training and Apprenticeship Act in 2003. This legislation initiated a new round of restructuring of the training system into an industry-led, privatized model as a crown agency renamed the ITA in 2004. Unlike with the previous ITAC consultation model amongst the primary stakeholders, training and qualification requirements were delegated to industry sectors through a reorganization of the system into several different Industry Training Organizations (ITO), with the construction trades falling under the Construction ITO. Although there was a Labour representative on the Board of Directors as well as on those of the other ITOs, union representatives were excluded from the new Construction ITO (BCFED, 2012; Goedbloed, 2014).

Subsequent efforts focused on exhorting employers towards greater support of apprenticeships through the hiring of apprentices and improved recruiting initiatives. This was to ensure that the apprenticeship system was solidly positioned to respond to the anticipated rise in demand for skilled workers in $\mathrm{BC}$ over the ensuing decade (Bond, 2015; Clark, 2014). More recently under Premier Clark and based on the 2014 McDonald Report, the ITA was functionally re-organized due to funding and governance inefficiencies (each ITO had its own Board of Directors). There was also a recognized need to improve the consultative process as previously noted by the BC Auditor General. The ITOs were disbanded while their functional responsibilities were absorbed centrally within the ITA. In their place, Sector 
Advisory Councils were created to ensure industry retained a direct role in decision making thereby preserving the "industry-led" approach introduced by Premier Campbell (McDonald, 2014).

Past reforms and the recent skills strategy demonstrate that the $\mathrm{BC}$ government has maintained an interest and taken initiative in the development of skilled workers through the apprenticeship training system. BC is not unique in this regard, as training systems in Canada (and other western economies) have commonly been of interest to policy makers due to the importance of such systems for producing skilled workers to meet industry demands, address unemployment, and to improve economic prosperity (Brunello, 2009; Sharpe \& Gibson, 2005b). However, the dramatic swings in reforms between the NDP and Liberal governments merit further analysis as to the underlying reasons for them. Differences in political ideology would be a logical starting point for rationalizing such actions, but do not adequately explain other contributing forces such as an underlying lack of consensus as to the role of apprenticeships. Fundamental questions relating to this lack of consensus require a deeper analysis as to whether the apprenticeship system in $\mathrm{BC}$ is conceptualized either as a production system designed to meet near-term labour requirements, or as an alternative form of post-secondary education to that of university or college studies designed to prepare individuals for a career in the trades sector of the broader workforce, or as a blend of both divided in overall purpose. 
In addition to the legislative actions and imposed structural changes to the governance of the apprenticeship system by each of these three governments is the associated political context. The NDP is a center-left party with a socially progressive ideology that is commonly shared by labour unions. Conversely, the Liberals in $\mathrm{BC}$ are a center-right party with a conservative ideology towards business and the economy that is shared by the non-union sector. Consequently, the legislation regarding regulation and deregulation of the compulsory trades, along with the structural reorganization of the governance structure created power imbalances that impacted the relationships between the primary stakeholders in the apprenticeship system (BCFED, 2012; Bourke, 2013; Johncox, 2001b).

\section{Summary}

The objective of this chapter was to describe the historical evolution of the structural and functional aspects of the apprenticeship system as a skills ecosystem within the broader VET system in BC, as well as to illustrate the situation (before, during and after the research period) in terms of apprenticeship registrations. This historical overview was then complemented by a contemporary snapshot of the state of BC's VET system.

One of the main points of emphasis that sets the scene for problematizing the apprenticeship system in $\mathrm{BC}$ is the recognition that apprentices are caught in the middle of complex VET system of systems that is shaped and influenced by the four 
primary stakeholders identified, each with partial influence over the apprenticeship system but with divergent or competing interests. Given the nature of the governance framework along with the highly-segmented institutionalization of the system, the individual apprentice is faced with systemic challenges in the steps towards the successful completion of their apprenticeship. Apprentices not only face the daunting challenge of securing the necessary workplace experience between each level of VET, they also find themselves in a system that provides minimal financial support and career guidance in a system of fragmented governance. As such, most apprentices are left to their own devices in navigating the alternating VET-work phases of each successive level of their apprenticeship while maintaining the motivation to achieve their Journeyperson CQ.

It is apparent that the underlying issues that persistently challenge efforts to reform BC's VET system, improve both apprenticeship results, and meet BC's industry workforce requirements for skilled tradespeople have yet to be fully understood let alone adequately addressed. While the VET system in BC is not unlike those in most other provincial jurisdictions in Canada, the situation in $\mathrm{BC}$ is unique due to the legislation introduced in 2003 by the Liberal government that effectively deregulated the skilled trades. Under then Premier Gordon Campbell, the government eliminated 'compulsory trades' and introduced modularized competency-based training, thereby enabling apprentices to achieve certification for specific skills sets en route to completing their Journeyperson CQ (Harris \& Company LLP, 2003). In effect, the result of this legislation was a decline in the 
market value of a CQ due to the market preference for reduced labour costs through the hiring of partially-trained trades workers with certifications for specific skills, rather than paying higher wages for a fully qualified Journeyperson, an outcome forewarned by Sharpe and Gibson (2005b). Given the significance of these legislative initiatives and the subsequent outcomes, as well as the polarized political perspectives and approaches of two very different governments, the period of 19932004 may shed light on the nature of the underlying challenges and provide clarity on how to more effectively address them.

The next chapter develops a conceptual framework, based on a selection of models and theories in the literature review as well as a conceptualization of the problems associated with the apprenticeship ecosystem as part of the broader VET system. The primary focus will be to integrate various theories that can be applied to the examination of the underlying institutional issues pertaining to the competing perspectives on the role of apprenticeship programs (as well as the associated training and qualifications) within the broader realm of VET. The resulting conceptual framework will be used to explain how these perspectives evolved, and why and how they negatively impacted the social settlement in the period of interest. 


\section{Chapter 3 - Problematizing and Conceptualizing the Apprenticeship Skills Ecosystem}

\section{Introduction}

The previous chapter traced the historical evolution of the structural and functional aspects of the apprenticeship system as a skills ecosystem within the broader vocational education and training (VET) system in British Columbia (BC). This chapter reviews the theoretical literature relevant to the apprenticeship system, and draws from it several frameworks that I will use in this thesis to analyze not only the relationships between the skills ecosystem, the education system, the labour market, and the provincial government, but also the state of the social settlement amongst the primary stakeholders that underpins those relationships and the inherent tensions amongst them. The core of the explanation will evolve from the logics that are in tension with each other along with the structural institutional challenges related to the dual oversight of the VET system by two different ministries. The pressures created by these core factors, and the tensions they amplified amongst the stakeholders are further exacerbated by the dramatic swings in legislative initiatives driven by the political and ideological differences between the New Democratic Party (NDP) and Liberal governments.

Given that no single theoretical framework can address and encompass the many complex aspects of the system, it is necessary to combine the components of several 
different complementary theoretical frameworks into a broader conceptual framework. In this chapter I will explain these components in detail, how they build on one another, and are integrated through the logics to form the overall conceptual framework that will be used to analyze the problem and address the core questions of this thesis.

\section{Developing a Conceptual Framework}

The literature on apprenticeship training contains a range of theoretical frameworks that conceptualize the many approaches to such training that exist within the VET systems of western market-based economies. This chapter reviews several of these frameworks, and uses them to construct one suited to the core questions of the thesis. A key theme that comes out of the literature is the importance of support mechanisms, typically at the national level, to promote apprenticeships amid the array of post-secondary options that prepare students for entry into the labour market.

The reviewed frameworks, built upon Historical Institutionalism (HI) as a foundational layer, include typologies of western economies as well as models of skills ecosystems and the related transition systems that lead into and out of apprenticeships. They also include two sets of logics - the tension between the education versus employment logic developed by Iannelli and Raffe (2007), and the tension between the intrinsic versus institutional logic introduced by Raffe et al 
(1997) and developed by Young (2003) - that will be used here to analyse the transitions systems and the implementation of the legislative reforms over the period 1993-2004, the stated objectives of those reforms, and their effects on the social settlement.

The following discussion begins with the development of the conceptual framework. This framework consists of several components which will be explained individually but eventually integrated into a composite whole. The first is the Varieties of Capitalism (VoC) framework (P. A. Hall \& Soskice, 2001) which distinguishes between coordinated market economies (CMEs) characteristic of Northern Europe and liberal market economies (LMEs) characteristic of Canada and Anglophone countries. This provides the basis for explaining the way in which the different institutional structures in each type of economy mediate relationships between vocational education and the labour market. While the VoC literature characterises national systems, the next section uses the skills ecosystems approach to understand differences that occur between industries and regions in countries. This will be followed by the introduction of the concepts of the tension between the education and employment logic as well as the tension between the intrinsic and institutional logic to understand the different types of relationships between VET and the labour market in LMEs and CMEs respectively. 


\section{Conceptualizing Apprenticeships as a Skills Ecosystem}

As explained in Chapter 2, apprenticeship training began in medieval times with craftsmen sharing their skills with a student who, in exchange for the master's mentoring, provided in return dedicated labour. The process of sharing stemmed from an ongoing combination of explanations (knowledge), demonstrations (skill training) and application (workplace experience) (Lyons et al., 1991; Stewart \& Kerr, 2010). Today, although apprenticeships have become institutionalized, they still retain the basic elements of combining instruction with supervised workplace experience in fulfilling the necessary requirements for a given trade through a structured process. The key purpose of apprenticeships is to provide an alternative form of PSE that is focused on developing skilled workers for vocational trades in a number of different industry sectors. However, in countries such as Canada and other LMEs, apprenticeships also tend to be viewed socially as an option for less academically minded students, and the trades as a lower status career path (Bosch \& Charest, 2008; Canadian Apprenticeship Forum, 2013; Conference Board of Canada, 2002; Sharpe \& Gibson, 2005b).

Although relatively few scholarly articles about VET and questions of system design in Canada exist, a few exceptions are Bosch and Charest's (2008), Lehmann et al (2015), Meredith (2011), Sharpe and Gibson (2005b) Taylor and Watt-Malcom (2010), and Watt-Malcom and Barabasch (2010). The value of these articles is that they consolidate and characterize important trends that are mentioned in much of 
the international literature, along with some specific data points relevant to Canada. The transformation of the skilled trades from the post-World War II era through to today in Canada and the United States is clearly related to several factors, of which deregulation of the construction industry is but one of several mentioned. Another important observation has to do with the gradual erosion of the power of trade unions; however, no causal correlation is established between the deregulation and the erosion of the unions' power, nor is there any correlation between the significant deregulation milestones (e.g., early 1980s and relaxation of the regulatory framework under President Reagan) and the reduction in trade union memberships and/or registered apprentices. The literature review can be divided into two categories: scholarly material, and 'grey literature'. Most of the scholarly literature reviewed were international articles focused primarily on vocational education and training in western developed countries. The literature selection was due not only to the limited number of scholarly articles relating to the apprenticeship systems in Canada, as has been noted by others (Stewart \& Kerr, 2010), but also to the richness of the discussions relating to theoretical frameworks, typologies and comparative analysis in the international scholarly literature.

Fortunately, there is a far greater supply of 'grey literature' available for Canada and $\mathrm{BC}$ in the form of reports, surveys, reviews, government documents, and media releases which can be used in the research. Certain organizations such as the Canadian Apprenticeship Forum as well as other non-governmental organizations produce a wealth of information in the form of reports and other publications. 
Similarly, government agencies such as Statistics Canada produce useful analytical reports that include information relevant to $\mathrm{BC}$ in the form of National Apprenticeship Surveys (1993, 1995 and 2007) and the Registered Apprenticeship Information System (RAIS). This information is useful in illustrating the situation in $\mathrm{BC}$ in terms of trends for apprentices such as completion rates, discontinuers, and other indicators, but is limited in that it does not clearly represent the aggregation of results nationally due to differences in definitions and ambiguity in lexicon between jurisdictions that detract from the reliability of the data. Crocker (2014) notes that with the elimination of compulsory trades in $\mathrm{BC}$, data collected by the Census and Labour Force Surveys (amongst other reports) introduced ambiguities in the data in that "anyone is free to label themselves as a trades person in most trades." This in turn impacts the tracking of apprentices as some may be unregistered while others may be 'qualified' in their trade.

Tracing the historical evolution of the VET system and apprenticeships in BC provides the basis for an explanation of the institutional tensions, which evolved over time, and reflects the exogenous impacts of the economy and periodic government interest in workforce development. From the perspective of the employment and education logic pair, it also reflects the societal classconsciousness of both Canada's colonial past with Great Britain, as well as that of other immigrants coming to Canada in search of better lives for themselves and their children. Furthermore, to best understand the more recent institutional tensions relating to the public funding and subsidization of apprenticeships in $\mathrm{BC}$, it 
is useful to conceptualize the unique nature of apprenticeship programs within the broader framework of the provincial VET system. More specifically, the work-based experiential aspect of an apprenticeship, which amounts to roughly $80 \%$ of its duration, not only reflects the employment logic tendency, but also underlies the institutional challenges of Ministerial responsibility (and the associated bureaucratic administration), as well as the differing perspectives over training curriculum, delivery and associated qualifications.

\section{Problematizing the Situation for a Theoretical Analysis}

The apprenticeship system is composed of multiple agents (with four primary stakeholders, as previously identified) interacting to advance their own interests against the backdrop of a market economy that generates unpredictable cyclical demands for skilled trades workers in the various industries in BC (i.e., construction, forestry, mining, automotive, etc.). Given that the primary stakeholders are composed of groups of people and that the apprenticeship system involves various institutions, the problem can neither be adequately conceptualized from the perspective of individuals operating as singular units within the system, nor from the perspective of identifiable cause and effect relationships that can be isolated from the multiple, overlapping interactions between the primary agents. Consequently, the problem needs to be conceptualized on different levels from apprentice up through specific groups to the institutional level, each level having different degrees of impact on the VET system's operation and outcomes. 
By viewing the training system as a spectrum from the secondary education system through to the labour market, it can be conceptualized as a system of systems composed of separate institutions that have a functional relationship that contributes to the production of skilled, qualified workers. Within the system of systems lies the apprenticeship skills ecosystem and the dynamics of competing interests by the four principal stakeholders identified earlier. Furthermore, the demand side of the apprenticeship ecosystem is further complicated by conflicting priorities of the unionized and non-unionized sectors regarding the scope of knowledge, skills and training to be provided to apprentices. The crux of the divergence is rooted in their different interpretations of trade occupations and skill qualifications.

The apprenticeships are subject to change due to the unstable structure of the broader VET system of systems in which they are situated as well as the apparent facility with which the competing interests of the primary stakeholders influence such changes. As such, the VET system in BC is both structurally complicated and highly complex in terms of its weak stabilizing mechanisms for reconciling these competing interests into a social consensus over the core inputs and outputs of the system itself. The multi-dimensionality of the situation renders individual assessment of sub-components of the system very difficult. Determining linear cause and effect relations between, for example, stakeholder input to the system and subsequent changes to apprenticeship completion rates are nigh impossible. Furthermore, the responsiveness of the system to feedback creates a dynamic of 
continuous change to the inputs, processes and outputs of the system that compound the challenges of assessing such causal relationships.

While the structural issues mentioned affect the system, the root problem is the divergent perspectives of the primary stakeholders. These differences, shaped by ideologies, social-economic class differences and market interests, have an impact both on the interpretation and implementation of government intent. I will analyse this social dynamic through the use of an intrinsic and institutional set of logic. As such, the conceptualization of the root problem needs to be taken from that of several dimensions, not simply that of a structural issue with clear, linear, causal relations.

Given the dynamics of the VET system, the approach followed here places less emphasis on simple measurable outcomes such as completion rates, and more emphasis on how the relationships amongst stakeholders have been influenced by government legislation and changes to the governance of the system. Such an approach requires a comprehensive conceptual framework that can establish the basis for the interests and perspectives of the primary stakeholders. Furthermore, it requires a research design and methodologies that permit an effective, qualitative analysis of how the VET system and apprenticeships in particular adapt institutionally to the shifting power imbalances between primary stakeholders. This becomes important in determining how these dynamics shape the process by which the requirements of trades are determined. 


\section{Theoretical Components of the Conceptual Framework}

The foundational theoretical framework that I chose for my thesis was Historical Institutionalism (HI), which helps in relating path dependencies and how institutions evolve to circumstances experienced by BC's VET system during the period of 1993 to 2004. Upon this theoretical foundation are added the additional layers needed to explain the basis of the pressures on apprenticeships, the economic factors influencing the stakeholder tensions, as well as the impacts of the dramatic swings in political legislative initiatives directed at the VET system during this same period. The VoC typology provides the framework with which to explain the high level relationship between VET and the labour market, while the skills ecosystem theory helps to explain the uniqueness of apprenticeships within BC's broader VET system. Finally, the tensions underpinning the education and employment logic on the one hand and the intrinsic and institutional logic on the other provide the means to integrate these three theoretical frameworks, operationalize the relationships between the layers, and explain the underlying structural pressures on the system as well as the tensions amongst the primary stakeholders.

These elements are integrated to form the components of the overall comprehensive conceptual framework and to provide the means to explain how the underlying pressures on apprenticeships as a unique skills ecosystem within the broader VET system, along with the structural institutional issues created by the oversight of two different ministries. The discussion of logics provide the means to 
explain these underlying issues, as well as to explain how the swings in political reforms and their stated objectives added further pressure on the system while perpetuating rather than reducing the tensions amongst the stakeholders. The following sections will serve to provide a brief overview of each theoretical component that was used, and to explain how they were each integrated into this conceptual framework.

\section{Historical Institutionalism}

While the apprenticeship system is conceptualized as a system of systems and therefore not an institution unto itself, HI provides a basis for exploring the adaptive processes by which the Industry Training and Apprenticeship Commission (ITAC) and the Industry Training Authority (ITA) adjusted to the government's influence over the research period. Furthermore, it is an important and useful means to explain what institutions are, what role they play in society, and how they interact with other institutions. Institutions are seen by some scholars as being underpinned by relationships, with governance being a central node for affecting the role, nature and influence of stakeholders, including the creation of power asymmetries (Bosch \& Charest, 2008). The literature provides several models with which to conceptualize the change process, including the circumstances that trigger such change. 
Thelen's $(1999,2004)$ model, which views institutional change as an ongoing process of negotiation in adapting to its political and social environment rather than a deterministic process theorised as path dependency, appears better suited to this research effort. In this model, political reforms may invoke "a renegotiation of the conditional base on which specific arrangements rest, even as such renegotiations drive important changes in the form these institutions take and the functions they perform" (Thelen, 2004). Establishing the governance system as the 'conditional base', HI provides a framework with which to examine the means through which such relationships are impacted by changes to governance, and how this in turn affects the social settlement underpinning apprenticeship programs in the construction trades in BC. The strength of the social settlement has been found to affect VET systems in terms of the narrowing or broadening of requirements for trades training (Wheelahan, 2015). Given the predominant influence of the government in directing the system, $\mathrm{HI}$ will be used in a similar fashion to explore how the NDP and Liberal governments came to the decision to implement their respective legislative initiatives pertaining to the compulsory trades in $\mathrm{BC}$. It provides a basis for explaining the path dependencies that the different governments faced in their attempts to reform apprenticeships and the broader VET system of systems.

Although much of the early literature relating to skills development in market economies was grounded in classical economic theory such as rational choice and human capital theory, it was found to be inadequate for complex, social systems 
involving multiple concurrent relationships (Lowndes \& Roberts, 2013; Oliver, Yu, \& Buchanan, 2018). HI diverged from the classic theories through a recognition that the evolution of an institution is not necessarily the result of a succession of rational decisions guided by a long-term strategy, but is quite often influenced by external social, political or economic circumstances (Thelen, 1999, 2004). The adaptive mechanisms of the institution determine its evolution, whether in response to gradual change or in reaction to significant external events such as sudden changes in political direction. HI gained popularity as a means to analyze the circumstances that led to the evolution of an institution by exploring decision processes that reflected the impact of different motives, perspectives and alliances of participants (Thelen, 1999).

Path dependency, a concept often associated with HI, postulates that once an individual or institution embarks upon a particular path, that over time it becomes increasingly difficult to break free from the evolving and complementary support systems that perpetuate the established behavioral pattern (Raffe, 2008; Thelen, 1999; van Vught, 2008). The concept of path dependency is an additional tool to conceptualize how the adaptive mechanisms of an institution may establish a change in direction from which it becomes increasingly difficult to reverse as time progresses. Alternatively, path dependencies can be seen to reflect the inertia of an institution that seeks stability through its established norms, procedures, rules and other elements including its relationships that comprise its functional character. 
When combined with critical junctures (key decision points undertaken by an institution), path dependency is considered useful by some to understand how an institution evolved to a new condition when examined from a historical frame of reference (Levy, 2008; Powell \& Solga, 2010; Thelen, 1999). Complementary to this aspect of $\mathrm{HI}$ is the classic work by Bowles and Gintis (2011) that theorizes that the socio-economic background of an individual and the concomitant impact of economic institutions on the development and career outcomes outweighs the efforts by the secondary and post-secondary education system to enhance career opportunities.

HI gained popularity as a means to analyze complex decision processes that reflected the impact of different motives, perspectives and alliances of participants by examining events not so much based on the isolation and identification of causal outcomes, but more from the context of the circumstances at the time of the event. Furthermore, it conceptualizes institutions as being responsive to their social and political circumstances through relationships and internal feedback processes, rather than operating in isolation of such externalities (Thelen, 1999).

From a higher-level perspective, the contribution of HI arises from its focus on the evolution of institutions over time, assessing the ways and means in which they adapt to gradually changing circumstances, modulated by extant path dependencies, as well as significant shocks arising from a critical event such as a shift in political direction (Lowndes \& Roberts, 2013). Additional literature reinforces the utility of 
HI for conceptualizing VET systems within the framework of institutions that are indeed adaptive in nature, whether in analyzing critical junctures (Thelen, 1999) brought on by significant exogenous events, or in simply adapting to the changing social, economic or political environment (Gonon, 2008; Lassnigg, 2011).

\section{Varieties of Capitalism}

The VoC literature emerges as a theoretical foundation that has been used extensively in the VET literature as a basis to compare western countries through a political economy lens using a model based on the level of coordination between institutions such as the training system and the market (P. A. Hall \& Soskice, 2001). The simplicity of their typological model, which is essentially composed of two ends of an analytical spectrum between CMEs and LMEs, is used to identify the level of support likely to be provided. Although Canada falls within the LME realm of the typological model based on its tendency towards a laissez-faire perspective on the market, the framework provides the basis to theorize the challenges facing the apprenticeship system in $\mathrm{BC}$ as well as the competing interests between the unionized and non-unionized sectors.

However, other scholars have found the model too simplistic. For example, Lassnigg (2011) argues that there is a need to further examine the underlying institutional structure, organizational logic and support systems for VET of different countries that demonstrate high-level characteristics of the VoC typology. Other such as Green 
et al. (2010) and Culpepper (2001) argue that another weakness in the model is its lack of focus on state intervention through laws, regulations, policies and programs in circumstances in which the state has only partial or negligible control, even though the state is seen as the predominant actor within the VET system. Thelen (2012) also argues against oversimplification, proposing that the underlying coalitional structures of institutions and the manner in which they adapt to the changing political landscape is a more appropriate basis to assess where a given institution falls within the VoC typology spectrum.

Alternative frameworks tend to characterize LMEs and CMEs in similar ways, although they may have a more differentiated framework that identifies different approaches in different parts of the world (Wheelahan, 2015). Regardless, the VoC typology is a useful basis to conceptualize apprenticeship systems since Canada overall and $\mathrm{BC}$ in particular are liberal market economies and given the heavy reliance on the labour market in mediating the apprenticeship system, will be used as a framework in this thesis.

The role of the institutions in the VoC literature provides insights into the apprenticeship training system at a macro level, particularly the interconnecting parts and the role of stakeholders. Additionally, within the literature are numerous typologies used to describe the nature, substance and relevance of vocational skills that are of interest to this research. Some of the work is specific to skills such as the categorization of skills proposed by Buchanan et al. (2001) based on their 
application: cognitive, technical and behavioral. Given the active role of the NDP and Liberal governments in attempting to shape the apprenticeship system, conceptualizing the means by which the system adapted to such changes at the institutional level becomes another important element of the thesis and an area of interest in the literature review. Hall and Thelen (2009) develop the means by which institutions resist and adapt to forces of change, either exogenous or endogenous. Furthermore, Hall (P. A. Hall, 2006; P. A. Hall \& Thelen, 2009) seems to accept a more graduated approach to the VoC theory which allows for greater specificity in dissecting the motives and means by which institutions adapt to the ongoing influences of their associated groups / individual firms. This includes recognition of divergent interests of actors who may be involved in several institutions.

Not only does this serve to reinforce the need for HI, but it also differentiates traditional economic cause-effect relationships with a more appropriate, granular and workable model for both explaining the "before-after" situation in BC following the 2001 election of the Liberal Campbell government. It also serves as a powerful model to assess potential courses of action for the BC provincial government in seeking to fulfill their stated intrinsic logic objectives. However, despite the many critiques of Hall and Soskice (2001) and the various weakness in the simplified typology, it provides a useful theoretical basis to explain the underlying realities of the pressures on the post-secondary system in $\mathrm{BC}$, and how this add to the tensions between the VET system and apprenticeships from the vantage point of the 
relationship between education and the labour market. This relationship can be further explained through the addition of the skills ecosystems literature that follows.

\section{Skills Ecosystems}

The skills ecosystems literature (J. Buchanan et al., 2001; Raffe, 2008) provides the means to conceptualize the characterization of skills and qualification within the broader context of social norms, values and perspectives. Finegold's (1999) research on skills ecosystems in Silicon Valley's high-tech sector provides the basis for conceptualizing how apprenticeships (as a subset of BC's broader VET system of systems) are driven by, and respond to, differences in industry requirements when comparing cases between different trades, regions and sectors. Subsequent expansion of Finegold's theory was refined to distinguish intermediate and low skills ecosystems and the identification of 'clusters' as "competences in a particular region or industry shaped by interlocking networks of firms, markets and institutions" (Buchanan et al., 2001). Estevez-Abe, Iversen and Soskice's (2001) skills typology added an assessment of the levels of employer security and state welfare associated with each the three skill categories (firm-specific, industryspecific and general), with the construction trades falling within the 'industry specific' category. This category is conceptualized as vocations requiring investments in training and education, but competitive market forces such as 'poaching' disincentivizes employers to make such investments. Consequently, the 
risks associated with an investment in training leads to employers seeking to reduce such investments either by reducing and/or compartmentalizing the skills training and qualifications, or by seeking to have the state and/or the worker pay for such skills training.

The literature on educational and labour market transitions (Ecclestone, 2010; Raffe, 2008; Wheelahan, Moodie, \& Buchanan, 2012a) relates to the social and cultural aspects of how apprenticeships are perceived as a career choice and a PSE option for self-improvement, as well as to explain the role of coordination mechanisms as determinants of success when viewing the apprenticeships as a program model within the broader VET system. Finally, literature on vocational occupations (Brockmann et al., 2011) rounds out the conceptual framework through a relational association of vocational qualifications with socio-economic status, as well a co-relation between the breadth of VET provided to an apprentice and their ability to adapt to changing labour demands (i.e. to transition from one job to another within their trade).

Others such as Estevez-Abe (2001) took a very different approach to developing a typology that related to both the degree of transferability of skills as well as the welfare support structure that associated with the different categories. While 'firmspecific' skills have a high degree of interdependency between employers and employees, trades workers find themselves in Estevez-Abe's (2001) middle category of 'industry-specific' skills which are highly transferable. While this provides 
excellent mobility, it also undermines employer interests in any meaningful investment in training due to fears of their trained employees being "poached" by competitors (Bosch \& Charest, 2008). Such typologies are important given that trade skills and qualifications are the currency of skilled workers, the basis for wages, and how they are able to secure employment. As such, theoretical discussion on skills, qualifications and occupations become another element of the overall conceptual framework as a means to analyze the basis for divergent perspectives on their value in the labour market and in society overall.

A variety of scholars (Brockmann et al., 2011; Wheelahan \& Moodie, 2016a), examine these and other important questions that elevate the discussion away from the nature of the skills and how they relate to industry requirements and into the higher order perspective of the role of trades workers in society, including the social status associated with vocational occupations. These perspectives can help inform policy to support state interests in attracting youth into the trades and ensuring that apprentices persist with their apprenticeships through to completion. The BCBTC characterizes the generational self-reproducing described by Willis's (1978) ethnographic research, as is seen in the demographics of the trades unions, specifically the gender divide. ${ }^{13}$ The VoC and skills ecosystems provide additional

\footnotetext{
${ }^{13}$ Despite a persistent and sincere effort by the BCBTC to welcome a higher percentage of females into their trade unions, the change in the male-female balance has only changed minimally (Canadian Apprenticeship Forum, 2013).
} 
explanations to understand the context in which young people make career decisions shaped by gender and class. The building trades have been traditionally composed of male and working, and Willis (1978) explains the relationship of this generational self-reproducing tendency within the broader context of the social, economic and institutionalized structures.

The literature pertaining to skills ecosystems typically focuses on successful clusters that can arise within smaller microcosms, such as a region or city as well as within a specific industry sector, such as the Silicon Valley, for example. Several scholars (J. Buchanan et al., 2001; Finegold, 1999; Wheelahan \& Moodie, 2016b) ground some of the theoretical discussions into the realities of the market requirements. The addition of the ethnographic research by Willis and the VoC typology can help explain how a skills ecosystem such as apprenticeships can expand beyond local and regional geographical levels into a broader existence at a provincial level, such as in BC. When this is combined with $\mathrm{HI}$, and the structural circumstances of education and labour in $\mathrm{BC}$ along with the link between the two ministries overseeing the VET system, it explains how apprenticeships could exist as a unique skills ecosystem at the provincial level. This could be applied nationally across Canada based on the delegation of education to the provincial and territorial governments, as mentioned in Chapter 2.

Other scholars (Iannelli \& Raffe, 2007; Raffe, 2008; Rauner, Smith, Hauschildt, \& Zelloth, 2009) have conceptualized the apprenticeships and the VET system from 
the perspective of a process that serves to allow individuals to transition from one station in life to another, as well as from a systemic approach by way of support mechanisms associated with the process. The transitions of interest are related to both entries into the apprenticeships (such as out of high school) as well as into the workforce upon completion. Raffe (2008) develops a framework composed of four levels from the individual experience up through institutional/structural, national and international levels, that allow for an examination of transitions that thereby provide additional ways to examine and cross-compare systems. For the sake of this thesis, I will focus on the individual and institutional levels, whether it is between compulsory and voluntary trades, or even between different occupations within the same regulatory framework.

\section{The tension between the Education and Employment Logic}

Iannelli and Raffe (2007) build on the VoC literature by defining the different relationships between education and the labour market in CMEs and LMEs as 'transition systems', and that they use the concept of education and employment logics to look at the dynamics that shape the relationship between education and the labour market in each type of system. Their logics provide a basis to explain how the tensions which shape institutional change are implemented and mediated in CMEs and LMEs as it pertains to the relationship and between the post-secondary education (PSE) system and the labour market. The CME countries tend towards an employment logic, with systems that are designed to prepare students for the needs 
of the labour market and where there are strong and dense networks of relationships that connect the VET system to the labour market and social partners.

VET systems that typify an education logic tendency are found in countries with an LME system wherein the coordination between the broader education system and occupations is distant and weak, and is mediated through an employment market. The primary focus is on generalized academic education in preparation for PSE studies and potential careers in various professional fields along with the associated social status such careers offer. Inefficiencies in the supply and demand of educated individuals seeking to enter the job market are left to market forces, while education costs are largely borne by the state and the individual rather than the employers. Education systems in LME countries such as Canada tend towards an education logic, within which VET is seen to be the better career path for academically weaker students. This is emphasized by the fact that in Canada, vocational careers in the trades such as construction are held in lower regard compared to professional careers in the fields of medicine, law, engineering or business (Bosch \& Charest, 2008; Brockmann et al., 2011). This phenomenon reflects the generational selfreproducing characteristic of the trade unions (Dolby \& Dimitriadis, 2004; Willis, 1978), as mentioned earlier.

CMEs tend towards an employment logic with strong coordination mechanisms between occupations and education system not only in sharing information on requirements, but also through a more active investment in the overall education 
and training system. CME type countries reflect this logic, with the dual-track secondary school/apprenticeship systems in Germany and Switzerland often used as reference points in the literature for best practices (Bosch \& Charest, 2008; Powell, Bernhard, \& Graf, 2012; Rauner \& Smith, 2010; Swars, 2014). The greater coordination with labour market demands also brings higher interest in vocational studies, given the stronger potential for employment.

\section{The Tension between the Intrinsic and Institutional Logic}

Raffe et al's concept of an intrinsic versus institutional logic pair (1994) provides a framework to conceptualize and explain the means by which government policy is operationalized within the VET system (Wheelahan, 2015), and built upon the foundation of $\mathrm{HI}$ and the economic relationship between education and the labour market explained by the VoC typology. The intrinsic logic tendency provides the rationale for policies and policy reforms by specifying the reasons, purpose and intended outcomes for reforms. Furthermore, the intrinsic logic tendency embodies the overall stated political intentions / objectives and the accompanying rationale, often in generic terms, thereby leaving these legislative reforms open to interpretation. However, legislative reform initiatives by the government are subsequently mediated by the forces of institutional logic which reflect the economic and social interests of different constituencies as well as the construction of the institutions that underpin these systems. 
So, while the intrinsic logic of government reforms may be to increase the supply of apprentices, ensure a good match between supply and demand for skilled labour, and support economic development, these high-level aspirations must undergo the necessary implementation process by the bureaucracy to produce results. It is during the subsequent implementation and ongoing service delivery processes that the institutional logic of the different institutions, bureaucrats and stakeholders come into play in shaping the interpretation and application of the legislative reform. The resultant outcomes and how they differ from the high-level political aspirations are conceptualized as the tensions that emerge between the intrinsic and institutional logic pair. Thus, by using this framework, it will be possible to differentiate between intended and actual outcomes, and to understand how such differences are influenced and operationalized by the institutions, processes and stakeholder interests involved (Young, 2003).

\section{The Conceptual Framework - Integrating the Theories and Models}

No single theoretical framework relevant to VET and apprenticeships can provide the necessary tools to conceptualize the scope and complexity of the VET system of systems in $\mathrm{BC}$, or to comprehensively examine the underlying challenges that have repeatedly kept government reforms from finding an optimal way forward for VET in general or apprenticeship programs in particular. For these purposes, an integration of multiple frameworks is necessary. As a means of integration, this thesis adopts a layered approach, using HI as the foundational layer upon which the 
VoC and skills ecosystems layers are added so as to explain the relationship with the labour market, education and the VET system. The further addition of the logic pairs serve to operationalize the relationships amongst these layers, to explain the origins of the pressures on apprenticeship, and to explain how this increases tensions amongst the stakeholders. This multi-layered approach serves to establish different frames of reference with which to analyze the puzzle as well as to identify appropriate research methodologies, as will be detailed in Chapter 4 .

As the primary layer, the HI theoretical framework provides the basis for conceptualizing the VET system of systems as comprising institutions that evolve and adapt on a continuous basis through the influences of their political, social, economic and cultural environments, as well as through their relationships with stakeholders. The intermediate tier integrates the VoC literature that establishes the necessary economic backdrop to situate BC's VET system and apprenticeship programs, given the inextricable link of the latter with the employment sector and associated industry sectors such as construction. Within that layer, the VoC's LME and CME typologies provide the basis to further understand the impact of social, economic and political perspectives on apprenticeships as a skills ecosystem rooted in an employment logic within the context of the prevailing priorities and interests of the government and public alike.

The final layer of the conceptual framework introduces the skills ecosystems literature, including skills typologies, to conceptualize vocational (skilled trades) 
occupations within BC's employment sector (with a focus on the construction industry) so as to conceptualize apprenticeships as a unique form of VET within the broader spectrum of VET delivery through BC's TDAs. While all three layers serve to explain the interests and perspectives of the primary stakeholders who will be the subject of the research, the ecosystems literature provides valuable insight into the underlying pressures on apprenticeships (given their uniqueness within the broader VET system), and how this exacerbates the tensions amongst the stakeholders. Figure 3 depicts the three layers of the integrated conceptual framework along with the two pairs of logic sets that serve as the operationalization mechanism to understand how these pressures relate to stakeholder tensions and the outcomes of legislative reform initiatives.

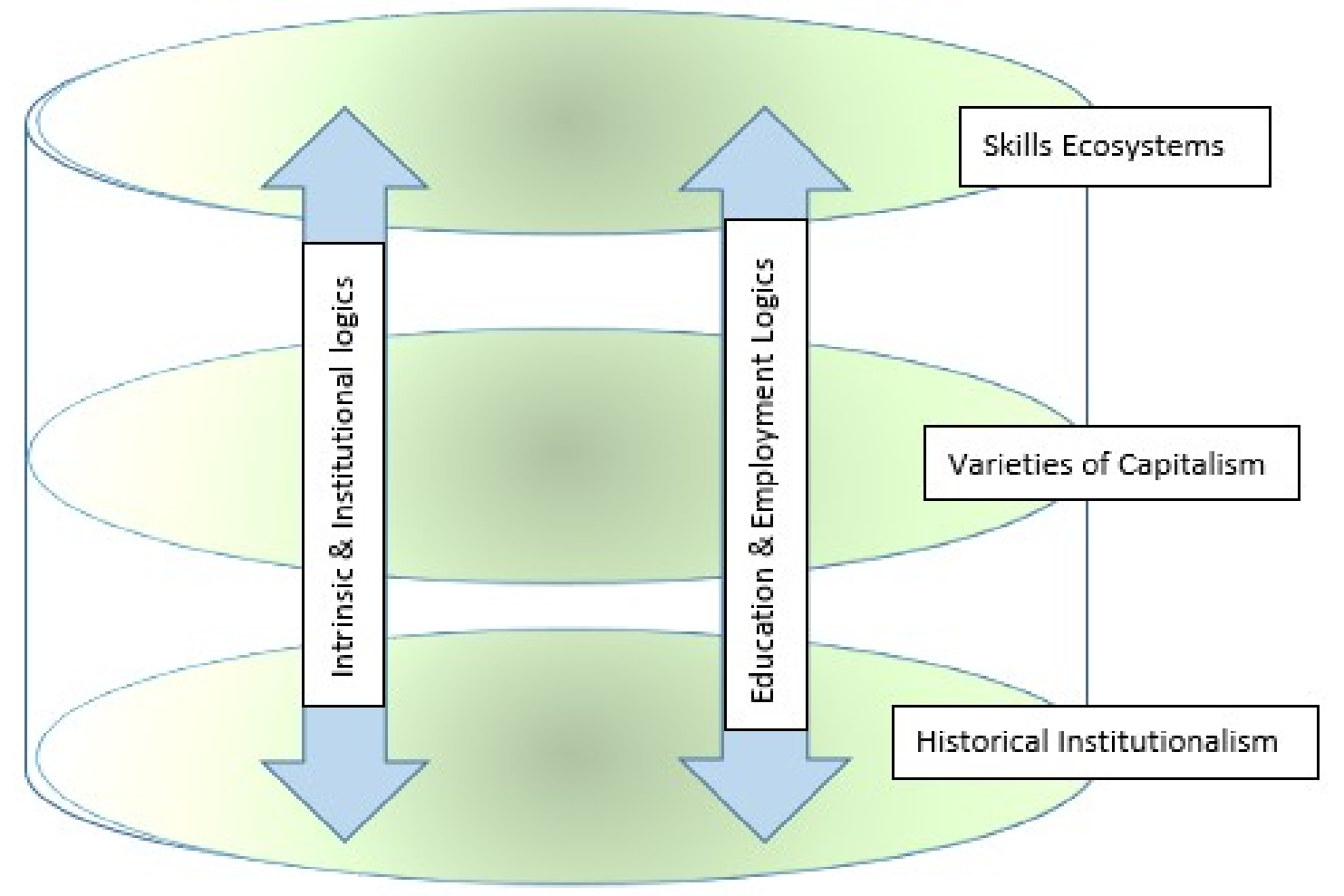

Figure 3: Visual depiction of conceptual framework 
The operationalization of the conceptual framework is achieved through the application of the pairs of logics. I used the educational versus employment logic pair to analyze the tensions between apprenticeships, the education system, and the labour market. The intrinsic versus institutional logic pair was used to understand the processes of political and institutional change by analyzing the intrinsic rationale for reforms and how they were justified, and how these reforms were mediated through the implementation process by institutional forces, stakeholder interests and other factors. The application of the intrinsic versus institutional logic pair facilitated an analysis of the gap between political aspirations / objectives with actual outcomes. Overall, this integrated and multi-layered conceptual framework generates a series of interrelated questions relating to government engagement in apprenticeships and the broader VET system of systems in BC, where that engagement is affected by the evolving influence that primary stakeholders have on the government of the day, and by how the trades training system responded to the series of legislative reforms. Central to the research was the role of the governance system in shaping such interactions, as well as the impact of any political influence stakeholders applied to serve their interests, and the result this had on the social settlement amongst them.

\section{Summary}

The literature review demonstrates the scope and depth of the scholarly work underpinning apprenticeships as a subset of VET, and introduces several different 
theoretical frameworks, typologies and models that can be drawn upon to create the conceptual framework required for this research. Although the volume of scholarly material relating to apprenticeships in Canada, and more specifically BC, is limited it is not limiting, and a substantial body of useful 'grey literature' was found both during the literature review phase as well as during the research phase of this thesis. In closing, the conceptual framework is the basis for establishing the research design and the selection of appropriate research methodologies, which will be discussed in detail in Chapter 4 . 


\section{Chapter 4: Research Design and Methodology}

\section{Introduction}

The previous chapter developed a comprehensive multi-level conceptual framework that integrated several theoretical frameworks and two pairs of logics as the means to conceptualize the structure and function of the apprenticeships as a skills ecosystem within the British Columbia's (BC) broader vocational education and training (VET) system. Having created this conceptual framework, the next step towards answering the core research questions of the puzzle is to determine a research design strategy, including appropriate and accepted methodologies.

As previously stated, the research effort focuses on the province of $\mathrm{BC}$ and the period of 1993 to 2004 because of the significant legislative reforms of the VET

system and apprenticeships introduced by two ideologically different governments. These circumstances provide the opportunity for a "before-after" within-case comparative study, an approach recognized for its utility in qualitative research, particularly for circumstances in which the political impetus for legislated reforms is central to the study of the subsequent outcomes (George \& Bennett, 2005). The rationale for this research decision and methodology will be developed later in this chapter in terms of the conceptual framework developed in the previous chapter, and how these relate to key components such as the pairs of logics. Given the decision to focus on the legislative initiatives that were introduced during the 
research period of interest, historical institutionalism (HI) figures prominently in its role as the foundational tier for the conceptual framework.

The central focus of the research plan is to establish a clearer explanation of the underlying factors that weakened the effective governance of the apprenticeship system in $\mathrm{BC}$ and influenced the tensions amongst the primary stakeholders, and to explain how they weakened the social settlement, thereby undermining the legislative reforms of the government. As such the core research questions are as follows:

1. How were the relationships between apprenticeship programs, the labour market and the post-secondary education system coordinated, governed and shaped in $\mathrm{BC}$, and why did they take the shape they did?

2. What motivated the New Democratic Party (NDP) and Liberal provincial governments to impose significant changes to apprenticeships and the governance structure?

3. What was the outcome of these processes of change on apprenticeships as a skills ecosystem within the broader vocational education and training system in $\mathrm{BC}$, and why did this particular outcome occur? 
As stated in the previous chapters, the research focuses on the construction industry in BC. The key stakeholders were identified as the provincial government and its bureaucracy, the unionized construction sector led by the BC Building Trades Council (BCBTC), the non-unionized construction sector led by the Independent Contractors and Business Association (ICBA), as well as the VET providers, namely the accredited public and private training delivery agencies (TDAs). Based on the two pairs of logic discussed in Chapter 3 (the education versus employment logic pair, and intrinsic versus institutional logic pair), examination of the three conceptualized levels of interaction with the apprenticeships is undertaken to address the core questions. For the purposes of this research, these three levels are categorized as the legislative (elected government and bureaucracy), governance (apprenticeship system's Board of Directors), and practitioner (those administering, training, employing and mentoring apprentices).

\section{Research Design}

My research interests are situated within the seams between disciplines and world views. I found that there is no single theoretical framework that addressed my questions, and that I needed to draw upon complementary theoretical frameworks to do so. Recognizing that the underlying basis of my research was that of social science rather than natural science, it became apparent that I would need to create my own conceptual framework to address my three research questions.

Furthermore, it was apparent that the answers would have to be derived though an 
interpretive analysis of a complex, multi-faceted, relational research object that was undergoing continuous and unpredictable change.

Unlike with the natural world, studies of the social world are founded on the human condition in which the endowments of free will, consciousness, and introspection enable individual and collective agency, albeit within normalizing culture of institutions. The adaptive responses of such agency are not bounded by predictable outcomes. Furthermore, my research questions required the means to interpret, analyse and explain the confluence of social, economic and political dynamics across the intersections of institutions, organizations and labour markets in terms of the pluralistic stakeholder relations, both formal and informal.

Consequently, for the purposes of my thesis, it was necessary to draw upon applicable components of the literature in order to establish a unique conceptual framework in order to address the three core requirements of my thesis as follows:

1. The nature of the object of my research (as previously mentioned);

2. The purpose of the study (as articulated through my core questions); and

3. The strategy underlying the research design, tools, data and methodology.

The research design draws from the conceptual framework introduced in the previous chapter, and allows one to explore the literature on transitions as they relate to the relations between the supply side of the education system (into 
apprenticeships) and the demand side of the skilled trades labour market (Iannelli \& Raffe, 2007; Raffe, 2008; Wheelahan, Moodie, \& Buchanan, 2012b). As discussed in previous chapters, Canada fits within Liberal Market Economy (LME) typology, in which a laissez faire free market ideology is prevalent (P. A. Hall \& Soskice, 2001), and for which the educational system typifies an education logic tendency. Accordingly, apprenticeships stand out as an exception to the general typological character of the Canadian post-secondary education (PSE) system in that they typify an employment logic tendency.

Raffe (2008) underlines the importance of examining a transition system from a historical perspective so as to better understand the evolution of the institutional linkages between the education system and the labour market, and this has been done with the VET system in BC as it pertains in particular to apprenticeships. Thelen (1999) underscores the social aspect of institutions by explaining that they are built and shaped by people, and that institutional linkages are highly influenced through the associated inter-relationships between members of the respective institutions, as well as more formalized interactions amongst these same institutions, such as through collective labour agreements or memoranda of understanding. Achieving a detailed explanation of the apprenticeship system, particularly for the purpose of addressing my research questions, requires a detailed analysis of these inter-relationships from a variety of individual and institutional positions. 
Such an understanding better informs policy makers of inherent weakness and/or disconnects that could affect the system's performance in terms of capacity, efficiency, effectiveness and/or results through the provision of an interpretative paradigm through which to see the system from a fresh perspective (Starman, 2013). Stake (1978) emphasizes the importance of the epistemological aspects of qualitative research, applying terminology and context that is relevant to those interested in the application of the research results from an institutional or individual practitioner perspective. It would follow that familiarity with the context and people involved in the research subject would enable richer insights to the analysis and results. This was found to be the case as will be explained further below during the process of completing the interview transcripts.

As previously discussed, the period of interest for this research effort (1993 - 2004) was chosen specifically to provide a "before and after" analysis of the changes to the VET system and apprenticeships resulting from the legislative initiatives of two different governments in power in $\mathrm{BC}$ over this time span. The fundamental differences in the opposing political ideologies between the New Democratic Party (NDP) and Liberal governments are of particular interest for this thesis in terms of both the critical junctures created by the different pieces of legislation that were introduced, as well as the changing dynamics of the social settlement between the primary stakeholders involved in the apprenticeship system. This will be examined through the lens of the intrinsic versus institutional logic pair from within the conceptual framework. 


\section{Historical Institutionalism}

...historical institutionalists see institutions as the legacy of concrete historical processes. In embracing this view, historical institutionalism brings questions of timing and temporality in politics [rather than equilibrium order] to the centre of the analysis of how institutions matter. (Orren \& Skowronek, 1994)

HI was chosen as the theoretical basis for the research design as it is recognized as an effective guide to political and public policy enquiries since it establishes the basis for an explanation of the processes associated with changes in policies within the dynamics of complex relationships between individuals, representative groups and institutions (Bates et al., 1998; P. A. Hall, 2013; Thelen, 1999). Relevant to this thesis is the accompanying qualitative characterization of institutions that comes from the HI literature. Such characterization includes the notion that institutions are less inflexible in terms of inertia based on extant organizational culture, customs, mores and standard procedures, than previously thought due to the fact that institutions are composed of people who are individually and collectively affected by both endogenous and exogenous social, cultural, economic and political forces (P. A. Hall \& Thelen, 2009).

$\mathrm{HI}$ and two of its commonly associated methods (case studies and process tracing) are selected to examine how the institutions engaged in a common system (BC's VET system and apprenticeships) adapted to a series of legislative initiatives, and thus the apprenticeship system and its outputs. The examination proceeds from two perspectives: the formal structure of these relationships through the governance 
system of the respective apprenticeship body, and the informal structure of the asymmetric level of power and influence amongst one or more of the stakeholders over the others.

The case study and process tracing methods will be discussed in detail shortly. However, it is appropriate at this point to explain why these methods were chosen as complementary methods associated with $\mathrm{HI}$ within the overall research design strategy. Given the complex social nature of the research topic as well as its historical uniqueness, the case study method was chosen to allow for a comprehensive exploration of the apprenticeship system and its associated institutions and stakeholder groups. A bounded, single case study covering the period of interest would be enriched by the epistemological aspects of the research data sources (interviewees in particular) to develop a comprehensive explanation of the apprenticeship system necessary to answer the core thesis questions (Stake, 1978; Starman, 2013).

Process tracing is a commonly applied method within $\mathrm{HI}$ research and is typically used to focus on a particular chain / chronology of events associated with critical junctures and policy feedback loops that are of interest in the analysis of institutional changes (George \& Bennett, 2005; Thelen, 1999). While critical junctures are loosely described as significant events typically of an exogenous nature (Thelen, 1999), for the purpose of this research the introduction of specific pieces of legislation by the respective provincial governments were seen to be 
catalysts for the institutional changes in BC's VET system and apprenticeship programs. The associated feedback loops were seen to provide valuable insights into the operationalization of institutional logic.

\section{Methodological Approach}

...institutions are conceived in relational terms; and institutional arrangements cannot be understood in isolation from the political and social setting in which they are embedded (Thelen, 1999).

A qualitative research design was most appropriate to respond to the thesis' research questions. I sought to engage in interpretative understanding (Sayer 1992) to analyse the different perspectives of the key actors involved in the governance of the $\mathrm{BC}$ apprenticeship system and their explanations for the different actions they undertook through interviews and through documentary analysis. This enabled me to engage in 'thick description', as part of the process of analysis through which allowed me to "establish the significance of actions, behaviors or events for the participants involved" (Dawson, 2010). Engaging in thick description does not mean accepting an interviewee's explanations of why things happened as they did, because many factors contribute to producing particular outcomes (Sayer, 1992). However, interpretative understanding enacted through thick description does allow one insights into the reasons that individual had for acting as they did, even if the outcomes were not as they intended (Sayer 1992). 
Given the complex social nature of this research topic, a qualitative descriptive research design is useful in developing a rich understanding of the apprenticeship system through interviews with key stakeholders at different points in the process, and through analysis of legislative, policy and institutional documents.

Within the framework of the research strategy and design was the interest in developing a rich description from a conceptual perspective as to how the pairs of logic (education versus employment, and intrinsic versus institutional) were operationalized through the formal and informal governance structures influencing adaptive changes to the VET system in BC during the period of new legislation. Such an explanation is best established through methods that permit the creation of a detailed "thick description" (Sayer, 1992) of both the series of events as well as associated perspectives of the primary stakeholders and subsequent changes to the system.

As previously mentioned, the case study and process tracing methods were selected for their utility and complementarity with the HI theoretical research design. I will examine their qualities and advantages for this qualitative research effort immediately below. 


\section{Case Study Method}

A single case was chosen for the research design, thereby allowing for a concentrated exploration of the subject. This allowed for an in-depth analysis that was able "to illuminate the characteristics and particularities of the case in question" (Dawson 2010). Dawson (2010) explains that thick description "has particular relevance for case study research because it highlights the importance of looking at phenomena in depth, going beyond the level of surface appearances". In undertaking thick description, researchers must pay attention to history and context that are the focus of attention.

The time period was deliberately selected so as to provide a specific within-case (before-after) study that was ideally suited to answering the central research questions. Case studies are used extensively within applied social science research (Creswell \& Creswell, 2018; George \& Bennett, 2005; Levy, 2008; Starman, 2013; Yin, 1994), particularly for enquiries in which the descriptive "what" and "how" aspect of a historical research topic are of primary interest. The central question is focused on the impacts of asymmetry in the level of influence that may have been applied within the relationships between the primary stakeholders as well as their influence on the apprenticeship system. The case study was further narrowed in scope to the construction industry, while the time frame was deliberately limited to a continuous but fixed period that allowed for the exploration of the results of such 
formal and informal distributions of influence under two, ideologically opposed governments.

From a research design strategy, the intent was to carefully limit the differences other than the primary comparative factor, that being the existence of two ideologically opposed elected provincial political parties: the left-leaning NDP holding power during the earlier half of the research period followed by the rightleaning (within the unique context of BC politics) Liberal Party during the latter half. Although this provided for a small $(\mathrm{N}=2)$ case study, from a research design perspective it was advantageous in terms of HI given the focus on the impact of changes to a common system of institutions. It is important to note that when one party was in power, the other was in opposition which meant that both parties were actively engaged in the development of particular legislative instruments that are studied during the period of interest, whether in seeking to introduce the legislation into law as the party in power, or to argue against it as the party in opposition.

\section{Process Tracing Method}

As previously mentioned, process tracing has become a well-established method within HI and case studies for social-political research (George \& Bennett, 2005; P. A. Hall, 2013; Thelen, 1999). For the purposes of this research, process tracing involves creating a chronology of events pertaining to the development of specific bills and the formal introduction through the Royal Assent process of legislation, as 
well as the subsequent events that follow during implementation. As such, it provides valuable insights not only into the rationale behind such government initiatives, but also the impetus for such actions whether it be political ideologies, lobbying influences of stakeholders in the VET system and apprenticeship programs in $\mathrm{BC}$, or a combination of both. Process tracing provides the means to recreate the narrative surrounding unfolding events thereby providing a richer understanding (George \& Bennett, 2005; Levy, 2008).

Of central interest to this research are the parallel activities relating to the formal governance structures and the informal efforts by one or more of the primary stakeholders to influence the government before and / or after the various legislative initiatives were pursued. It is not unusual for stakeholders to seek to influence the legislative process through a variety of means such as election campaign financing, lobbying, publication of opinion pieces, the submission of unsolicited thought papers on legislative initiatives, and so on. Through process tracing and a detailed scrutiny of the chronology of events, it is possible to see an association between these documents and subsequent actions and / or statements by the government, particularly by the Ministers of Advanced Education and Labour. In some specific cases it is possible to establish probable links between the informal stakeholder efforts to influence government and subsequent policy statements / positions by the government as recorded in debates in the $\mathrm{BC}$ Legislature (via Hansard), or in the resultant acts and ministerial policies that were implemented. 
For this reason, process tracing provides valuable insights into the context that led to various legislative initiatives pertaining to VET and apprenticeships prior to the period of interest as well as the ability to establish such links with different stakeholders. As such, many of these useful documents were found during the research phase through specific references made in the BC Hansard or by interviewees. For example, in tabling Bill 43 (Industry Training and Apprenticeship Act) on 23 June 1997, the NDP government of the day made several references to a joint study conducted by its Ministries of Education and Labour entitled Revitalizing Apprenticeship: A Strategic Framework for British Columbia's Apprenticeship Training System that had been released several months earlier, and was seen as having been shaped by the BCBTC (British Columbia Construction Association, 1997).

Similarly, the rationale put forward by the Liberals in second reading debates in the BC Legislature pertaining to Bill 34 (Industry Training Authority Act) that was tabled on 30 April 2003 closely resembled the arguments developed by Johncox (2001a) in his paper entitled Compulsory Certification in Selected Trades - Where to from here in B.C., as well as the recommendations put forward in the December 2002 discussion paper by the Ministry of Advanced Education entitled A New Model for Industry Training in British Columbia (2002). In other circumstances, timelines were used for contextual clarification, such as establishing structural changes of key ministries involved with the apprenticeship system, mainly those pertaining to post-secondary education and the workforce, with bureaucratic issues pertaining to funding (e.g., 
changes in government as well as cabinet shuffles sometimes led to restructuring, including amalgamation, of ministries).

\section{Data Selection}

...the interdependencies among the various parts of the system are central to the analysis (Streeck, 1997).

A qualitative research design strategy was purposefully selected to address both the historical nature of the thesis, as well as the intent to develop the basis for explaining the "what" and "how" that took place during the period of interest, as this was determined to be the best approach to answering the core research questions.

That said, a mixed methods approach that used quantitative data to supplement the qualitative methods would have been beneficial, but as explained in Chapter 3, this was not feasible because the available data on the apprenticeship results in $\mathrm{BC}$ were unreliable, as reported both by the Auditor General's assessment in 2008 (Doyle, 2008) and in a comprehensive review of the ITA in 2014 (McDonald, 2014) as directed by Premier Clark. The review reported that the "ITA information systems currently do not collect or report on the progress of registrants in an accurate and useful manner (McDonald, 2014). The reliability issues relate to inconsistencies in terminology, definitions and the nature of the practices between provincial jurisdictions as well as within $\mathrm{BC}$ over different periods of time. As such, the limited use of data that is included in Chapters 2 and 6 are included simply to provide a 
picture of the apprenticeship system in BC in terms of key measures (e.g. completion rates) before, during and after the research period. But as noted above, the unreliability of the data means that they are included for illustrative purposes only, and not as a basis for quantitative certainty. ${ }^{14}$

For this study, qualitative data provide the primary source material to establish the basis for a "thick description" (Sayer, 1992) from which insights into the stakeholder perspectives, objectives and desired outcomes were derived. Such data were obtained through one-on-one interviews with individuals who largely held key roles in the legislative initiatives, governance and had first-hand involvement in the apprenticeship system in BC over the period 1993-2004.

Details derived from document analysis complement the interviews, enabling me to prepare for and identify how each interviewee's unique experience could further

\footnotetext{
14 Within BC, the means by which the data were collected over the period of interest (1993-2004) were negatively impacted in several ways. First of all, the software tools that were introduced to collect the apprenticeship data changed several times, thereby creating rectification issues that resulted in lost or irretrievable data. Secondly, with the dismantling of ITAC in 2001, and the minimal staff assigned to administer the apprenticeship system, both during the two-year period in which the Ministry of Advanced Education looked after the system, and thereafter during the early years of the ITA in which staffing was severely limited.

Furthermore, the archiving of such data lacked a guiding protocol or careful process. The data collected were not retained by either ITAC or the ITA once a registered apprentice successfully completed their CQ, or dropped out of the program. Instead, the data were transferred to the applicable Ministry that oversaw ITAC or the ITA. However, given that the responsible Ministry underwent changes over the period of interest, either through amalgamation with another Ministry, or physically changed buildings, the actual location of the archived files were forgotten as bureaucrats came and went.
}

The other detracting issue relates to the practices used in the collection of data on apprenticeship registrations, completion rates, and other details that could otherwise provide powerful analytical tools for assessing the success of apprenticeship programs with consistency and accuracy. The problem is further exacerbated when comparisons are made between provinces and territories, or aggregated at a national level, such as with National Apprenticeship Surveys (NAS) or the Registered Apprenticeship Information System (RAIS). These issues with the unreliability of apprenticeship data have been reported by several scholars as highlighted in the literature review in Chapter 2 (R. Brydon \& Dachis, 2013; Crocker et al., 2010; C. Laporte \& Mueller, 2013; Meredith, 2011). 
enrichen the observations and explanations obtained from the others. Such documents include reports, official policy papers, Hansard transcripts and other written records that capture the arguments for the applicable legislative initiatives that impacted the VET system and apprenticeships, as well as select documents such as thought papers, trip reports and lobbying initiatives. Such materials also offer contemporary accounts of specific time periods, and thus serve as a counterweight to the narrative accounts of the interviewees whose observations would inevitably be shaped through the reflective lens of knowing how events unfolded over time (Bowen, 2009; O'Leary, 2014). Combining data from the interviews and documents allows for a more comprehensive explanation of how and why the different stakeholders sought to change the VET system and apprenticeship programs, as well as of the intended and unintended outcomes that ensued. In some cases, such a synthesis was achieved through triangulation of perspectives (Creswell \& Creswell, 2018) by cross-referencing differences in the commentaries of two or more interviewees with other references such as the Hansard transcripts from the BC Legislature library.

\section{Interviewee Selection Framework}

Selecting a range of interviewees provided a diversity of first-hand perspectives by key participants in the legislation, governance and practical involvement in the VET system, while keeping the interview process feasible (between 15 and 25 interviews total). The derivation of a thick description of the VET system was integrated into 
the research design, which sought the unique stakeholder perspectives at the political, governance and practitioner levels within BC's VET system. The goal was to provide a balanced selection of stakeholder perspectives. Such a selection also provided insight into the impetus and rationale for the legislative initiatives taken by the respective NDP and Liberal governments within the broader context of the exogenous economic circumstances in $\mathrm{BC}$ as well as the endogenous influence of the institutions involved.

For the exploration of the impetus, the objective was to select interviewees who could offer representative perspectives from each of the four primary stakeholder groups, with an emphasis on the tensions created in considering the intrinsic versus institutional and education versus employment logics which served to operationalize the conceptual framework. By seeking to capture these perspectives, as well as the values, interests and beliefs that influenced them, the objective was to develop an explanation for the nature of the social, structural and institutional dynamics within the apprenticeship system. The interview questions were openended to provide latitude for the interviewees to reflect on the underlying factors that influenced their perspectives on events as well as their opinions on the questions posed. In most cases, the interviewees were open to providing such additional context.

For the latter, effort was made to obtain interviewee perspectives from the legislative, governance and practitioner levels which were chosen deliberately. The 
political level was deemed essential, necessary to gain insight into the rationales of political leaders in making changes to the VET system and apprenticeship programs. Consequently, the objective was to solicit interviews with key political figures from both the NDP and Liberal parties who were involved in the creation and passage of legislation that affected the institutional structure of BC's VET system. For the governance level, the objective was to solicit interviews with stakeholder representatives who were either Board members of the Industry Training and Apprenticeship Committee (ITAC) and the Industry Training Authority (ITA) including their respective sector advisory councils involved in the construction industry. Finally, at the practitioner level, the objective was to interview individuals who were either directly involved with apprenticeships (such as training delivery, employment of apprentices, and/or providing support to apprentices) or who had interests in the training and certification aspects of the VET system.

From a research design perspective, the main objective for including the vantage points from the three hierarchical levels was to mitigate the anticipated bias in the interviewee's comments. This was largely achieved through the resulting 19 interviews that were undertaken during the field research phase. Together they provided for a balanced, well-rounded set of perspectives. Table 3 below provides an overview of the framework used for the selection of interviewees, as well as the number of interviewees that provided perspectives at one or more of the three 
levels. ${ }^{15}$ It is important to note that several interviewees held a governance position during one period, and a practitioner role in the other. In another case, one of the interviews was part of the government opposition in one period, and a legislator as part of the elected government in the other period. In all cases, the interviewees were familiar with what was happening with BC's VET system and apprenticeships throughout the period of interest. Consequently, they often provided comments that were comparative in nature between the time when the NDP and Liberals were in power.

\section{Table 3: Framework for selection of interviewees ${ }^{16}$}

\begin{tabular}{|c|c|c|}
\hline $\begin{array}{c}\text { Level of } \\
\text { Interaction }\end{array}$ & Interviewee selection framework results & $\begin{array}{c}\text { Number of } \\
\text { Interviewees }\end{array}$ \\
\hline Legislative & $\begin{array}{c}\text { Former Premiers and Ministers of both parties } \\
\text { (NDP \& Liberal) }\end{array}$ & 4 \\
\hline Governance & $\begin{array}{c}\text { Former members of ITAC \& ITA Boards, as well } \\
\text { as members of the respective advisory } \\
\text { committees (construction sector) to each Board }\end{array}$ & 10 \\
\hline Practitioner & $\begin{array}{c}\text { Individuals engaged in training delivery (public } \\
\text { and private), contractors/ employer } \\
\text { associations, union \& non-union construction } \\
\text { associations }\end{array}$ & 11 \\
\hline
\end{tabular}

\footnotetext{
${ }^{15}$ Although only 19 people were interviewed, some of them were able to provide more than one of the key perspectives. For instance, in one case an interviewee was a governor of the ITAC, then later a practitioner under the ITA.

16 Given that the thesis case study covers two distinct sub-periods of political governance (NDP \& Liberal), certain interviewees were able to provide a governance perspective for one period, and a practitioner perspective for the other.
} 


\section{Document Selection Framework}

As previously stated, documents were identified as another important source of research data that complemented the interviews through the provision of contemporaneous insights and observations into historical events. As with the selection of interviewees, a separate research design framework was established for the selection of documents. In this case, the objective was to critically examine the separate instruments of legislation pertaining to the VET system and apprenticeships that were introduced by both governments. A specific emphasis was assigned to examine how the arguments for these changes had become government priorities, and why the government was compelled to focus its efforts and resources on such changes. These legislative initiatives were seen as the theoretical "critical junctures" (Thelen, 1999) that reflected changes to the apprenticeship system; the documents provided the data for tracing the processes associated with the impetus behind these bills. Similarly, emphasis was assigned to explaining what the outcome of these changes had been in accordance with the core thesis questions. The framework for the selection process proved to be a relatively simple and effective approach.

I had anticipated that the interviewees might make reference to additional documents that had not been identified for consideration, documents that were used to either influence the creation of new legislation, or provide an analysis of the results that came from the changes triggered by the legislative initiatives of interest. 
In such cases, every effort was made to find the cited documents and to analyse them accordingly.

\section{Hansard Records and Acts}

The BC Hansard provided a wealth of transcripts pertaining to the legislative initiatives (specific bills) that were tabled and debated in the BC Legislature in the domains of PSE, labour regulations, and skilled trades training. I had anticipated that these transcripts might provide valuable clues as to the basis of the legislation, such as commissioned studies, reports, recommendations (such as from audits or investigations), thought papers, or other references. Once such references were identified, they would contribute to the second part of the selection framework. Moreover, the Hansard proved to be a useful source for the identification of references that were cited by the ministers tabling and defending such new legislative initiatives. Additional references came from other studies and scholarly articles that touched on the apprenticeship system in $\mathrm{BC}$ during the time of interest.

\section{Government Reports}

The final component of the document selection framework was to review government reports that would provide a critical analysis of results pertaining to the apprenticeship system, ideally in the realms of performance and deficiencies. The 2008 BC Auditor General's Report (Doyle, 2008) was a prime example that was 
included. Although it was possible to locate most of the documents, there were some that were never found, despite the use of search-engines and library assistants. I visited the $\mathrm{BC}$ Legislature Library as well as the $\mathrm{BC}$ Archives on several occasions in order to find documents. In other cases, I contacted the author of specific documents for assistance in securing copies that couldn't be found on-line or in archives. Some documents proved to be too difficult to find due to how they had been archived. Given that the ministries relating to PSE, the VET system and apprenticeships had been subject to several different re-organizations over the years up to the present, the location of particular files had been forgotten or lost. An overview of the different types of documents that were selected for my research is provided below:

\section{Table 4: Overview of documents selected}

\begin{tabular}{|c|c|c|}
\hline $\begin{array}{c}\text { Type of } \\
\text { Document }\end{array}$ & Application to Answering Thesis Question & $\begin{array}{c}\text { Number of } \\
\text { Documents }\end{array}$ \\
\hline $\begin{array}{c}\text { Hansard } \\
\text { (Transcripts) }\end{array}$ & $\begin{array}{c}\text { Record of government intent (intrinsic logic) as } \\
\text { well as critical points raised in debates }\end{array}$ & 4 \\
\hline $\begin{array}{c}\text { Legislated } \\
\text { Acts }\end{array}$ & $\begin{array}{c}\text { Actual result (purpose, scope and limitations) } \\
\text { after debates/amendments }\end{array}$ & 4 \\
\hline $\begin{array}{c}\text { Official } \\
\text { Reports }\end{array}$ & $\begin{array}{c}\text { Reports commissioned by the provincial } \\
\text { government conducted by bureaucrats }\end{array}$ & 4 \\
\hline $\begin{array}{c}\text { Opinion } \\
\text { Pieces }\end{array}$ & $\begin{array}{c}\text { Discussion papers, lobbying submissions to } \\
\text { government \& published articles (institutional } \\
\text { logic) }\end{array}$ & 11 \\
\hline $\begin{array}{c}\text { Economic } \\
\text { Analysis }\end{array}$ & $\begin{array}{c}\text { Discussion papers \& published articles related to } \\
\text { the construction industry, apprenticeships and } \\
\text { the state of the economy in BC }\end{array}$ & 7 \\
\hline $\begin{array}{c}\text { Historical } \\
\text { Analysis }\end{array}$ & $\begin{array}{c}\text { Overview of the evolution of the apprenticeship } \\
\text { system in BC and reports on results of } \\
\text { apprenticeships (registrations, completions, etc.) }\end{array}$ & 14 \\
\hline
\end{tabular}




\section{Data Collection and Recording}

Each of the selected interviewees was contacted by e-mail that clearly identified myself as the researcher what my intentions were with respect to the interview process, and the measures that would be taken to protect the interviewees' confidentiality and, finally, to confirm the accuracy and completeness of their question responses. I identified the interviewees through their public positions at the three levels of analysis (political, governance, practitioner). Additional interviewees who were deemed to possess unique and comprehensive first-hand insights were also selected based on a snowball approach (suggestions from initial selection of interviewees). Given the criteria and the limited number of primary stakeholders, the final pool of interviewees totalled 19.

The interviewees were given the choice of having the interview recorded or not, as well as the opportunity to withdraw their interviews up until a specified deadline. Only one interviewee declined to be recorded, and none of the interviewees withdrew their interview, although three offered minor changes to the draft of their respective interview transcript. Although one of the originally selected interviewees chose not to participate in the interview (along with two others who were recommended by someone on the original list of interviewees), the majority of the interviewees supported the research and cooperated in the interview process. I personally transcribed all the recorded interviews rather than use a third party. A copy of the notes was used for the one interviewee who declined to be recorded but allowed notes to be taken during the conversation. Although the transcription 
process was lengthy, it had a three-fold benefit: it reduced the risk of a confidentiality breach, it ensured a higher degree of accuracy given my familiarity with the context, terminology, acronyms, organizations, and individuals cited by the interviewees.

Reviewing the recordings in their entirety during the transcription process allowed for deeper reflection on the how the data would serve to answer the questions and inform the findings. In keeping with Carleton University's research guidelines, all files created to store the data were anonymized and password protected, with each of the voice recordings destroyed after the transcripts had been reviewed by the interviewee for correctness and completeness.

In accordance with ethical research requirements at Carleton University, an approval for the use of interviews from the Carleton University Research Ethics Board-A was obtained in August 2017, prior to undertaking contact with selected interviewees.

\section{Interview Format}

The interviews were semi-structured ensuring both a consistent set of questions for each interview while providing the necessary latitude for interviewees to provide context and insight without constraining them to strict interpretations of what the questions were asking or the definition of words within the questions (Al-Yateem, 
2012; DiCicco-Bloom \& Crabtree, 2006; R. Hall, 2008). The underlying objective of the questions was to guide the interviewees into reflective, contextual responses to the primary research interests of the dynamics of stakeholder relations and institutional adaptation to legislative initiatives relating to the apprenticeship system. For example, the interviewees were asked to define what a stakeholder was and who the stakeholders were in the apprenticeship system in BC during the period of interest. A complete list of all the interview questions can be found in Appendix 1.

\section{Ethical Issues and Concerns}

The primary ethical concern was maintaining interviewee anonymity by taking measures to anonymize the data. Given that many of the selected interviewees held stakeholder positions of importance within BC's VET system while others held senior public offices in $\mathrm{BC}$, it is possible that they may be indirectly identifiable. As such, reasonable efforts were made despite this risk, to minimize the possibility that any specific citations by these public figures (or any of the other interviewees) could be attributed to them through the findings. In accordance with the Carleton University Research Ethics Board's (CUREB-A) ethical guidelines, appropriate measures were taken to anonymize the specific comments and identities of all interviewees involved in this research. This was achieved through an aggregation of the comments in the analysis through the thematic categories and generalized descriptions. Although some quotations were used for emphasis in select areas, they 
were chosen in a manner that would mitigate the possibility of direct attribution to any particular interviewee. Pseudonyms were used in all citations for this purpose while also providing clarification as to which of the three tiers they were associated with. ${ }^{17}$ While the process tracing methods involved the identification of key actors in particular events, such as political initiatives, care was taken not to make any direct correlation with the interviewees.

\section{Data Organization, Coding and Interpretation}

Following the guiding principles of the Qualitative Data Analysis - A Methods Sourcebook (Miles, Huberman, \& Saldana, 2014), the data were coordinated by using deductive methods to organize and concentrate the data in relation to each of the core questions. In addition, an inductive, phenomenological methodology was applied to establish thematic groupings that aligned with the relational aspects of interest amongst the stakeholders. This allowed for a cognitive understanding, from an HI perspective, of the impact of these formal and informal relationships of the primary stakeholders on the apprenticeship system's functionality and outcomes, amongst other changes resulting from legislative initiatives by the NDP and Liberal governments during the period of interest.

\footnotetext{
17 The three tiers were those of legislative, governance and practitioner. As such a former politician might be cited as 'Politician 01 NDP', with the number allowing for differentiation amongst the interviews from the legislative tier.
} 


\section{Data Organization}

The first level of data organization was deductive in nature, and was achieved through the use of two separate Microsoft Excel spreadsheets, in which the rows contained each of the core questions, while the columns were dedicated to the qualitative material selected for use. For reasons of manageability, one of these spreadsheets was used for the interview transcripts, and the other for the documents selected for inclusion in the analysis. Each transcript and document was reviewed thoroughly, with segments of specific text captured and saved within the applicable cell on the spreadsheet, thereby significantly reducing the volume of text that needed to be organized and evaluated. While reviewing each of the interview transcripts and documents, a conscious effort was made to identify and record emerging themes that would be used later.

As the review process advanced, a growing number of themes emerged reflecting the various vantage points of the interviewees as well as the documents. Applying the lens of my conceptual framework to interpret the data, in particular the tensions between the pairs of logics, allowed me to establish the connections between the labour market and the education system, namely the VET system and apprenticeships. Another insightful aspect of the review process of the interviews was the differences in the nature of the perspectives of interviewees, depending on their hierarchical vantage point. It was not uncommon to witness an increasing degree of detail and specificity in response to the interview questions depending on 
which tier the interviewee belonged to, with the most specific details on outcomes from the legislative reforms coming from interviewees at the practitioner level.

Such detail came across through specific examples that had been witnessed or experienced on a first-hand basis However, the scope of the perspective of the interviewees also tended to become narrower at the practitioner level, thereby potentially inhibiting their ability to link their observations with other events or stakeholder groups. As such, a balance of perspectives from various levels was seen to mitigate against these factors while adding to the explanation of the nature of the tensions within the social settlement. Once the deductive analysis had been completed, the next step was to synthesize the collection of themes through a systematic approach that permitted the further concentration of data into a more manageable form within a reduced number of principal themes.

\section{Inductive Organization - Principal Themes}

The selection of the principal themes that were used for the second phase of data organization and categorization was an important exercise before proceeding with the findings. As previously mentioned, during the initial phase of deductive analysis, a number of themes emerged through the analysis. As the initial phase progressed, these themes were occasionally adjusted to reflect the level of recurrence that was observed, as well as to remain related to the core research questions. For instance, discussions relating to training costs arose on a recurring basis, but the nature of 
interest in the training costs varied depending on circumstances. As an example, training costs could be related to a discussion pertaining to the apportionment of public funding for training delivery, a discussion point that arose multiple times in interviews as well as in some of the documents. In other cases, training costs might be related to the financial aspects of apprentices in terms of tuition costs, grants or other financial subsidies that could impact recruitment into the trades as well as completion rates. Whereas in other cases, training costs might have been part of a broader discussion relating to industry and employer concerns about a return on investment for any costs they might incur as a result of the apprenticeship system, including the cost of allowing an apprentice to return to school for additional training when their labour is required in the workplace.

Although this is only one example, it reflects the complexities associated with the process of amalgamating the numerous themes into principal groupings and determining how they would be analysed. The other aspect of this process related to the core questions of the thesis itself, namely those pertaining to governance, relationships between the primary stakeholders, changes in the nature of these relationships, and institutional changes resulting from the legislative initiatives. The resulting four principal themes that emerged from this synthesis process were then placed into a third spreadsheet matrix. This new matrix was composed of these same principal themes as columns with the interviews and documents as rows. As with the previous two spreadsheet matrices, each of the interviewees and documents was examined for relevant selections of data that corresponded with the 
principal themes, with a critical eye to the overall relevance to answering the core research questions.

These themes were cross-referenced with the theoretical logics of the conceptual framework discussed in Chapter 3, with an emphasis on the tensions between the intrinsic versus institutional and education versus employment pairs of logics that operationalize the conceptual framework. The intent of the cross-referencing was to seek an explanation of what was being revealed by the interviewees and documents in terms of the tensions described through these two pairs of logics within the VET system and apprenticeships, and what changes, if any were identified as a result of the legislative changes. Furthermore, the intent of associating themes with these same theoretical logics was to see if patterns emerged across stakeholder perspectives, namely if stakeholders from the same group shared a common perspective. For example, did stakeholders from the BCBTC share a common view on how the employment logic of the apprenticeship skills ecosystem may have improved under the NDP government? Differences in views by members of the same stakeholder groups would potentially reveal anomalies that merited further analysis.

For the purpose of the analysis, anomalies are defined as being observations or events that stand out amidst the results because of inconsistencies (compared with overall trends), uniqueness (not mentioned in other interviews or selected documents), or for the unexpected nature of the item (seemingly out of context with 
the interview topic). As will be explained below, such anomalies appeared only upon completion of the inductive organization of the data into a colour-coded, detailed matrix that included additional descriptors. The visual representation provided visuals clues for inconsistencies by way of overall resultant trends. In other cases, potential anomalies were flagged during the process of completing this same matrix wherein a statement, fact or example appeared unique and/or unusual given the context of the interview when they emerged.

These potential anomalies were then re-examined upon completion of that particular theme, and all the transcripts and selected documents had been analysed under that same theme. Additional effort was made to determine if the item had been addressed in other transcripts or documents, or if there was anything else that may have been missed that might support or contradict the potential anomaly. Only after this process was completed was a flagged anomaly considered worthwhile to retain as a useful anomaly that merited an in-depth analysis for inclusion in the findings and analysis that will be presented in Chapter 5 .

\section{Data Coding Process}

In completing each square of the matrix, a coding process was undertaken in which one of several pre-determined descriptors was attributed to the results. These descriptors were chosen purposely to determine if the formal governance process contributed to the state of the social settlement amongst the stakeholders, either in 
a positive reinforcing manner, or in a negative destabilizing manner. Furthermore, they served to highlight trends as well as potential anomalies for each of the principle themes once the matrix was completed. Finally, each of the principal themes was divided into two columns to allow for the allocation of a descriptor for each of the two periods: when the NDP were in power (1993 - 2001), and when the Liberals were in power (2001 - 2004) ${ }^{18}$ as the provincial government.

The descriptors were also annotated to include three adjectives to indicate changes that were described by the interviewees and documents, namely how changes introduced by the respective government had affected the apprenticeship system and stakeholder relations (improved, unchanged, or worsened). For each of the interviews and documents, the most applicable descriptor was assigned (by its associated, abbreviated coding), as well as a colour-coding, which was used to indicate whether the situated had worsened, remain unchanged, or had improved for each of the two periods within each of the primary theme categories.

The overall intent with this coding system of descriptors and colour-coding was to provide an overall visual pattern that would facilitate the identification of trends, groupings and potential anomalies. Anomalies were used to identify an apparent differentiation from emerging patterns, as well as to indicate views that appeared to run counter to trends and/or revealed new perspectives. The process of identifying these potential anomalies was applied to ensure they received additional analysis

\footnotetext{
18 These dates are in regard to the period of interest. The Liberals would in fact remain in power as the BC provincial government from 2001 until 2017).
} 
once the matrix was completed. It was expected that some anomalies might not be of value, in that it might be a highly biased statement or unjustified comment. Conversely, it was anticipated that some of the anomalies would reveal a perspective that other sources were unaware of or elected not to discuss.

The four principal themes that were established and used in the third spreadsheet matrix (see Appendix 2), along with their associated descriptors and codes, were as follows:

Governance Process - Power Distribution (PD), Decision Making Process (DMP), Stakeholder Representation (SR)

Institutional Change Issues - Mandate, Authority \& Effectiveness (MAE), Unexpected Outcomes (UO), Changes in Collaboration \& Relations (CCR)

Funding Frictions - Allocation Issues (AI), Student Impacts (SI), Return on Investment (ROI)

Training, Certification and Regulatory Implications - Delivery Approach Disagreements (DAD), Value of Standards \& Requirements (VSR), Impact on Apprentice (IA) 


\section{Limitations}

While most of those who were approached for an interview agreed to take part, there were three who did not. However, the 19 interviewees and their diverse backgrounds reflected the desired range of perspectives. That said, one of the difficulties in qualitative research is dealing with the volume of material (Creswell \& Creswell, 2018; Yin, 1994). As such, a conscious decision was made during the research phase to limit the number of interviews to ensure a manageable data set, while seeking a sufficient participation level of interviewees to achieve the desired balance of differing stakeholder perspectives.

The other concern relating to this research was the potential influence of my own personal bias to the research design, data interpretation and findings. Over a period of six plus years, I was the National Executive Director of the Helmets to Hardhats Canada program, a non-profit initiative that assists serving and retired members of the Canadian Armed Forces in finding rewarding new career prospects in the skilled trades, primarily through apprenticeships. Prior to that, I had served for nearly 30 years as a commissioned officer in the military. The military embraces a culture of training and values qualifications as a measure for career progression, and the offering of a CQ for veterans transitioning through our program was an attractive feature to veterans due to their military experience. More importantly, the CQ offered these veterans the opportunity to work all across Canada, as well as the opportunity to become supervisors, instructors or open their own business. As such, 
I realized that my background would be inclined to supporting the development of a skilled qualified workforce. My engagement with my supervisors and committee meant that I had to visit these assumptions throughout my research efforts.

The Canadian Building Trades Unions were a core supporter of the program, both in terms of funding as well as in terms of placements of military veterans into apprenticeship programs through the auspices of their nation-wide network of union locals and their affiliated contractors and Joint Apprenticeship Training Committees (JATCs). As such, I am well versed in the ideological differences pertaining to apprenticeship training in terms of the scope of necessary VET, the issues pertaining to the value of certifications in society, as well as the perspectives on the pedagogical debates regarding the design of apprenticeship programs. In order to strengthen the credibility of the findings from the data analysis and interpretation processes, a combination of measures were taken with the data in terms of mitigation of bias (conscious or unconscious) by the interviewees and the researcher, as well as to corroborate emerging themes/perspectives of interest.

Furthermore, the focus of the core questions pertaining to the social settlement amongst the primary stakeholders was designed to avoid determining which of these stakeholders was the most correct in their perspective, but rather to assess the impact of any possible asymmetries in their respective power/influence on the implementation and outputs of government initiatives. This in turn was supplemented by an effort to differentiate between perceived and actual influence 
of one or more of the primary stakeholders on the unfolding of events, through triangulation of applicable data, that being the interviews, selected documents and observations (i.e. published opinion pieces and documented lobbying efforts). In the case of some documents, particularly discussion papers and opinion pieces regarding pending or recent legislated changes to the apprenticeship system, it was useful to undertake a two-stage process of initial review followed by a higher-level analysis. The initial review served to capture and categorize specifics relating to key discussion points, whereas the analysis served to identify recurring themes in terms of particular perspectives, ideologies or beliefs.

Given that many of the points and counterpoints raised were seen to be perspectives of the interviewees rather than documented findings, this provided a means to follow the positions of the stakeholders and to ascertain comments relating to asymmetric influence that any might have with the government. It is hoped that this research will contribute to a much broader understanding of the political processes through which the governance of the apprenticeship system is mediated in $\mathrm{BC}$, thus perhaps offering both conceptual as well as practical insights into how it is currently governed. In particular, through the focus of this research on the factors that negatively impacted the social settlement between the primary stakeholders, within the broader context of the labour market and the evolution of the PSE institutions in $\mathrm{BC}$, the findings provide a useful explanation as to why apprenticeships as a skill ecosystem continue to experience pressure to change. Similarly, it is hoped that from a practical point of view, policy-makers will come to 
understand the importance of a holistic understanding of the entire apprenticeship system, and recognizing the associated inter-dependencies between the various components in assessing the potential unintended consequences of any proposed new efforts to legislate changes in pursuit of a desired objective.

\section{Summary}

Collecting original data in the form of interviews was a critical element of the research strategy. It was particularly fortunate that I was able to secure interviews with the individuals that participated as they represented a rich cross-section of perspectives. Furthermore, the majority of the interviewees held positions of leadership and/or influence within their respective stakeholder group, and were very familiar with what transpired within the apprenticeship system in $\mathrm{BC}$ across the span of my period of interest. The use of the BC Hansard was also particularly useful in capturing the intrinsic logic of the legislators, and was helpful in preparing for the interviews through the provision of valuable context in terms of expressed government intentions and expectations. The data organization and coding served to enable the next important step and the basis for the next chapter, namely the analysis of the data and the findings that resulted from the processes described in this chapter.

The findings provide the basis for addressing the research questions and to explain the core aspects of the research, namely the tensions between apprenticeship 
programs as a skills eco-system that typifies an employment logic within a broader PSE system (including VET) that is predominately typified by an education logic. The findings will provide the basis for establishing why and how these issues, as well as the differences in logic, reflected the tensions in the relationships amongst the primary stakeholders, and caused further divergence in the social settlement. Similarly, the findings provide the basis to explain why the various legislative initiatives and changes to the governance of VET and apprenticeships led to the outcomes they did. 


\section{Chapter 5: Findings}

\section{Introduction}

This chapter presents the main findings, applying the multi-layered conceptual framework to explain the "why and how" aspects of the findings as they relate to the research questions. It uses the conceptual framework to undertake this analysis using the concepts of critical junctures and path dependencies from historical institutionalism (HI). The Varieties of Capitalism (VoC) theory and the liberal market economy (LME) typology, along the educational and employment logic tendencies, skills ecosystems, as well as the intrinsic and institutional logic tendencies are also used to complete this analysis.

This chapter is organised through the key themes that were identified in the previous chapter, namely: governance processes; institutional change; funding frictions; and, training, certification and regulatory implications. The chapter first discusses the historical context of the political and economic circumstances in British Columbia (BC) during the period of 1993 to 2004 and then discusses each of these themes in turn relative to the contextual circumstances. The chapter then discusses the key themes which includes discussion of any unexpected outcomes expressed by the interviewees (or through the documents) pertaining to these themes. 
The chapter concludes by integrating the findings for each theme, and relates them to the structural and institutional pressures, along with the broader aspects of the conceptual framework. It does not attempt to relate the findings to the broader substantive literature on governance of apprenticeship systems and relationships between vocational education and the labour market, as this is the role of the discussion chapter which follows this chapter.

\section{Two Different Governments - Two Different Approaches}

Given the predominant role of government in shaping change in BC's apprenticeship system through a variety of instruments including legislation, policies and funding, it is useful to understand the degree of polarization between the different approaches the government (usually led by the ministers who were responsible for Advanced Education) took to not only the training of skilled workers, but also broader aspects of the regulatory environment ${ }^{19}$ for the trades, public infrastructure projects, industry requirements and the economy. As explained in Chapter 1, the period of 1993 - 2004 included the very different legislative initiatives taken by the New Democratic Party (NDP) and Liberal governments that were aimed at the VET system in BC. Before exploring these initiatives, it useful to compare the differences in perspectives and approaches between the NDP and Liberal governments that were in power in $\mathrm{BC}$ during the period studied, as

\footnotetext{
${ }^{19}$ For the purposes of my research, the focus was primarily on the construction industry, but in reality the skilled trades in BC serve many different industries such as forestry, mining, automotive, hair styling and so on.
} 
provided in Table 5 (BC Hansard, 1994, Vol. 14, No. 15; BC Hansard, 2003, Vol. 14, No. 12; Sashaw, 2011).

Table 5: Comparison of BC's NDP and Liberal governments (1993 - 2004)

\begin{tabular}{|l|l|l|}
\hline \multicolumn{1}{|c|}{ Perspectives } & \multicolumn{1}{|c|}{ NDP } & \multicolumn{1}{c|}{ Liberals } \\
\hline Political ideology & $\begin{array}{l}\text { Socially progressive - } \\
\text { equality of outcomes }\end{array}$ & $\begin{array}{l}\text { Fiscally conservative - } \\
\text { equality of opportunity }\end{array}$ \\
\hline $\begin{array}{l}\text { Views on } \\
\text { government } \\
\text { regulations }\end{array}$ & $\begin{array}{l}\text { Regulation enables checks } \\
\text { and balances in the } \\
\text { market, as well as in social } \\
\text { programs }\end{array}$ & $\begin{array}{l}\text { Deregulation enables market } \\
\text { competition, strengthens } \\
\text { economy, and enables job } \\
\text { creation }\end{array}$ \\
\hline $\begin{array}{l}\text { Views on economic } \\
\text { intervention }\end{array}$ & $\begin{array}{l}\text { Social intervention (i.e. } \\
\text { Community Benefit } \\
\text { Agreements) }\end{array}$ & $\begin{array}{l}\text { Enable free market capitalism } \\
\text { by reducing or eliminating } \\
\text { bureaucratic inefficiencies }\end{array}$ \\
\hline $\begin{array}{l}\text { Views on } \\
\text { Journeyperson CQ }\end{array}$ & $\begin{array}{l}\text { Value qualification (social } \\
\text { status, wages \& mobility) }\end{array}$ & $\begin{array}{l}\text { Value modular credentials } \\
\text { (specific needs \& lower wages) }\end{array}$ \\
\hline $\begin{array}{l}\text { Views on trades } \\
\text { training }\end{array}$ & $\begin{array}{l}\text { Broad training / resilience } \\
\text { in employability }\end{array}$ & $\begin{array}{l}\text { Specific training based on } \\
\text { market requirements }\end{array}$ \\
\hline $\begin{array}{l}\text { Approach to VET } \\
\text { governance }\end{array}$ & $\begin{array}{l}\text { Inclusive governance - } \\
\text { stakeholder consensus }\end{array}$ & $\begin{array}{l}\text { Exclusive governance - } \\
\text { industry directed }\end{array}$ \\
\hline $\begin{array}{l}\text { Views on } \\
\text { subsidization of } \\
\text { trades training }\end{array}$ & $\begin{array}{l}\text { Public subsidies for } \\
\text { apprentices to enable } \\
\text { greater participation \& } \\
\text { allow more generalized } \\
\text { training }\end{array}$ & $\begin{array}{l}\text { Reduce tax burden on public } \\
\text { purse through streamlining of } \\
\text { training, privatization \& lower } \\
\text { subsidies to improve economy } \\
\text { and job creation }\end{array}$ \\
\hline $\begin{array}{l}\text { Views on } \\
\text { administration of } \\
\text { VET system }\end{array}$ & $\begin{array}{l}\text { Increase staff support to } \\
\text { assist students, monitor } \\
\text { progress \& intervene as } \\
\text { necessary }\end{array}$ & $\begin{array}{l}\text { Reduce staff support / provide } \\
\text { liberty of choice by students } \\
\text { and employers for greater } \\
\text { flexibility }\end{array}$ \\
\hline
\end{tabular}

\section{Overview of BC's Economy (1993 - 2004)}

The VoC approach (P. A. Hall \& Soskice, 2001) compares and contrasts liberal and coordinated market economies (CME) to highlight their differences in economic performance and social well-being. This approach provides the basis for a brief 
overview of BC's economy during the period of interest, and it forms a component of the conceptual framework given that apprenticeship programs are interwoven with the workforce (80 per cent of the apprenticeship involves employment under supervision in the workplace). Furthermore, the production of skilled trades workers to meet industry requirements in $\mathrm{BC}$ has been an important aspect of $\mathrm{BC}$ 's economy due in part to the nature of its primary industries (forestry, mining, construction, etc.). For that reason, it is useful to provide a brief overview of the nature of BC's economy during the period of interest as well as some performance indicators.

Other than for the more diversified regional economies of the lower mainland and greater Victoria areas, the majority of BC's economy has been cyclical in response to global demand and prices for BC's export commodities from the forestry, mining, energy (oil), fishing and agriculture industries (Hallin, 2001). The commodity market declined from the period of the early 1980s until 2001. However, in 2001 (corresponding with the new Liberal government), there was a sudden rise in commodity prices other than in forestry which saw a drop in demand due to softwood disputes with the United States (Lee, 2004). Despite the decline in commodities, BC also saw a sharp rise in its population in part from inter-provincial relocations of Canadians to $\mathrm{BC}$ in search of employment, as well as a significant influx of immigrants from the far east between Expo 86 and the return of Hong Kong to Chinese rule in 1997. During this timeframe, BC's population grew by approximately 33 per cent, or from approximately three to four million people 
(McMartin, 2009). This growth in population, predominantly in the lower mainland and greater Victoria areas, led to a growth in construction to meet public infrastructure requirements, commercial interests and massive residential housing demands. Consequently, construction became an important component of BC's economy employing approximately 10 per cent of the workforce, with the residential sector of construction representing a third of the Gross Domestic Product (GDP) provided through construction, and largely concentrated in the lower mainland and greater Victoria areas (McMartin, 2009; Sashaw, 2011).

Both the NDP and Liberal governments began their terms (1991 and 2001, respectively) with a "weak" economy. Over the course of the decade that the NDP was in power, the province saw an average growth in GDP of approximately 3 per cent, whereas the Liberals saw an average growth of 2.8 per cent. In addition to the slow decline in commodity prices under the NDP and growth in BC's population, the provincial government also had to deal with the significant reduction in transfer payments from the federal government in the mid-1990s, as Prime Minister Chrétien undertook to bring the fiscal deficit under control (as explained by Politician 01 NDP ${ }^{20}$ ). Conversely, under the Liberal government BC benefited from a sudden rise in global demand for commodities other than softwood, a sharp drop in

\footnotetext{
${ }^{20}$ In order to preserve the anonymity of the interviewees, a coding system was used to keep track during the analysis. The three labels were Politician (person elected as a provincial politician), Governor (person involved with governance), and Practitioner (person involved as a practitioner from a union, employer, trainer or educator perspective). The numbers identified the different interviewees within each category.
} 
interest rates that favoured investment, and a weak Canadian dollar that favoured exports (BC Ministry of Finance, 2004). ${ }^{21}$

The supply of skilled workers at competitive wages, along with other tax reduction incentives have been used, along with deregulation measures, to attract foreign and domestic investments in major infrastructure projects. For the BC public, such investments would in turn create new jobs while also injecting money into BC's economy through royalties such as in the gas of liquid natural gas exports, taxes and the salaries of the work force allowing for greater consumption within BC (Sashaw, 2011).

\section{Critical Junctures}

Within HI theory, critical junctures are seen as significant events that exogenously invoke or endogenously compel institutional change (Thelen, 1999). While the VET system in $\mathrm{BC}$ is comprised of several different public and private institutions that may either contribute to or depend upon the apprenticeship ecosystem, it operates under the purview of the government. Furthermore, the influence of the government can be significant due to its ability to exogenously impose change on several important components of the apprenticeship system such as altering the regulatory framework, directing substantial public subsidies towards training

\footnotetext{
21 The Bank of Canada overnight rate dropped from 6.5 percent to 2.0 per cent within a 12 month period in the 2001-2002 timeframe.
} 
delivery, introducing innovative programs to recruit new apprentices and so on. For the purpose of effectively solving the puzzle described in Chapter 3 (which manifested as an inability to improve apprenticeship completion rates despite repeated efforts by different governments), and to answer the core questions of this thesis, the thesis' research strategy was designed to focus on legislative initiatives as the starting point of the enquiry. More specifically, the starting point was the legislative initiatives that were introduced by the NDP and Liberal governments during the period of 1993 - 2004 that were directed towards reforming the VET system and apprenticeships. These legislative reforms not only characterized the conceptual nature of critical junctures, but also provided a useful point of origin to compare the intrinsic versus institutional logic to explore the underlying stakeholder tensions and the impact of these tensions on outcomes to the VET system in general and apprenticeships in particular.

The comparative component of this case study examines the impacts of two different government approaches to apprenticeships and is aligned well with using their legislative initiatives as critical junctures, given that the Liberals essentially repealed the NDP's initiatives directly after assuming power in 2001. Table 6 below provides a guide to the key legislative reforms that formed the foundation for this research. Note that the dates provided for each bill denote the date that they received Royal Assent and became law in $\mathrm{BC} .{ }^{22}$

\footnotetext{
22 Bill passage in the BC Legislature followed the Westminster model, and was comprised of a sequence of events that could take many weeks to complete in some cases. The series of events, which included the tabling of
} 
Table 6: Legislative critical junctures (1993 - 2004)

\begin{tabular}{|l|l|l|}
\hline Bill & Title & Purpose \\
\hline $\begin{array}{l}\text { Bill 37 (NDP) } \\
\text { 10 June 1994 }\end{array}$ & $\begin{array}{l}\text { Skill Development \& } \\
\text { Fair Wage Act }\end{array}$ & $\begin{array}{l}\text { Regulation of publicly funded } \\
\text { infrastructure projects \& work } \\
\text { experience for apprentices }\end{array}$ \\
\hline $\begin{array}{l}\text { Bill 43 (NDP) } \\
\text { 30 July 1997 }\end{array}$ & $\begin{array}{l}\text { Industry Training and } \\
\text { Apprenticeship } \\
\text { Commission (ITAC) Act }\end{array}$ & $\begin{array}{l}\text { New crown agency \& } \\
\text { empowerment of stakeholders } \\
\text { in governing apprenticeship } \\
\text { system }\end{array}$ \\
\hline $\begin{array}{l}\text { Bill 22 (Liberals) } \\
\text { 27 August 2001 }\end{array}$ & $\begin{array}{l}\text { Skill Development \& } \\
\text { Fair Wage Repeal Act }\end{array}$ & $\begin{array}{l}\text { Deregulation \& elimination of } \\
\text { compulsory trades }\end{array}$ \\
\hline $\begin{array}{l}\text { Bill 11 (Liberals) } \\
\text { 30 April 2002 }\end{array}$ & $\begin{array}{l}\text { Miscellaneous Statutes } \\
\text { Amendment Act }\end{array}$ & $\begin{array}{l}\text { Major changes to ITAC - } \\
\text { reduction in support to } \\
\text { apprentices (mentoring \& } \\
\text { subsidies) }\end{array}$ \\
\hline $\begin{array}{l}\text { Bill 34 (Liberals) } \\
\text { 29 May 2003 }\end{array}$ & $\begin{array}{l}\text { Industry Training } \\
\text { Authority (ITA) Act }\end{array}$ & $\begin{array}{l}\text { Industry-led governance \& } \\
\text { changes to certification } \\
\text { (competency-based training) }\end{array}$ \\
\hline
\end{tabular}

\section{Governance Process}

Of all the themes that emerged, governance was of particular interest, as the first of the three core research questions. Originally, the intent was to focus on the formal governance processes that existed both for the ITAC and the ITA, but during the interviews and analysis it became apparent that the informal processes of influence over the governance of the apprenticeship system were too important to ignore in terms of understanding the dynamics of the social settlement amongst the primary stakeholders. The formal governance was composed of the Board of Directors who

the bill and the statement of the government's intentions and aspired outcomes, allowed for debates over the contents of the Bill. This was all captured in the BC Hansard as detailed transcripts and provided excellent clarity on the government's intrinsic logic. 
were appointed to govern the ITAC and the ITA, as well as the Chief Executive Officer (CEO) who was hired to administer the organization under the guidance of each Board. Conversely, the underlying informal avenues of influence were far less constrained by such structures or limitations, as they were based on the relationship individual stakeholders established with the government of the day. In some cases, these relationships included a shared political ideology or worldview that accompanied the government informally providing greater support to one stakeholder over the others.

However, it will be shown that the weakening in the social settlement amongst the primary stakeholders stems in part from the creation and perpetuation of the bifurcated government oversight of the VET system and apprenticeships in BC by two different ministries (labour and education) as explained in Chapter 2. When the NDP government conceived of creating a new, arms-length crown agency in 1997 to oversee the VET system and apprenticeship programs in BC, it was a significant departure in governance as administration of apprenticeships had always resided within a government ministry as a bureaucratic entity that was accountable to the Minister. The vision (intrinsic logic) for this new approach to governance that was articulated by the NDP Minister of Education, Skills and Training at the time was both specific in detail and ambitious in scope:

The mandate of the commission as set out in this act [Bill 43] is: first, to create a more integrated and coordinated system which facilitates a smooth transition from school to work and which promotes ongoing skills upgrading and lifelong learning; second, to expand the number 
of skilled persons in designated trades and occupation, based on identified labour market need; third, to increase the proportion of members of underrepresented groups in designated trades and occupations; fourth, to develop a system of provincially recognized credentials that promote laddering, portability, mobility and transferability; and finally, to make the best use of available resources (BC Hansard, 1997, Vol. 7, No. 6, Part 2).

However, the Minister's explanation of the persistent (more than two decades) bifurcated overlap between the two ministries in their financial support and administration of the apprenticeship system in BC (apart from the brief period of unification from September 1993 to February 1996 when apprenticeships and education were in the same ministry) was quite revealing. The government's intrinsic logic was illustrated in the debates accompanying the advancement of Bill 43 in which the then Minister of Education, Skills and Training implicitly delegated responsibility for resolution to the new ITAC and its Board of Directors to resolve the funding and training issues:

That's why this commission has responsibility for what used to be the apprenticeship training under the Minister of Labour and for entry level trades training [ELTT], which was the responsibility of the Minister of Education, Skills and Training. Both those programs and that funding will be the responsibility of the commission....[while] this commission [will empower]....industry and workers themselves to decide how the training is delivered... (BC Hansard, 1997, Vol. 7, No. 69, Part 1).

The implementation of legislation (the intrinsic logic) was mediated by the interests of stakeholders (the institutional logic). However, the process of implementation was also interpreted by the bureaucracy, often with advice by the stakeholders publicly or privately. It was also mediated by stakeholders who had a direct interest, 
and who may or may not have been involved in governance. In terms of governance, a recurring point that was raised by all three levels of interaction with the apprenticeships system amongst interviewees (legislative, governance, and practitioner) and by the majority of the stakeholders was that of the disruptive impact of an informal system of stakeholder influence. This informal influence operated in parallel with the more formalized governance process within both the ITAC and ITA, thereby causing additional tensions. One practitioner interviewee summed it up succinctly as follows:

I've got to say that there is formal and informal [governance], in my mind. The formal is the composition of the Board in terms of the public view of the Board that is overseeing ITAC, and the public view of the Board that's overseeing ITA...So, with the formal, there is also the informal, the influencers of these two different governments acting behind the scenes (Practitioner 02). ${ }^{23}$

In the majority of these observations by interviewees, the informal influence was identified as having had a greater impact on changes to the VET system and apprenticeships than that of the governance process itself, particularly during the NDP period of government, due to issues with the decision making process within the ITAC that will be elaborated further below. Regardless, the existence of such an informal system is not unusual given that lobbying of government by special interests groups is not uncommon in BC (Politician 03 NDP). However, what was unexpected were the observations that such an informal system was not only

\footnotetext{
${ }^{23}$ Pseudonyms were assigned to each of the interviewees depending on whether they were a legislator, governor or practitioner).
} 
embraced by certain stakeholders, but the degree to which it weakened the formal governance system that was established for both the ITAC and the ITA by the NDP and Liberal governments respectively. This was illustrated by one of the practitioners when explaining the growing informal influence of the then President of the ICBA on the ITAC through its CEO: "What I recollect when I was working at the UA [United Association union] at that time, was that they [President ICBA \& CEO ITAC] had become tight, and they were really interrupting the ability of ITAC to function, at every angle" (Practitioner 05).

In most cases, the informal influence was identified to exist between two particular stakeholder groups; the BC Building Trades Council (BCBTC) with the NDP government, and the Independent Contractors and Businesses Association (ICBA) with the Liberal government. As explained by one of the practitioner interviewees:

The lobby group behind the scenes of the Building Trades created that Act [Skills Development and Fair Wage Act]. So equally, when the government changed, it was the ICBA involved with the repeal [of the same Act]...behind the scenes, that drove that agenda (Practitioner 02).

In some cases, this asymmetry of informal influence was seen within the governance process as well, primarily with influence of the ICBA over the composition of the ITA Board of Directors. This was explained by an interviewee who had been directly involved "under ITA we had a non-stakeholder Board, so we appointed people who seemed to fit. We didn't go for anyone representing a constituency" (Governor 07 ITA). Such a finding suggests that despite the intrinsic logic of the NDP and Liberal 
governments' efforts to reform and improve the formalized governance system of the ITAC and the ITA respectively, the impact of any informal influence was significant. Ironically, such informal influence resulted from favouritism of one or more stakeholders by the government in power, thereby adding to the existing tensions amongst these same stakeholders.

In terms of the social settlement, this would also suggest a lack of confidence in the formalized governance system in achieving a stakeholder's objectives, reinforcing the need to undertake additional informal efforts to influence specific outcomes by certain stakeholders, as had been the case under both the NDP and Liberal governments. Perhaps, as one of the practitioner interviewees proposed, the degree of informal influence may have been the result of the polarized nature of $\mathrm{BC}$ politics, and that the recurring swings in legislation from one extreme to another were the result of the significantly differing political ideologies of the political parties involved:

The biggest problem that occurs when we have changes in government, especially when they are too influenced by special interest groups, is that you have a pendulum that just goes too far in both directions. Then you lose stability (Practitioner 03).

This perspective was shared by Haddow's (2008) own findings from this same timeframe, namely that "[political] reforms ran counter to institutionally entrenched patterns of behaviour in BC's political economy, which favour conflict between business and labour". However, despite the existence of these informal practices of 
favouritism by both the NDP and Liberal governments during the period of interest, the degree of the impact on the social settlement appeared greater under the Liberals after the 2001 election. In fact, despite the alignment of the BCBTC and other unions with the NDP government, they were not seen by interviewees as having a disproportionate amount of formal influence within the Board of Directors for the ITAC, due to the nature of the established decision-making process:

So we brought in this voting structure that required a quorum in each of the four stakeholder groups, otherwise we couldn't hold a vote at that meeting. So as a result, each group had a veto simply by not showing up (Governor 03 ITAC).

Furthermore, based on multiple data sources, it was clear that the formal ITAC governance model not only avoided favouring any particular stakeholder, it was largely seen as ineffective in making any decisions of importance thereby putting the credibility of the ITAC into jeopardy as related by one of the interviewees who had served on its Board of Directors: "the basic flaw was the four corners of governance and the 25 people, with a governance system that allowed any of the four of them to block change" (Governor 01 ITAC).

Interviewees from the BCBTC stakeholder group identified these problems themselves, and confirmed that the formal decision-making process impeded their ability to influence ITAC Board decisions due to internal infighting. Such infighting manifested in circumstances in which the unionized members of public colleges and the BC Federation of Labour would collude against the efforts of the BCBTC. 
So the college union people would sit with the BC Federation of Labour people for a caucus prior to our Board meetings, to prepare where they were going, especially if they thought it would mess with their collective agreement (Governor 03 ITAC).

The comment by another interviewee involved with governance of the apprenticeship system in $\mathrm{BC}$ goes straight to the point: "the ICBA and industry came to have better influence than Labour [namely the BCBTC] did because of this infighting" (Governor 04 ITA). However, despite the inability of the BCBTC to achieve greater stakeholder influence within the ITAC's governance model, members of the opposition parties and the ICBA stakeholder group still retained the belief that the BCBTC did in fact have undue informal influence over the NDP government, as exemplified by an opposition MLA during the Second Reading in debates in the BC Legislature related to the earlier initiative to introduce Bill 37, the Skills Development and Fair Wages Act of 1994:

As a matter of fact, I believe the statistics show that about 70 per cent of the work was done by non-union, non-NDP allies. I am sure that the pressure to expand came from people who were very influential with this government (BC Hansard, 1994, Vol. 14, No. 15).

Other interviewees shared a similar view that this was indeed a deliberate intervention by the NDP government to provide a greater market share of construction jobs for the unionized sector through the associated regulations accompanying Bill 37. The observation by the following practitioner interviewee was typical of what several other stakeholders had to say: 
Yes, some stakeholders are more important than others. In the NDP era, the Labour movement had an inordinate amount of influence, far beyond their place in the market. And when the Liberals are in power, the Labour movement has far less influence. The employers instead were the dominant stakeholders under the Liberals (Practitioner 07).

The majority of the observations relating to the decision making process were directed towards the ITAC and were critical of the inefficiency of the governance model which was widely seen as dysfunctional due to the size of the Board membership ${ }^{24}$ that resulted from the NDP government's determination to achieve an inclusive representation (Jothen, 2001; The Coalition of BC Businesses, 2001).

In terms of efficiency, the ITA governance model introduced by the Liberals in 2003 was seen as an improvement over the ITAC's large Board and ineffective decisionmaking processes by those who had first-hand experience with both. However, in terms of the outcomes of the ITA's decision making process as it pertained to changes in the VET system and apprenticeships or addressing stakeholder requirements, it was perceived negatively by the excluded stakeholders (the BCBTC and the public colleges). This was later confirmed by a 2008 review of the ITA by the Liberal appointed Auditor General;

The ITA did not sufficiently consult or collaborate with its stakeholders in developing its plans and strategies. Given the significance of the changes being introduced and the numbers of stakeholders involved, this was a large omission (Doyle, 2008).

\footnotetext{
24 The Board was designed to have 25 members total, of which eight were from the business community, eight from the labour community (including the BCBTC as well as other unions), four from the VET system and four from government. The Chair would be the $25^{\text {th }}$ member.
} 
Furthermore, although the intrinsic logic of the Liberal government envisioned the ITA as "an industry-led system that is responsive to trainees and employers' needs, as well as to economic change" (BC Hansard, 2003, Vol. 14, No. 12), a government sponsored review of the ITA in 2014 revealed otherwise. Instead, it was determined that the crucial links with employers, namely the Industry Training Organizations (ITOs) that represented specific industry sectors (such as construction) and that reported up to the Board of Directors, were rendered ineffective, as they reported that they felt like "they are micro-managed [by the ITA] in a marginalized role" (McDonald, 2014). Thus, while the ITA sought to address the inefficiencies of ITAC's inclusive consensus-based approach to governance by limiting its new Board to only nine members (including the Chair) and a majority vote system (Ministry of Advanced Education, 2002), the exclusive representation created new issues. By excluding primary stakeholders (BCBTC and the colleges), not only was the social settlement weakened, the Board became detached from the training side of the VET system as underlined by one of many interviewees:

And all of a sudden, not only did they change compulsory trades and eviscerate the system, but we had no avenue to deliver messages of concern...no feedback mechanism. I remember training coordinators throwing their hands up into the air and saying 'what the __ is going on?' (Governor 04 ITA)

Although the highly restrictive governance model of the ITA had not only served to weaken the social settlement amongst the primary stakeholders, it also fell short of achieving the government's expected outcomes of improved responsiveness to industry requirements. While the government (namely the then Minister of 
Advanced Education) had articulated a clear vision and objective, namely to ensure that the ITA would be more responsive to the needs of the industry employers and apprentices, the governance model forged a different outcome through its efforts to marginalize the inputs of some of the stakeholders.

The majority of comments pertaining to stakeholder representation reinforced this finding as they related to the ITA under the Liberal government. Furthermore, negative comments were made by the BCBTC, and were linked directly with their exclusion from participation on the ITA Board of Governors after the ITA was established in $2003^{25}$. The following observation was typical amongst the comments made by interviewees: "So there was a real bias when the Liberals came in to exclude unions, to exclude their opinions, and frankly the colleges as well" (Practitioner 01). Conversely, for those who were included within the ITA and its governance system, they had a positive perspective on stakeholder representation because they felt it ensured a focus on industry requirements rather than stakeholder interests, as per ITA's mandate.

Well I know that when we built that model, we said the primary stakeholders were the customers...employers and employees....and then started to talk about suppliers and other stakeholders. The colleges, in particular, went apoplectic. They did not want to be called 'suppliers'...We didn't see it that way. We saw them as providing a service that allowed people to get jobs and for employers to grow businesses (Governor 07 ITA).

\footnotetext{
${ }^{25}$ In the years after my period of interest, the rules pertaining to the composition of the ITA Board of Directors was relaxed to allow for one union stakeholder, albeit within the existing framework of majority rule decision making.
} 
In terms of anomalies, apart from the earlier point about the existence of a subtle but important informal system of influence, the other anomaly that stood out pertained to the distribution of power amongst stakeholders within the ITAC under the NDP. Only one interviewee identified the public colleges as having a disproportionate level of 'political' influence on the apprenticeship system in the sense that the government recognized the potential influence that they might have on the electorate of one or more of the elected Members of the Legislative Assembly (MLA) in BC, and thus acted with favouritism with that stakeholder as explained by one interviewee:

The colleges are often the largest employer in many cities and towns around the province, so they carry a lot of weight with local MLAs. And we would have ${ }^{26}$, who was the President of \{a public college ${ }^{27}$ and...he'd say, 'I don't care what you say, I'm here to protect the interests of BCIT, so I will not support this change in funding away from foundational programs into apprenticeships. And I will have 16,000 people in every community who will be writing letters to their MLA' (Governor 03 ITAC).

This initially seemed odd given that only one person characterized the colleges as an influential stakeholder (most identified both the ICBA and the BCBTC as the more active and influential stakeholders), so it was flagged as a possible anomaly during the completion of the matrix. While the initial reaction to this singular observation was that it was likely erroneous, it became apparent during the subsequent review process that there was a basis for this unique observation.

\footnotetext{
26 The name was provided by the interviewee, but removed to respect the individual's privacy.

$27 \mathrm{BCIT}$ is the acronym for the British Columbia Institute of Technology, the largest public college in BC.
} 
Using process tracing to review the historical context prior to the creation of the ITAC (as discussed in detail in Chapter 2) revealed the existence of a long-standing friction and divergence between VET and traditional apprenticeship programs that originated with the establishment of pre-apprenticeship training in BC in 1957 (B. Cowin, 2012).

The rise in demand for pre-apprenticeship training led to the construction of VET schools in the early 1960s in BC, which later evolved into publicly funded, regional community colleges where the mandate was broadened considerably to include a big focus on pathways to universities through associate degrees as well as the provision of more occupationally focused credentials (B. Cowin, 2012). The public colleges subsequently came to be recognized over time as the primary providers of pre-apprenticeship training, more commonly known today as ELTT. Given that public colleges fell under the ministry responsible for post-secondary education, and apprenticeship programs fell under the ministry responsible for labour, a wider institutional divide continued to emerge (B. Cowin, 2012).

As a result, one of the fundamental objectives in the creation of the ITAC was to use it as a means to converge ELTT with apprenticeship programs towards a common objective of strengthening the apprenticeship system in BC (Ministry of Labour, 1997). However, even with the creation of the ITAC, there remained two different ministries engaged with the ITAC, each with their own separate budgets (the Ministry of Advanced Education for ELTT, and the Ministry of Labour for 
apprenticeship programs). This bifurcated reporting arrangement between the ITAC and the Ministry of Advanced Education, Skills and Training, led to frictions in funding decisions within ITAC (Governor 03 ITAC).

Conversely, another governance interviewee saw extraordinary informal influence being applied within the formal governance process, but in reverse, with the unelected bureaucrats of certain ministries acting to protect the interests of the colleges rather than acting to uphold the interests of the apprenticeship system as part of their fiduciary responsibilities as a Board member:

There was a perception from some of us [on the ITAC Board] that the Deputy Ministers and the senior bureaucrats in the Ministry of Advanced Education felt some degree of obligation to protect the public post-secondary institutions from our change, which was threatening, because we were talking about reducing funding, or changing the funding formula, or changing the relationship with the public institutions (Governor 01 ITAC).

This perspective was reinforced by another individual who had the experience of being on the Board of Directors for both the ITAC and the ITA who put the situation in more pragmatic terms:

To be fair, if the ITA or ITAC wanted to close a program at a local college in a small town, the political process would kick in. I think it's naive to think otherwise. The shareholder of this entity is the government, and if the shareholder wants something, he, she or it is going to do something (Governor 06 ITA). 
Of even greater interest was the perceived perpetuation of this influence by the public colleges after the Liberals took power and the ITA was created, given that the public colleges were initially excluded from the Board of Directors along with government bureaucrats. Instead, the colleges undertook informal measures to influence the apprenticeship system and protect their interests as noted by the following two observations of another interviewee involved with the governance system as well as a practitioner: "And the colleges also lobby the employers through employer advisory committees...and under ITA, these committees really grew" (Governor 03 ITAC). And, "the Presidents of the colleges also formed their own group, but this was in the mid-2007 timeframe I believe. And this gave them a voice on all issues affecting the colleges, and still exists today" (Practitioner 04).

It's also important to note that the public colleges were not the only VET providers in BC's VET system, as there were other privately owned Training Delivery Agencies (TDAs) such as several unionized training centres that were established across the province $^{28}$. Furthermore, the Liberals undertook to expand privatization of the provision of VET after they came to power in 2001 by relaxing the requirements for certified training providers; however, it was the public colleges that were seen to wield significant influence during both the NDP and Liberal periods, not the private VET providers. Regardless, the public colleges clearly demonstrated tremendous formal and informal influence over both governments through a variety of means.

\footnotetext{
${ }^{28}$ Examples include the United Association's (local 170) Piping Industry College and the International Brotherhood of Electrical Workers (Local 213) Electrical Joint Training Committee's apprenticeship training facility in Port Coquitlam. Both are provincially accredited and licensed as TDAs in BC.
} 
In short, the additional observations that were uncovered through a renewed examination of the comment by one of the interviewees led to useful revelations. They revealed that the level of complexity of the relationships amongst the stakeholders and institutions involved in the apprenticeship system, as well as the variability of tactics that were applied to advance their stakeholder interests particularly outside of the formal governance structure, were significant in shaping outcomes.

\section{Institutional Change Issues}

One important aspect of the findings for this theme was the difference in the results between the period when the NDP were in power (1993 - 2001) and when the Liberals were in power (2001 - 2004 and up to 2017). This particular set of findings contributed to answering the second question, while informing the first and third as well. Of particular interest were the similarities in the perspectives provided by the interviewees from the legislative group, regardless of their political party association, with respect to the approach to advancing legislative reforms. All shared the view that such initiatives require bold, disruptive measures in order to overcome the perceived institutional inertia within the bureaucracies involved with the administration of the apprenticeship system.

Several of the interviewees who held elected office in BC acknowledged, albeit in different ways, the practical realities and limitations of transposing political reforms 
into tangible results aligned with the original objectives. As one legislator stated, "I think the challenge is, to be candid about it, is that the status quo is really overwhelmingly powerful as an opponent of change" (Politician 04 Liberal). Another legislator said that, in hindsight, even greater disruptiveness was required to effect the desired changes: "I personally underestimated that sort of psychological difference that was required to try to bring about a sort of fundamental shift" (Politician 02 NDP). A third legislator clearly perceived the institutions to be an obstacle to change in stating that "the bureaucracy was a bit ossified, a bit resistant to change within the Ministry and the apprenticeship system" (Politician 01 NDP).

The inputs provided by the interviewees from the legislative group strongly suggest that they not only believed that their political initiatives would encounter resistance upon implementation, but that such resistance had to be countered with strong reforms that implied boldness. However, little documented evidence was ever provided (for instance during debates on associated bills in the BC Legislature) that unequivocally supported the reasoning for the boldness of each party's proposed new measures. Instead, the reasoning was more typically associated with assumptions and platitudes rather than measurable results. For instance, the debate over Bill 37 (the Skills Development and Fair Wages Act of 1994) came down to platitudes like "Competition is healthy" or that the introduction of regulatory measures such as fair wages "fights the worldwide economic trend of the last few decades [of]...concentrating wealth into as few hands as possible, so that a few people can be very wealthy" (BC Hansard, 1994, Vol. 15, No. 15). 
Regardless of the motives, the impact of the shared inclination towards bold reforms by legislators from both governments resulted in a polarized political tug of war between the NDP and the Liberals during the period of interest. One such example was the repeal of the NDP's Skills Development and Fair Wage Act through the passing of Bill 22 by the Liberals within weeks of taking power in the summer of 2001 (BC Hansard, 2001, Vol. 2, No. 27). Similarly, the Liberals eliminated ITAC several months later through the passing of Bill 11 in March of 2002, even though it would be another 14 months before the ITA would be established through the passing of Bill 34 to replace it (BC Hansard, 2003).

In fact, the BC Hansard provides a clear record of each government's intrinsic logic for each piece of legislation that was introduced that related to the VET system and apprenticeships. Although the debates tested some of the positions put forward by the government of the day, it was found that the articulated goals tended to express broad and bold change objectives, along with the anticipated benefits that would accrue from such changes, but tended to lack details on implementation or the allocation of specific resources to achieve these same goals. For example, the Liberals made legislative changes to reform the apprenticeship system through the introduction of competency based training (CBT), but professed that they would not negatively impact qualifications or apprentice completion rates. As stated by the Minister of Advanced Education, Bill 34 and the establishment of the ITA would not lead to a "major changing of standards" given that she was instead "looking at 
developing new standards for new credentials that will exist under the new model" (BC Hansard, 2003, Vol. 15, No. 10).

As will be discussed in Chapter 6, the outcomes of the legislative reforms were quite different than those originally envisioned. In due course, the reforms were eventually altered or abandoned due to the negative consequences that they had caused in the VET system overall, but particularly the reversal in interest by new apprentices in these specific apprenticeship programs. ${ }^{29}$ The Liberals were certainly true to their word in terms of seeking to introduce bold changes in governance by excluding the BCBTC and public colleges from formal participation on the ITA Board of Directors, as well as changes to the funding mechanism for training, wherein the ITA controlled the transfer of funds rather than the ministry as had been the case. While the Liberals seemed to be particularly motivated to reduce the influence of the BCBTC and the colleges, the resistance to their dramatic changes came from within their own bureaucracy as related by an interviewee directly involved in the governance of the apprenticeship system in $\mathrm{BC}$ :

Of the change we were trying to make, the senior bureaucrats within the provincial government either openly or indirectly blocked change, and it was frustrating...because we were talking about reducing funding, or changing the funding formula, or changing the relationship with the public institutions (Governor 01 ITAC).

\footnotetext{
${ }^{29}$ One case in point was the creation of carpentry sub-trades that were introduced in 2003 under Bill 34 (BC Hansard, 2003, Vol.15, No. 2). While they initially attracted interest through apprenticeship registrations, the narrow scope of these trades combined with the limited opportunities for progression through to completion of the CQ, resulted in a gradual decline in new registrations, and an eventual abandonment of these sub-trades in favour of the broader carpenter trade.
} 
Such institutional influences reflect the institutional logic. In the case of BC's VET system, such transformation results from a combination of the interpretation of the legislation within the context of the institutional culture, in competition with other priorities and limited resources. Furthermore, the implementation process in not contained within one institution, but rather divided amongst a number of different vocational TDAs across the geographical regions of the province. These TDAs include not only the public colleges, but also accredited private training institutions such as those funded and operated by a number of BCBTC union locals (as previously mentioned).

As pointed out by the Auditor General's review of the ITA in 2008, it is not uncommon for the government of the day to underestimate the resources required to effectively implement change or to introduce new programs, whether those resources involve additional funding, hiring of new staff or adjusting existing priorities (Doyle, 2008; Hyslop, 2012). This in turn brings into question the quality of the analysis that supported such associated policy development. In the case of the Liberals, the Minister of Advanced Education expressed a belief that cuts to staff that would comprise the new ITA could be offset through the use of the internet for registration and administration of apprentices and their employers, while providing greater data collection for analysis of system success in terms of tracking new registrations, completions and employer participation (BC Hansard, 2003, Vol. 15, No. 10). However, this reduction in support to individual apprentices, and the negative impact it had on completion rates, were both identified as shortcomings by 
the Auditor General of BC several years after the ITA was created, and later by an indepth review directed by Premier Christy Clark (Doyle, 2008; McDonald, 2014).

Accordingly, even if the VET-related institutions are fully supportive of the legislation and its political objectives, such constraints will detract from fulfilling such objectives, whether in terms of timelines, scope or scale. The comments of the legislator interviewees indicate that they were well aware of bureaucratic inertia as a significant obstacle to change, and sought to find ways to overcome it. However, bold reforms without the necessary resources to implement and support them, along with the weak social settlement (further exacerbated by political favouritism), undermined the realization of the desired outcomes of both the NDP and Liberal governments.

\section{Funding Frictions}

Funding was a recurring theme amongst the different levels of interviewees as well as in many of the documents. While discussions relating to funding were not unexpected, given that public funding was allocated to subsidies for VET, to incentives for employers to indenture apprentices and for apprentices to complete their training. However, what was not expected was the friction that arose amongst the stakeholders about how public money was allocated for VET delivery and how it was spent on registered apprentices in particular. Consequently, these findings 
addressed both the first (governance) and second (political motives) research questions.

The genesis of these funding frictions appears to have originated in the decades prior to the period studied here, and were the result of a divergence between VET in general and apprenticeships in particular. As discussed in Chapter 1, an apprenticeship is a particular form of VET, in that the majority of the time required (approximately 80\%) involves gaining experience in the workplace under the supervision of a qualified Journeyperson. The formal (classroom) education is broken up into block periods of several weeks to several months (depending on the level), and is interspersed in between lengthy periods of employment on the worksite. Importantly, an individual has to secure the sponsorship and commitment of an employer before they can become an apprentice who is registered in BC's apprenticeship system. Given that employment is a condition to becoming a registered apprentice, it is often a competitive process to earn an employer's sponsorship.

As highlighted in Chapter 2, the $\mathrm{BC}$ government began providing public funds in the early 1960s to open several colleges in preparation for the wave of baby boomers who were passing through the secondary school system, but also in response to a seminal report (Macdonald, 1962) that foresaw the need for enhanced VET at the post-secondary level to meet the increasingly sophisticated technological needs of various industries (BC Hansard, 1971; Minister of Education Science and 
Technology \& Minister of Labour, 1979). Although the bulk of pre-apprenticeship training continued to be delivered by vocational schools throughout the remainder of the 1960s in BC, this changed in 1971 when the BC government announced significant funding to build new colleges throughout the province along with VET subsidies. This was a critical juncture in the VET system, in that the public colleges essentially took over VET delivery, but also introduced ELTT, which was designed to prepare students for a wider scope of skills training beyond that offered through apprenticeships (B.Cowin, 2012).

Underlying these changes and the growth in public colleges in $\mathrm{BC}$ was the government's broader strategy modelled after California's approach, which was to also increase the provision of PSE in the academic realm to provide a pathway for students into university studies from all regions of BC. In fact, the University of British Columbia in Vancouver was the only university available in BC in the early 1960s, until the University of Victoria was established in 1963 (J. R. Cowin, 2017). Consequently, VET was neither the primary focus of these colleges, nor the bulk of the courses provided, with apprenticeships being an even smaller piece of their overall mandate. However, with the introduction of ELTT came a departure from pre-apprenticeship training (which continued to be offered by several BCBTC training facilities) as well as with other training providers. The departure came in the form of a drift away from industry requirements, both in terms of curriculum as well as in the forecast of the number of apprentices that would be required for indentureship. 
The departure was further exacerbated by the previously discussed bifurcated structural problems in that the Ministry of Education oversaw the public colleges and provided the funding subsidies for ELTT whereas the Ministry of Labour oversaw apprenticeships and the grants provided to students and employers. While pre-apprenticeship programs were designed as a lead into apprenticeships, and therefore mindful of employer needs, the ELTT became increasingly disconnected from the labour market. As such, the ELTT programs led to an oversupply of graduates with expectations of becoming indentured, and an apprenticeship system that lacked a sufficient number of sponsoring employers to hire them. While the PAB was aware of these disconnects, it operated on an advisory basis, and was nested within the Ministry of Labour.

Regardless, the issues associated with this divergence between ELTT, preapprenticeship training as well as the bureaucratic disconnects between the Ministry of Education and the Ministry of labour did not go unnoticed, and became the focus of a government sponsored task force in the late 1970s (Minister of Education Science and Technology \& Minister of Labour, 1979). Consequently, while the discontent amongst the stakeholders pertaining to the limited public funding for apprenticeship training was noted, the degree of discontent among the public colleges stood out. Public colleges sought to use their formal and informal influence to preserve their funding interests, as highlighted earlier in this chapter. In fact, the public colleges had created a niche within the VET domain. 
When the federal government began to severely cut back on transfer payments to the provinces in the mid-90s in their efforts to reduce the federal deficit, this had a negative impact on federal subsidies ${ }^{30}$ previously earmarked for apprenticeship training, and dating back to the Technical Vocational Training Assistance Act of 1960 (Ministry of Labour, 1997). In order for these institutions to survive financially, they sought to draw more students into their classrooms. In the case of the public colleges, this meant that ELTT had become more profitable than pre-apprenticeship training because it covered more trades and it was not constrained by the limited opportunities for students to become indentured into a formal apprenticeship. These efforts were identified by several different interviewees as well as in the documents. As reported by an interviewee involved with the Board of Directors for the ITAC:

The way things evolved in apprenticeship over the years up into the mid-90s was [that]...entry-level trades training, had become really large, and most of the funding and delivery was on that side of things as opposed to apprenticeship technical training (Governor 01 ITAC).

This reinforced the finding that the informal influence of the public college extended to government bureaucrats. Even though the government representatives (namely senior public servants) who served on the ITAC Board of Directors had a fiduciary responsibility to advance the apprenticeship system, one of the Directors note that:

\footnotetext{
30 In the mid-1990s, federal funding for apprenticeship training in BC was significant; $\$ 7.7$ million for technical training and \$20 million for apprentice income support and allowances (BC Hansard, 1994, Vol 15, No. 15).
} 
There was a perception from some of us that the Deputy Ministers and the senior bureaucrats in the Ministry of Advanced Education felt some degree of obligation to protect the public post-secondary institutions... because we were talking about reducing funding, or changing the funding formula, or changing the relationship with the public institutions (Governor 01 ITAC).

After the Liberals came into power, one of their initiatives was to change the funding model by giving the ITA control over allocation of public funding, whereas with the ITAC such funding was transferred directly from the Ministry to the public colleges. Additionally, funding was widely extended to private training organizations such as union-operated training centres by the Liberals in an effort to privatize the VET training industry (BC Hansard, 2003, Vol. 15, No. 2), making it more attractive by eliminating the previous tuition freeze and allowing for higher education fees and greater profit margins (Lee, 2004). While privatization provided greater access to VET across the geographic regions of BC, the higher tuition costs also had the effect of restricting access to the skilled trades by the same minority groups that the government had sought to include (BC Hansard, 2003, Vol. 15, No. 2 ) - an effect recounted by an interviewee involved with VET delivery:

It felt as though it was kind of a total attack on vocational education and training [rise in tuition fees]. So the result was that it eliminated access to my programs and other vocational course for folks that were amongst the working poor, or on income assistance. So that was big, because we had been trying to help people get into vocational (Practitioner 04). Finally, as previously noted under the governance theme, the public colleges were also excluded from having a representative on the 
ITA Board of Directors (as with the BCBTC). However, despite these deliberate measures, the informal influence of the public colleges remained significant under both the NDP and Liberals as revealed by some of the interviewees who were directly involved in the governance of the apprenticeship system in BC:

The battle with the educators was incredibly intense after the change in government [to the Liberals in 2001] (Governor 05 ITA).

We were trying to change that [the post-secondary system] through the ITA...but it eventually led to the resignation of the first CEO [of the ITA] due to funding fights with public colleges and the BCIT President in particular (Governor 06 ITA).

However, when examining the actual funding, it becomes apparent why the public colleges fought to retain the public funding they had grown accustomed to under the NDP, and why they favoured the ELTT programs over the pre-apprenticeship training:

ELTT programs take up roughly two thirds of the entire budget dedicated to Apprenticeship Training (over $\$ 50$ million of the $\$ 78$ million budget)... Public costs are estimated at $\$ 4,489$ per ELTT student. This compares to $\$ 1,308$ per apprentice (J. Barrett, 2003).

In fact, public funding for apprenticeships at this time came from the federal government in the form of grants to apprentices and employers sponsoring them in apprenticeship programs, as well as directly to the colleges from the Ministry of Labour, and the Ministry of Education, Skills and Training. The direct funding to the TDAs and the provision of ELTT was approximately 75 per cent of this total, compared with approximately 25 per cent directed towards apprenticeship 
programs as explained by the Ministry of Labour (1997) report entitled Revitalizing Apprenticeship: A Strategic Framework for BC's Apprenticeship Training System, and as shown in

\section{Table 7.}

Table 7: Funding allocations for VET and apprenticeships in BC

\begin{tabular}{|c|c|c|}
\hline Program & Budget & Funding Agency \\
\hline $\begin{array}{c}\text { Apprenticeship Technical Training } \\
\text { (Public Training Providers) }\end{array}$ & $\begin{array}{c}>\text { \$15.0 million (includes \$7.7 } \\
\text { million in federal contributions) }\end{array}$ & MEST / ML \\
\hline $\begin{array}{c}\text { Apprenticeship Technical Training } \\
\text { (Private Training Providers) }\end{array}$ & $\$ 3.1$ million & MEST / ML \\
\hline Secondary School Apprenticeship & $\$ 0.5$ million $/ \$ 1.0$ million (est.) & ML / MEST \\
\hline Co-op Apprenticeship & $\$ 0.9$ million & MEST \\
\hline Skills Upgrading & $\$ 0.91$ million & ML \\
\hline Curriculum Development & $\$ 1.2$ million & ML \\
\hline Expansion and Equity Programs & $\$ 0.7$ million & ML \\
\hline Entry Level Trades Training (ELTT) & $\$ 45.0$ million & MEST \\
\hline TOTAL & $\mathbf{\$ 6 8 . 3 1}$ million & Combined \\
\hline MEST sub-total & $\mathbf{\$ 6 1 . 9}$ million) & MEST \\
\hline ML sub-total & $\mathbf{\$ 6 . 4 1 ~ m i l l i o n ) ~}$ & ML \\
\hline
\end{tabular}

Legend: MEST = Ministry of Education, Skills and Training. ML = Ministry of Labour Source: Revitalizing Apprenticeship: A Strategic Framework for BC's Apprenticeship Training System (Ministry of Labour, 1997).

As such, the colleges were able to secure more funding through their ELTT programs, but were reluctant to share with the ITA how these funds were actually applied, leading to suspicion that the funds were being used for requirements beyond VET delivery as related by one of the interviewees who served on the ITA Board of Directors: “They [BCIT] got $\$ 20$ million from us and they couldn't provide a clear statement to show what they did with the money" (Governor 05 ITA). 
While the Minister of Advanced Education's stated objective of collecting "more accurate and timely data [that] will result in improved reporting of information and also monitoring of funding" (BC Hansard, 2003, Vol. 15, No. 2), the efforts by the public colleges to retain the status quo funding formula and obfuscate the manner in which such funds were spent within the colleges demonstrates the depth of the differences in perspectives. In fact, the inability of the ITA to achieve fiduciary data tracking and funding control measures the minister had originally mandated did not go unnoticed by the provincial auditor general when he audited the ITA in 2008:

We found that the ITA's funding allocation decisions are consistent with its priorities, but are based on inadequate or incomplete information about demand and delivery costs...recommended that more work is undertaken...to produce high quality information for determining funding decisions (Doyle, 2008).

A later investigative report on the apprenticeship system that dated back to the establishment of the ITA in 2003 also revealed that the public colleges had received additional funding concessions that were not provided to the non-public VET providers (including the BCBTC owned training centres) when fewer students attended courses than planned: "private training institutions do not have the benefit of holding $30 \%$ of funds to cover administrative costs as do public institutions" (McDonald, 2014). 
The findings related to training and certification provided insight into the ideological differences between the NDP and Liberal governments as well as between the ICBA and BCBTC. The ICBA and BCBTC were of particular interest given that they represent the employers who both indenture apprentices and who drive the demand for skilled trades workers in BC. These ideological differences were represented in qualitative terms (in the interviews, Hansard debates and the majority of the documents), but were tightly aligned with economic imperatives, labour costs and the impact on BC's construction industry, a major source of investment and employment. As such, this set of findings addresses both the second and third research questions.

The NDP emphasized the importance not only of the quality and safety of infrastructure projects, but also of motivating British Columbians to undertake careers in the skilled trades. The Minister of Skills, Training and Labour mentioned both of these goals during debates pertaining to Bill 37, the Skills Development and Fair Wage Act:

Through the apprenticeship training system, we not only would give those people the kinds of skills that benefit the public construction ...ensuring that the quality of construction is first-rate...but we would also give those individuals, those real British Columbians, the opportunity to acquire that trades qualification ticket, which improves their individual position (BC Hansard, 1994, Vol. 15, No. 24).

Furthermore, the NDP government emphasized the importance of ensuring that apprentices earned their Red Seal endorsement not only because this would allow 
them to continue to seek employment in neighbouring Alberta or elsewhere when BC's economy weakened during a down cycle, but also because they had to fulfil their commitment to the interprovincial trade agreement. This in turn meant that completion rates were important, since an apprentice had to achieve the Journeyperson CQ in order to obtain the Red Seal endorsement. Consequently, the NDP Minister of Labour of the day established a strategy of creating Sector Advisory Committees that would report to the Provincial Apprenticeship Board (PAB), and that "Pursuant to the Labour Mobility Chapter of the Agreement on Internal Trade (1995), promote the expansion of the Red Seal in occupational training, examinations and certification (Ministry of Labour, 1997). The proposed advisory committees were actually included into the soon to be established ITAC within a few months.

Conversely, the Liberal reforms focused on improving the economic conditions that would attract greater investment in the construction industry, thereby creating jobs (which will be discussed further in Chapter 6). Although they too were interested in apprenticeship programs in order to meet the expected increase in demand for skilled trades workers, it was from the different perspective of finding ways to meet the specific needs of employers. More specifically, they sought to lower labour costs so as to make private investment in $\mathrm{BC}$ projects more profitable, and thus more attractive. Consequently, despite professing the importance of the Red Seal endorsement and the value of apprenticeships, the Liberals took measures that would negatively influence completion rates even if this was not their expressed 
intention. This was achieved through the introduction of CBT which helped to facilitate efforts to weaken unionization of the labour market, and deregulation. These reforms resulted in the elimination of the compulsory trades (trades that involve work in regulated domains and required a Certificate of Qualification (CQ) for safety reasons), the elimination of ratios (number of supervisors that had to be present on a worksite for each apprentice), and the enforcement arm of the new ITA $^{31}$.

The Liberal government professed support for apprenticeships, greater completion rates and the importance of the Red Seal endorsement on the one hand, but on the other hand expressed the need for changes to the training system with less emphasis on certification. These multiple objectives are expressed through three key arguments put forward by the Minister of Advanced Education in a discussion paper entitled A New Model for Industry Training in British Columbia, published a few months before the tabling of Bill 34 that established the ITA:

Government's review of industry training identified a number of problems with the system administered by the ITAC...Inflexible training methods based on time rather than competencies have been a barrier to innovation in training design and delivery (Ministry of Advanced Education, 2002).

Government will ensure the new model allows employers and learners across the province to participate and benefit...There is a continuing and necessary role for government in maintaining

\footnotetext{
31 Under the NDP and as part of the enforcement branch of the ITAC, inspectors were authorized to randomly inspect construction work sites to ensure that regulations pertaining to apprentice to supervisor ratios were respected, that workers had proper certifications, and that safety requirements were not being violated. Under the Liberals enforcement was eliminated from being an ITA mandate, and was left to other agencies to carry out inspections within their narrower areas of responsibility.
} 
standards and credentials for provincial and interprovincial (Red Seal) trades (Ministry of Advanced Education, 2002).

A competency-based system would allow workers to be tested when they are ready...If the employer does not require all the task and skills competencies for a full trade credential, he or she should be able to identify the tasks and skills required for the job and work with a trainer to develop the training if necessary. This approach would allow many young people into trades who currently do not have opportunities (Ministry of Advanced Education, 2002).

When Bill 34, the Industry Training Authority Act, was finally tabled in the BC legislature after several months of heated public town hall debate of the discussion paper around the province, the Minister of Advanced Education was aware of the serious concerns by some stakeholders, and sought to reassure them that the reforms would responsibly address these concerns:

I want to make it perfectly clear that the system we develop will not see the quality of training in this province compromised. Enforcement of safety standards and consumer protection in compulsory certification trades...will be maintained. We are not going to dilute the trades. In fact, current standards will be maintained, including the national Red Seal standards (BC Hansard, 2003, Vol. 15, No.2).

The Bill set the stage for introducing deregulation of the compulsory trades and deskilling of the workforce through the introduction of modularized CBT. Compulsory trades have typically achieved higher completion rates across all Canadian jurisdictions (Stewart \& Kerr, 2010) due to the fact that the CQ is required by industry standards to work in those trades, primarily for safety reasons (e.g. electrical, high pressure welding on boilers, as well as steam and gas lines). While BC had safety nets through other regulatory bodies such as electrical safety 
regulations under the Safety Standards Act, this still resulted in a lower requirement for certification as the hard requirements were limited to specific tasks, thereby lowering the demand for skilled workers with the $\mathrm{CQ}$ in the former compulsory trades (Prism Economic and Analysis, 2017). Through CBT, trades workers could achieve certifications for subsets of the trade that would allow them to work in these former compulsory trades without the full CQ credential. Consequently, the application of these reforms was seen to have little regard for the welfare of the apprentices themselves as related by an interviewee who was on the ITA Board of Directors:

Well the apprentices were overlooked even though the legislation stated that we were to design a system for the apprentices and the employers, and when I was on the ITA Board, I had to remind the other Board members of this on several occasions...that the apprentices had a role. They viewed them more as a commodity than a stakeholder (Governor 03 ITAC).

Regardless of the language of legitimation of the Liberal government's intrinsic logic, the institutional logic of the newly created ITA was clearly one of prioritizing the economy and employer needs, including cheaper labour, as related by another ITA Director: “It was a fiduciary model, the ITA model, so you weren't representing a specific stakeholder, you were there to represent the best interests of the province" (Governor 06 ITA). It's important to recall that the composition of the new ITA Board of Directors excluded two of the primary stakeholders, namely the BCBTC and the public colleges, and as such the Board's perspective was heavily in favour of the ICBA's interests. A prominent member of the ICBA who was seen by many as 
having influential ties with Premier Campbell certainly saw the BCBTC as getting in the way of how the changes to apprenticeship programs would be implemented by the newly established ITA: "So the Labour movement felt excluded. And part of the reason their influence was less was because the Board wanted to broaden [the ITA's focus] beyond apprenticeship" (Practitioner 07). This same individual went on to explain the underlying rationale behind the exclusion of the BCBTC from the ITA Board of Directors when it was first established:

And each craft had a craft union associated with it to deal with it. So, the training system was very important to their business model, and the Liberal government was challenging that sort of framework, breaking them apart, because the training system was not designed to fit a particular business model, it was designed to provide skilled workers to employers. The kind of skilled workers that employers need at the right time (Practitioner 07).

Clearly, the Board embraced a laissez faire approach to the market and less regulation by the government. This perspective supported the rationale for eliminating the compulsory trades and introducing CBT. The subsequent outcome of the underlying stakeholder tensions was to produce semi-skilled trades workers who would possess narrow but sought after skills and at lower wages. One example that was used repeatedly by a number of different interviewees was the manner in which the carpenter trade was broken up into sub-trades, such as door-framer, to meet the needs of the lucrative residential construction sector. The comparison of projected differences between the new ITA and the previous ITAC as foreseen by the Minister of Advanced Education's (2002) discussion paper can be seen in 


\section{Table 8:}

Table 8: Projected differences between ITAC and the new ITA

\begin{tabular}{|l|l|}
\hline THE TRAINING SYSTEM & \\
\hline New Model & ITAC \\
\hline One training system. & $\begin{array}{l}\text { Two training systems: ELTT and } \\
\text { apprenticeships. }\end{array}$ \\
\hline Multiple entry and exit points for learners. & Limited entry and exit points for learners. \\
\hline $\begin{array}{l}\text { Modular and competency-based training (CBT). } \\
\text { Time-based training continues where appropriate. }\end{array}$ & Time-based training. \\
\hline Tuition fees at approximately 15\% of cost. & $\begin{array}{l}\text { No or very low tuition fees for } \\
\text { apprenticeship training. }\end{array}$ \\
\hline $\begin{array}{l}\text { Credentials with flexibility to facilitate additional } \\
\text { training. }\end{array}$ & $\begin{array}{l}\text { Credentials provided only on final } \\
\text { completion. }\end{array}$ \\
\hline Use of Red Seal certification continues. & Focus on Red Seal certification. \\
\hline Emphasis on innovation and new delivery models. & $\begin{array}{l}\text { Emphasis on the core business using } \\
\text { traditional methods. }\end{array}$ \\
\hline $\begin{array}{l}\text { Focus on attracting secondary school students. } \\
\text { Local flexibility to develop a variety of transition } \\
\text { programs that may include technical training. }\end{array}$ & $\begin{array}{l}\text { Secondary School Apprenticeship program } \\
\text { comprises work experience only. CTC } \\
\text { programs may offer some post-secondary } \\
\text { training credit. }\end{array}$ \\
\hline Utilizes full range of public \& private trainers. & Focuses on public training institutions. \\
\hline $\begin{array}{l}\text { Multiple funding sources contemplated with the } \\
\text { Board allocating the funds. }\end{array}$ & $\begin{array}{l}\text { Virtually all provincial funding. Ministry of } \\
\text { Advanced Education allocates funds. }\end{array}$ \\
\hline THE RISKS & ITAC \\
\hline New Model & Inflexible to changing market needs. \\
\hline $\begin{array}{l}\text { Puts additional responsibility on the learner to } \\
\text { fund \& for the learner to make employment } \\
\text { connections. }\end{array}$ & $\begin{array}{l}\text { Leaves much of employment need definition } \\
\text { to training organizations rather than } \\
\text { business. }\end{array}$ \\
\hline $\begin{array}{l}\text { Puts additional responsibility on industry to } \\
\text { Relies extensively on coordination of action being } \\
\text { undertaken by the main participants. }\end{array}$ & $\begin{array}{l}\text { Puts the coordination role in the hands of } \\
\text { ITAC with the attendant costs. }\end{array}$ \\
\hline $\begin{array}{l}\text { Sounce Dsced and employ learners. } \\
\text { ingand }\end{array}$
\end{tabular}

Source: Discussion Paper: A New Model for Industry Training in British Columbia (Ministry of Advanced Education, 2002).

While industry determined the skills to be taught and "new delivery models" to support the employers, while the apprentices were to not only pay more for their 
training (as opposed to the employers), but were also given the "additional responsibility" of coordinating their VET with finding work on their own (Sharpe \& Gibson, 2005a). In fact, the ITA staffing was reduced dramatically "from around 125, which was what ITAC had, down to about 12" (Governor 03 ITAC), which meant far less support for the apprentices. Moreover, with the introduction of modularized training rather than the common levels of block release apprenticeship training, some apprentices were deemed ineligible for federal grants that they would otherwise receive upon the completion of successive levels of their apprenticeship (Hyslop, 2012).

The concerns of those who supported apprenticeships with broad training that led to the Journeyperson CQ were pragmatic in their view of what had transpired under the new Liberal government and the influence of the ICBA on the VET system and apprenticeships.

They [the ICBA] didn't actually want highly skilled, highly trained people. They wanted to de-skill elements of the business. They wanted to de-unionize and break the trades down into semi-skilled jobs that they could train faster, and they were cheaper (Politician 02 NDP).

Conversely, a practitioner within the unionized BCBTC stated that:

...they [Liberals] were in favour of dismantling the trades training, because they saw it as a way for cheaper labour, not understanding that...If you keep driving down the cost of your labour, you're only going to drive down the skill of that labour (Practitioner 03). 
The outcome from these reforms was that the public colleges and the BCBTC both began to push back against these reforms and became aligned in their support for full apprenticeships, broad-based training and attainment of the CQ, but for different reasons. This was noted by one of the Board members of the newly created ITA:

The qualifications were heavily influenced both by Labour, but also by the training institutions, both wanting to retain the broader requirements. In fact the trainers were interested in preserving this, as they were in the business of delivering such training and wanted to preserve their role (Governor 07 ITA).

From the BCBTC perspective, a generalized apprenticeship program with a variety of different work assignments produced new Journeypersons who could apply their broader experience and training in terms of critical thinking, thereby enabling them to not only produce better and safer work results, but have the ability to adapt to a broader array of work assignments. This adaptability, along with the CQ and Red Seal endorsement, also provided mobility to work in other provinces during a down cycle in BC's economy, making the prospect for a good career in their trade more realistic. However, it would take several years for the efforts of the colleges and BCBTC to have much effect given that they had been deliberately shut out of the formal governance of the ITA, and had little favourable support from the Liberal government on an informal basis as noted by BC's Auditor General's report:

The ITA did not sufficiently consult or collaborate with its stakeholders in developing its plans and strategies. Given the significance of the changes being introduced and the numbers of stakeholders involved, this was a large omission (Doyle, 2008). 
As such, while each of the stakeholders had an interest in both the training and education component of apprenticeships as well as the certification aspects, the basis for the divergence of the social settlement related mostly to the economic interests of each. While the public colleges supported a broader VET for apprentices, which appeared to align with the BCBTC's perspective, it was for entirely different reasons, whereas the ICBA and the Liberal government were in favour of lowering labour costs in favour of employers. For the latter, deregulation, along with CBT, were key elements in the strategy. This allowed for the division of certain trades such as carpentry into sub-trades that met the more specific requirements of contractors building new homes and condominiums in the residential sector while creating a subsequent increase in new apprentices who were enticed by this sectoral building boom in the lower mainland of BC (discussed further in the next chapter). Conversely, the apprentices themselves were left by a reduced ITA staff with less support, less employment protection (through deregulation and the elimination of ratios), greater tuition costs, and less financial impetus to complete their apprenticeship due to the elimination of compulsory trades.

\section{Conclusion}

As was shown through the findings and developed through the analysis using the conceptual framework from Chapter 3 and process tracing, divergence within the social settlement - if anything - increased over the period studied (1993 - 2004). This divergence can be attributed to stakeholder tensions that arose from 
differences in perspectives and objectives. These tensions can be conceptualized through the differences between the intrinsic logic, the stated political intentions and aspirational objectives associated with each of the legislative bills that were enacted into law, and the actual outcomes that reflect the impacts of the institutional logic. Regardless of the motives, the impact of the shared inclination towards bold reforms by legislators from both governments resulted in a polarized political tug of war between the NDP and the Liberals during the period of interest.

However, upon further analysis this divergence within the social settlement, as reflected in the bifurcated structural challenges of the two different ministries with interests in administering the apprenticeship system, can be better understood by considering the tensions across stakeholders, through the tensions arising between the education and employment logic. Conceptually, the bifurcated government arrangement can be understood as being the result of the existence of a traditional skills ecosystem (apprenticeship programs) that typifies an employment logic, becoming subsumed within a broader VET system that typifies an education logic in terms of delivery, requirements and certification. As the PSE system embraced alternative forms of VET, namely the ELTT model it created a tension between industry requirements (demand for skilled trades workers), and the supply side of an LME that had effectively commoditized the delivery of VET in BC. In short, the tension between the intrinsic and institutional logic show the process through which things occurred while the tension between the education and employment logic provide a deeper explanation as to why they occurred. 
This chapter described the findings from the research under the four themes that were identified through the analysis. The next chapter discusses the findings and addresses the core research questions by using the logic pairs to combine stakeholder-based and structure-based approaches to derive the answers. 


\section{Chapter 6: Discussion}

\section{Introduction}

This chapter discusses the findings presented in Chapter 5 and it addresses the core questions of this thesis. It situates the findings in the broader literature on vocational education and the labour market. It considers the implications of the literature for my findings by considering the extent to which my findings are supported by the literature. The chapter also considers how my findings complement and extend the literature.

The primary focus of this penultimate chapter is to address the research questions by contextualising the findings of Chapter 5 within the scholarly literature. It also examines the iterative relationship between structure and agency, recognizing that the primary stakeholders operated within the confines of institutional structures, extant logics and the limitations of their own perspectives and objectives. This in turn helped to structure the institutional conditions within which the next group of agents operated. The final part of this chapter includes an examination of the limitations of the conceptual framework that was developed for and applied to this research, and examines the contribution of this thesis to the theoretical literature. 


\section{The Core Questions}

The research questions addressed in this thesis - each of which will be examined in terms of the theme-based findings from Chapter 5 - were as follows:

1. How were the relationships between apprenticeship programs, the labour market and the post-secondary education system coordinated, governed and shaped in $\mathrm{BC}$, and why did they take the shape they did?

2. What was the impetus for the NDP and Liberal provincial governments imposing significant changes to apprenticeships and the governance structure?

3. What was the outcome of these processes of change on apprenticeships as a skills ecosystem within the broader VET system in BC as a result of the NDP and Liberal legislative changes aimed at improving the system?

\section{Historical Context - A Basis for Interpreting the Elements of Change}

Historical institutionalism (HI) provides the underlying basis for the conceptual framework that was developed in the methodology in Chapter 3. One of the fundamental aspects of $\mathrm{HI}$ is the impact of "timing and temporality in politics" (Orren \& Skowronek, 1994), particularly in the form of critical junctures (Thelen, 1999) in analyzing institutional change within a dynamic environment involving a 
multiplicity of stakeholders, events and forces of influence (George \& Bennett, 2005). The vocational education and training (VET) system in BC was described in Chapter 1 as a system of systems because it involved several different institutions and stakeholder groups, and because it overlapped with both the secondary school system at one end and the skilled labour market at the other. Importantly, the fact that the core of BC's VET system and its apprenticeship programs had been (with the exception of a brief 30 month period under Premier Harcourt) divided between two separate provincial ministries meant that it was subject to a complex environment of governance and administration. While the titles of these two ministries changed with time, they essentially represented the labour market and the post-secondary education (PSE) systems respectively. Apart from the dynamics of such a bifurcated oversight arrangement at the government level (examined in this chapter), this arrangement is important in explaining the stakeholder tensions conceptualized by the tensions between the education and employment logics.

\section{Discussion of the Findings in Answering the Core Research Questions}

Underlying structural issues were central to the weakness of the social settlement amongst the primary stakeholders. This was primarily due to the continued divergence in their perspectives on VET curriculum, training delivery and the value of the associated qualifications linked to apprenticeship programs. While apprenticeships were treated as another program within BC's VET system, this created tremendous pressure. As a unique skills ecosystem, apprenticeships differ 
from other VET programs. The pressures resulting from these differences were increased by the challenges of the bifurcated ministerial oversight of apprenticeship programs (Labour and Advanced Education) that evolved and persisted. These structural challenges were experienced by the Board of Directors of both the Industry Training and Apprenticeship Commission (ITAC) and Industry Training Authority (ITA), as revealed in the interviews and mentioned in some of the documents. The perpetuation of this structural duality, and the associated inefficiencies it created, reflected institutional path dependency.

More specifically, throughout the research period the social settlement was shaped by both structural changes to the formal governance arrangements, and by informal mechanisms which grew from the partisan favour by each of the NDP and Liberal governments towards one or more of the primary stakeholders. Tensions remained because of the institutional pressures coming from the persistent treatment of apprenticeships as another component of BC's VET system (that followed an education logic tendency), when in fact apprenticeships were a unique skills ecosystem (that followed an employment logic tendency). These structural pressures weakened the social settlement and undermined the legislative reforms by both the NDP and Liberal governments.

As explained in Chapter 2, prior to the election of the NDP in October 1991, the VET system and apprenticeships were administered by the Provincial Apprenticeship Board (PAB), which was a subset of the Ministry of Labour run by bureaucrats. The 
creation of the ITAC by the NDP in 1997 ushered in a new era of structural administration of the VET system in BC. Governance of this new crown agency consisted of a Board of Directors appointed from the primary stakeholder groups, as well as other stakeholder organizations, such as the BC Federation of Labour. While the ITAC governance model was built upon the principle of inclusiveness, its large size made it unwieldy (25 Board members) and, as a result, ineffective in decisionmaking, as reported in the findings of Chapter 5 . Conversely, the governance model for the ITA established by the Liberal government in 2003 was of a very different nature, with a smaller Board of Directors (nine Board members). Furthermore, the ITA Board excluded primary stakeholders from the colleges as well as the BC Building Trades Council (BCBTC).

For both the ITAC and ITA, the flaws in the formal governance structure exacerbated informal influence on the VET system and apprenticeships, whether through exploitation of a favoured relationship of one or more of the stakeholders with the government in power, or through other means to pressure the government into supporting a stakeholder's interests. The findings in Chapter 5 reveal perceptions that the BCBTC held a favourable position with the NDP government; however this did not result in greater influence through the ITAC formal governance system due, again, to the large size of the ITAC Board of Directors and its flawed decision making ability. The situation was quite different later when the ITA was established. Not only had the Independent Contractors and Business Association (ICBA) gained a highly favoured position with the new Liberal government, but they also initially 
held a monopoly over the ITA Board membership and thus wielded real and effective power in the apprenticeship system.

The formal governance structures were either ineffective in decision making or exclusionary in representation, as well as the favouritism that both the NDP and the Liberal governments respectively offered to one or more of the primary stakeholders, resulted in continued tensions, distrust and weak cooperation. Coordination amongst the stakeholders was mostly limited to the formal structures of the ITAC and the ITA, which meant that with the creation of the ITA, the relationships were further weakened given the exclusion of the public colleges and the BCBTC from the Board of Directors. This in turn fostered greater autonomous efforts to advance their interests, which meant that in the absence of a coordinating structure, they focused on their self-interests as a stakeholder group. Arguably, the ICBA did the same thing, albeit with the benefit of exclusive control over the ITA Board of Directors.

Consequently, in terms of addressing the first and second questions, the social settlement amongst the stakeholders weakened throughout the period of 1993 to 2004. The impetus for both governments to impose changes to apprenticeships during this same period was driven by their respective partisan relationships with one or more of the primary stakeholders. However, in addition to the internal tensions arising from the nature of governance of the apprenticeship system, the pressures on the social settlement were also influenced by circumstances that were 
exogenous to the governance structures of the ITAC and ITA (e.g., global commodity prices, exchange value for the Canadian dollar, etc.), as well as the asymmetric influence that resulted from government favouritism of one or more of the stakeholders. Consequently, the interaction between the governance arrangements and $\mathrm{BC}$ 's liberal market economy (LME) environment contributed to the weakening of the social settlement.

The bifurcated oversight of apprenticeships as a skills training ecosystem originated in the early 1960s when VET was shifted from the secondary school system into the broader PSE system. During this time, public colleges took on an expanded role in VET as part of the broader government strategy to increase PSE to British Columbians through the "California model" in which colleges provided associate degrees, which are the first two years of a degree. The outcome of this transformation of the PSE institutions was that the ministry responsible for advanced education ${ }^{32}$, and the public subsidies apportioned to PSE, led to the growth of Entry Level Trades Training (ELTT), which was designed to prepare students for being indentured into an apprenticeship under the auspices of a sponsor employer. As was highlighted in the findings of Chapter 5 under the theme of Funding Frictions, the public colleges exerted significant informal pressure on the government in order to preserve the status quo.

\footnotetext{
32 As previously mentioned, and as shown in Appendix 4, the name of this Ministry changed several times over the years.
} 
From a conceptual perspective, the broader issues can be understood in terms of the tensions between the different logics and the Varieties of Capitalism (VoC) typologies. While the two pairs of logic (education versus employment logic, and intrinsic versus institutional logic) are not to be construed as immutable laws; they provide a theoretical lens which can be used to analyse trends or tendencies (Wheelahan \& Moodie, 2017). In the case of the VET system and apprenticeships in $\mathrm{BC}$, these pairs of logic and the $\mathrm{VoC}$ typologies can be applied to recognize different levels of pressure on the system and the tensions amongst the primary stakeholders that weakened the social settlement. More specifically, the tension between the intrinsic and institutional logic show the process through which things occurred amongst the stakeholders, while the tension between the education and employment logic provide a deeper explanation as to why they occurred based on the structural issues within the VET system.

Given the nature of apprenticeships, such as the fact that registered apprentices are integrated into the workforce as part of their development and that employers are invested in this development through the provision of training in their company, apprenticeships follow an employment logic. Conversely, the public colleges and Canadian society typify the dynamic of an education logic, to secure higher levels of generalized education and credentials. As was discussed in the findings under the Training, Certification and Regulatory Implications theme, tensions arose amongst the stakeholders in terms of what should be taught in the VET system in $\mathrm{BC}$, as well as to the purpose of the resulting credentials. 
Underlying the stakeholder tensions between the employment and education logic is the VoC argument in which Canada typifies an LME, which typically prefers a laissez-faire approach to the market, deregulation and privatization (Green et al., 2010). As was discussed in Chapter 5, the deregulation of compulsory trades and apprenticeship ratios that occurred under the Liberal government, along with the introduction of competency based training (CBT), created significant challenges for apprentices while also further exacerbating the tensions amongst the primary stakeholders. As was seen in the literature review in Chapter 2, the unique nature of apprenticeships in which apprentices follow a staged progression of development through both classroom VET and supervised workplace experience creates tremendous challenges for the individual apprentice (Canadian Apprenticeship Forum, 2011; Deissinger \& Gremm, 2017).

In the absence of a supportive structure of coordination between the VET system, the apprenticeship administrative body (i.e., the ITA), the employers and the apprentices, the pressures on the individual apprentice are significant. Apprentices must go on unemployment benefit for the time they undertake school-based training in the college. Willingly leaving a job and giving up the associated income to return for another level of VET (in which the apprentice must also pay for their courses), without a guarantee of re-employment thereafter is a daunting proposition, and one which is not asked of apprentices in countries such as Australia (McDowell, 2011). While Australian researchers have found that support for apprentices' on-and-off-the-job learning has declined, they at least have the relative 
security of a continuous employment contract while they are undertaking training (J. Buchanan, et al., 2016).

In addressing the third question (outcomes), and as was seen through the findings in Chapter 5, the support mechanisms for apprentices were weakened under the Liberal government and with the establishment of the ITA. The administrative staff was reduced to a fraction of what existed in the ITAC, and field representatives who formerly mentored apprentices across the province and liaised with employers were eliminated. Apprentices and employers alike were expected to go "on-line" and undertake a large share of the administration; namely learning the processes as well as completing registrations, filing reports and providing feedback. In addition to the increased burden of administration and reduction in field support, the apprentices faced the rising costs of tuition fees and, in some cases, missed opportunities to earn federal subsidies due to discontinuities between BC's new modularized training programs and the traditional apprenticeship programs. ${ }^{33}$

In addressing the question about the outcomes of the processes of change on apprenticeships, it is useful to examine this in terms of the contribution of apprenticeships to stakeholders, apprentices and the economy. The apprenticeship skills ecosystem typifies an employment logic, the commitment by employer sponsors to participate in the development of apprentices, and the expressed

\footnotetext{
33 The Apprenticeship Incentive Grant is a federal subsidy that is awarded after the successful completion of the first two years of apprenticeship training, and then each year thereafter. With the changes introduced in 2003, it became more difficult for apprentices to prove completion of traditional levels of an apprenticeship.
} 
interest by numerous provincial governments to strengthen the production system of skilled trades workers in $\mathrm{BC}$. Therefore, it is useful to consider the impact of apprenticeship programs in terms of the broader economic circumstances that the NDP and Liberal governments had to consider.

\section{Contribution to Theory}

As previously mentioned, this research seeks to explain the relationships, including the apparent asymmetries in effective influence, amongst the primary stakeholders involved in the VET system and apprenticeships for the construction related trades in $\mathrm{BC}$. It derives and applies a conceptual framework to identify within this case study the sources of the underlying and persistent social un-settlement that contributed to repeated shortfalls in the legislative initiatives (by different provincial governments over many years) to improve the outcomes (measured in part by completion rates) of the apprenticeship programs in BC from 1993 to 2004. The research reinforces the scope, depth and complexity of the challenges that beset apprenticeship programs in $\mathrm{BC}$ due to the juxtaposition of the stakeholder tensions. These tensions can be tied to differences in perspective within the PSE system as conceptualized by the tensions between the employment and education logic. At the same time, the tensions between the intrinsic and institutional logic illustrates the gap between the stated political objectives of each legislative initiative, and the subsequent results. The following discussion evaluates the conceptual model that was created for this research. 


\section{Evaluation of the Conceptual Framework}

The conceptual framework helped to explain the tensions amongst the primary stakeholders within the broader vocational education system, which operated according to an education logic, and the apprenticeship system which operated according to an employment logic. It also provided unexpected riches in analysing the interaction between the two. Scholars have positioned skills ecosystems based on employment logics (such as in the trades or nursing) within broader dominant national logics in LMEs (Wheelahan et al. 2015; Wheelahan and Moodie 2017). They also argued the status of the vocational education system was a consequence of the tensions created by the dominant logic or tendency (employment logic or education logic). So, for example, they argue that while apprenticeships are held in high regard in Australia, ${ }^{34}$ the low social status of the vocational education system overall was typified by tensions of the predominant education logic, similar to the situation in Canada and other countries within the LME typology (Iannelli \& Raffe, 2007;

Streeck, 2011).

Arguably, this resulted in a rather static analysis with the broader vocational education system cast as low status and operating according to an education logic, and the apprenticeship system cast as a higher status option and operating according to an employment logic. This research shows that there is interaction between the two, and in this case study that the stakeholder tensions attributable to

\footnotetext{
34 Possibly more so than in Canada, although this would require further research.
} 
the employment logic underpinning the apprenticeship system in $\mathrm{BC}$ was undermined and weakened by the education logic underpinning the broader vocational education system and by the dynamics of an LME. This negatively impacted the social settlement amongst the primary stakeholders as explained in Chapter 5. In turn, this led to the fragmentation of apprenticeships in the construction industry and governance arrangements that opened the apprenticeship system more to the logic of the market, including deregulation, privatization and competition.

The interaction between the two was facilitated by the use of the intrinsic and institutional logics. The research demonstrates that while the intrinsic logic of government reforms in both cases was to strengthen apprenticeship programs, the institutional logics according to which the different stakeholders operated mediated how these reforms were put in place, which was negatively impacted by the divergence in the social settlement amongst the primary stakeholders in the VET system and apprenticeship programs. This divergence served to exacerbate the long-standing institutional bureaucratic disconnects between the Ministry of Labour and the Ministry of Advanced Education (rather than convergence towards resolution), while enabling the asymmetries in influence of certain stakeholders (as furthered by both the NDP and Liberal governments during the period of research) to further shape the institutional logic and resulting outcomes. 
A limitation of the conceptual framework is in explaining the role of the state, namely the $\mathrm{BC}$ government, as a primary agent of successful and sustainable change rather than simply that of a catalyst. The scholarly literature is divided on the significance of this role (P. A. Hall \& Soskice, 2001; P. A. Hall \& Thelen, 2009; Smith, 2013). Although the research used HI to analyse the impact of government legislative initiatives as critical junctures, it became apparent that the government retains agency in shaping the institutional logic as well as the intrinsic logic. The research identified the importance of asymmetries in the influence of different stakeholders, and how the influence shifted amongst them depending on the ideology of the elected government, and the government (often led by the Premier and Cabinet) was the architect of these power shifts. The government itself retained agency and operated according to its own institutional logic, and this changed as the governments changed. The two governments remained engaged in the governance structures of both the ITAC and the ITA through board membership, and the ongoing working relationships both organizations retained through the Ministry of Advanced Education and the Ministry of Labour. However, the conceptual framework and associated theories concentrated more on exogenous factors (LME capitalist market and predominant education logic culture) rather than on the potential for endogenous factors to influence outcomes. Again, the tension between the intrinsic and institutional logics helped to analyse these dynamics.

The findings demonstrate that despite the tremendous pressures that have been exerted on apprenticeship programs in $\mathrm{BC}$ as a result of these exogenous factors, 
apprenticeship programs have persisted. As a unique training ecosystem that is influenced by stakeholder tensions that reflects an employment logic, the research shows the importance of coordinating mechanisms between the classroom phases and the supervised employment phases of the different levels of an apprenticeship. While the generic Joint Apprenticeship Training Committee (JATC) model provides one template for better coordination between the classroom and supervised employment phases as well as greater mentorship support for apprentices, the research did not explore the potential applicability of the JTAC model to BC's VET system.

That said, based on the findings and subsequent analysis, the principal constructs underlying such a model merit further study to determine if they could yield improvements in several key areas such as in completion rates, access to a larger pool of employer sponsors, and convergence in the social settlement amongst the primary stakeholders who have interests in apprenticeships in BC. A recent study that examined a similar model ${ }^{35}$ in Australia correlated mentorship and apprentice support with completion rates (O’Dwyer \& Korbel, 2019). Furthermore, the government could play a pivotal role by institutionalizing and subsidizing such a model, adapted uniquely to the employment logic of apprenticeships to offset the challenges created by the LME market environment and predominant education logic that exists in BC. Over time, institutional path dependencies fostered by such

\footnotetext{
35 In Australia, apprentices have two pathways to an apprenticeship; indentureship with an employer or through a Group Training Organization, which serves to administer apprentice progression through their apprenticeship, and to coordinate their work assignments with a pool of small and medium sized employers.
} 
government involvement could lead to long term stability, as suggested by recent studies pertaining to institutionalism (Busemeyer \& Vossiek, 2016).

The other limitation of the conceptual framework was the VoC typology itself. Although this typology was a core element of the conceptual framework as a means to situate the exogenous factors and market environment within which apprenticeship programs exist in $\mathrm{BC}$, it has also been criticized as being overly generalized. More specifically these criticisms have identified a failure to take a detailed examination of the specific logics, factors or conditions that impact coordinating mechanisms, such as those deemed important to the success of completion rates in apprenticeship programs as one of several skills ecosystems in BC and Canada (P. Hall, 2015; Oliver et al., 2018). However, for the purposes of this research, it provided a solid mid-layer to the conceptual framework, and the basis within which to examine the relationship between the VET system and the labour market.

HI was also an important component of the conceptual framework, providing the foundation for integrating the stakeholder tensions associated with institutional logics as a means to examine the impact of the critical junctures resulting from legislative initiatives. The integration of $\mathrm{HI}$ within the conceptual framework pointed to how the exogenous market factors extant in BC impacted the VET system during the period of interest, but with a limited focus on the relation system of the education system with the labour market. Scholars such as Lowndes and Roberts 
(2013) have brought a revised thinking to institutionalism that may provide the necessary additional insight into the complexities of how institutions operate where the $\mathrm{VoC}$ typology is seen to be incomplete. They argue that while there are different approaches within institutionalism (new and old, and different varieties of institutionalism) that it is possible to draw conceptual tools from different models to provide richer insights, particularly into public policy. Both of these areas merit further consideration in terms of assessing the potentially constructive role of the state in terms of supporting legislative change initiatives and the longer term outcomes in terms of the creation of institutional path dependencies that perpetuate stakeholder collaboration of apprenticeship programs despite the predominance of LME market forces and the education logic tendency.

\section{Summary}

Returning to the conceptual framework and the theories provided by VoC and HI, Hall and Thelen (2009) speak of the importance of analysing the dynamics of institutional change, particularly between the stakeholders and the changing nature of their relationships to effectively assess the nature of the coordinating mechanisms and competing interests.

...coalitional analysis...also provides the basis for a dynamic account of how shifting alignments of interests bring about the reconfiguration of institutions and forms of coordination in both liberal and coordinated market economies (P. A. Hall \& Thelen, 2009). 
As noted by Deissinger and Gremm (2017), the predominant education logic found in Canada is closely tied with the societal legacy adopted from its influential British heritage, as was discussed in Chapter 2. Overcoming these societal legacies and raising the profile of VET, apprenticeships and the skilled trades as a rewarding career choice, requires a concerted effort to counter the negative stigma commonly associated with "blue collar" employment an effort that would require the government, PSE institutions and employers to embrace the employment logic and to bring a professional status to the skilled trades. Political efforts have been made in the past, as with the NDP in 1993 when a Journeyman millwright was assigned the cabinet position of Minister of Skills and Training (Politician 01 NDP). However important such political gestures may be to raise the social status of the skilled trades, the importance of a collaboration and coordination amongst the other primary stakeholders, namely the public colleges, employers and unions, would provide apprentices with a much more supportive pathway through their apprenticeship. Such collaboration and coordination, led by a sincere commitment by the government towards the objectives of higher completion rates and a more productive VET system, could serve as a catalyst for convergence in the social settlement and long term stability as Deissinger and Gremm explain:

The institutional aspect seems to be another relevant factor which has to be considered. The VET system needs to be recognizable as such, and it should represent good quality teaching and learning opportunities. In order to guarantee the quality of VET it is necessary to include a "practical learning route" in work orientation. In addition, a close collaboration between government and business is needed, so in the case of Canada the state has to be involved...(Deissinger \& Gremm, 2017). 
The final chapter provides a summary of the results of this study, as well as recommendations for future research that could build upon what has been done here. 


\section{Chapter 7: Conclusions and Recommendations}

\section{Research Questions}

This final chapter provides a summary of the thesis in the form of conclusions drawn from the discussion of the findings in Chapter 6, and forward-looking recommendations for others seeking to build upon this research. The conclusions resulting from the research and the answers to the core questions can be summarized as follows: based on a combination of structure and agency, the primary stakeholders operated within the confines of institutional structures, extant logics and the limitations of their own perspectives and objectives.

\section{Question 1: Relationships}

The research results demonstrate that the relationships between the apprenticeship programs, the labour market and the post-secondary education (PSE) system were affected by differences across stakeholders in their priorities and objectives. Those differences can be interpreted as a consequence of apprenticeships, constituting a skills ecosystem shaped by an employment logic, being situated within a broader vocational education and training system in British Columbia (BC) shaped by an education logic tendency. The tensions across stakeholders were further heightened by the shifts within the liberal market economy (LME) of BC (and the rest of Canada) that moved it towards deregulation, privatization and competition. 
Consequently, coordination between the apprenticeship programs, the labour market and the PSE system was weak. Although the governments' intrinsic logic reflected a desire to improve apprenticeship programs, as well as the broader vocational education and training (VET) system, the dominant education logic and characteristics of an LME had a much greater influence on the associated institutions, bureaucrats and staff. As such, the impact of stakeholder tensions relating to the institutional logic was significant in terms of the outcomes that reflected persistent inefficiencies in apprenticeship completion rates as well as in terms of the weakening in the social settlement amongst the primary stakeholders. Genuine collaboration and efforts towards outcomes underpinned by consensus were curtailed not only by the apprenticeship skills ecosystem being at odds with the prevailing education logic and LME preferences, but also in terms of the obvious predilection by both governments to favour some stakeholders over others. This in turn served to undermine the formal governance structures that were introduced through their legislative initiatives in creating both the Industry Training and Apprenticeship Commission (ITAC) as well as the Industry Training Authority (ITA). As was seen in the analysis of the findings in Chapter 5, the shifting locus of influence held by different stakeholders came to shape the formal composition of the governance models for the ITAC and the ITA.

Central to weakness of the social settlement amongst the primary stakeholders and the continued divergence in their perspectives on VET curriculum, training delivery and the value of the associated qualifications linked to apprenticeship programs is 
the underlying structural issue. While apprenticeships were treated as another program within BC's VET system, this created tremendous pressure. As has been explained in earlier chapters, apprenticeships are a unique skills ecosystem that differ from other VET programs. The pressures on apprenticeships was increased through the challenges of the bifurcated Ministerial oversight (Labour and Advanced Education) that evolved and persisted. These structural challenges were experienced by the Board of Directors of both the ITAC and ITA, as revealed in the interviews and in some of the documents. The perpetuation of this structural duality, and the associated inefficiencies it created, reflected institutional path dependency. However, policy makers under both the New Democratic Party (NDP) and Liberals appeared to have underestimated the problems this structural issue had on advancing new initiatives due to the tensions it continued to cause amongst stakeholders. The weakness of the social settlement was explained by the tension between the intrinsic and institutional logic, and these tensions undermined the reforms of both the NDP and Liberal governments.

\section{Question 2: Political Motives}

The second question relates to what motivated both the NDP and Liberal governments to impose significant changes to apprenticeships and the governance structure. The findings strongly suggest that both governments were influenced by one of more of the primary stakeholders to intervene in the VET system. Furthermore, given the commonalities of the political ideologies of the BC Building 
Trades Council (BCBTC) with the NDP, and the Independent Contractors and Businesses Association (ICBA) with the Liberals, both of these stakeholders worked to have modifications that accommodated their specific interests without fully appreciating the legitimacy of the perspectives of other stakeholders. Furthermore, such changes were arguably more in reaction to changes of previous governments, particularly in the case of the Liberals following their 2001 political victory in which they sought to reverse core aspects of the initiatives introduced by the previous NDP government. Such reversals were clearly evident in both the governance structure of the VET system as well as in the efforts to deregulate, thereby significantly impacting the training requirements and value of the Journeyperson certificate of qualification (CQ). This suggests that such asymmetric influence by the BCBTC and the ICBA on the NDP and Liberal governments respectively, may have indirectly undermined the policy development process by the bureaucrats. The findings about this claim were suggestive rather than definitive and it may be an area that merits further research.

\section{Question 3: Outcome}

In terms of the third question, the outcome of these processes of change during the period of research was also found to be shaped by the influences of the BCBTC and ICBA as well as a result of the tensions that can be attributed to the predominant education logic and LME preferences that reside in BC and Canada as a whole. Furthermore, while the apprentices are stakeholders, they had very little agency 
within the governance structures of the ITAC and ITA, and no voice to influence either government. As such, the outcomes were measurably worse for the apprentices as a result of the Liberal legislative initiatives as previously explained in the findings. In short, the outcome was that the apprenticeship skills ecosystem, as a unique form of VET that reflected an employment logic, was under extraordinary pressures to change in terms of curriculum, requirements, training delivery and the overall value associated with the CQ specifically and the skilled trades as an occupation as a whole within Canada's social class consciousness.

These pressures were exacerbated by both the NDP and Liberal governments who were complicit in giving more influence to one or more stakeholders in apprenticeships over the others. With the exception of the unionized Joint Apprenticeship and Training Committee (JATC) model, BC failed to establish a supportive coordination system to advance the interests of the apprentice or the consistent output governments sought from apprenticeship programs. It also failed to produce a skilled trades workforce of British Columbians to meet industry demands, and to improve the provincial economy. Consequently, despite repeated legislative efforts by successive governments in BC to reform apprenticeship programs as part of the broader VET system, the differences in perspectives and objectives amongst the primary stakeholders, as well as the lack of a priority in establishing better coordination mechanisms to support the apprentices, undermined the success of the desired outcomes. The government commissioned 
review of the ITA by former Liberal Premier Christie Clark, captured this key finding rather succinctly:

While the ITA's role...does not currently operate within a seamless system with all partners and decision makers working towards the same identified priorities, strategies and targets... Conflict between views as to the "right" policies, programs and funding priorities has led to deep silos in the system, with each partner focusing on their own interests. Because different concepts benefit different interests, these approaches have become associated with ideological positioning and the system is somewhat resistant to open discussion. A shift towards multi-year planning based on common evidence, clear demand-related targets and consistent accountabilities is a key step that would enable the system to work together more closely and achieve the best possible outcomes (McDonald, 2014).

The $\mathrm{BC}$ government has repeatedly sought to improve the quality and availability of its skilled trades workforce - as more recently demonstrated under Premier Christie Clark and her government's plan entitled B.C.'s Skills for Jobs Blueprint: Reengineering Education and Training. Fundamentally, and from a practical perspective, what has emerged from this thesis and its focus on the period 19942003 is that repeated efforts by successive governments to improve BC's apprenticeship programs have been undermined by two factors. The first was an underestimation of the scope, depth and complexity of the broader VET system in terms of the potential unintended consequences of any legislative initiatives. Like a delicate mechanical piece amongst many moving parts in a fine Swiss watch, apprenticeships have emerged as a unique skills ecosystem of training skilled trades workers embedded within a broader VET 'system of systems' in BC. As such, any efforts to improve upon a component of the complex system appears to have been 
undertaken without a full understanding of the unique nature of apprenticeships, along with the underlying structural pressures that undermined the social settlement of the primary stakeholders and government reform initiatives.

The second was a failure by government of different parties to pursue reforms that sought to achieve an effective, long-term improvement to apprenticeships in $\mathrm{BC}$ through leadership in establishing measurable outcomes, and in fostering an environment of collaboration amongst the primary stakeholders in which all would reap the benefits. Creating a model that coordinates the efforts of the stakeholders within a structure that provides greater benefits through collaboration than competition is a strategy that merits serious consideration.

\section{Recommendations}

While the primary intention behind this thesis was to answer the core questions to explain why successive $\mathrm{BC}$ governments fell short in their efforts to improve apprenticeship results, one of the findings of this research is the need for politicians to recognize the real time challenges of policy makers as well as the importance of allowing sufficient time to assess recent changes before seeking to introduce new legislative initiatives. Institutional change is tempered by the many normalizing conditions and structural restrictions that impact individual and collective human agency. By failing to allow sufficient time for institutions to adapt to the changes 
imposed through legislative reforms, this impatience undermined the achievement of the outcomes sought.

However, the pragmatic realities of politics cannot be dismissed either. This suggests the utility of a process that provides greater independence of policy makers from the influence of the political forces, which is easier said than done, but would permit policy makers to avoid pressures to introduce quick fix solutions sought by the government without broader consideration for potential secondary and tertiary unintended consequences. The research suggests that in policy areas involving multiple institutions, and thus complex relations not just amongst stakeholders but also amongst those implementing the change initiatives, that broader considerations and analysis have greater importance due to the higher risks for unintended consequences. For the government, emphasis should also be placed on bringing stakeholders together into constructive collaboration. More specifically, a government led initiative that introduces a coordination mechanism that is designed to build broad agreements between different stakeholders (rather than privileging some social partners over others) so as create a constructive environment that supports and facilitates apprenticeship programs for British Columbians seeking a career in the skilled trades. While it is unlikely that consensus could ever be achieved in circumstances where stakeholders have competing interests, the introduction of a more structured governance model, clearer delineations of responsibilities, and tighter decision making guidelines could serve to enable improvements in the functionality of the ITA. 
From a theoretical perspective, the findings pertaining to the pressures on apprenticeships in $\mathrm{BC}$ could be applied to the other provinces and territories across Canada, as they are all situated in within the LME environment that typifies Canada as unique skills ecosystems within broader VET systems. The conflicting logics and the resulting tensions are most likely negatively impacting the effectiveness in apprenticeship programs in these jurisdictions as they have in BC. On a different level, the findings are of particular value in highlighting the ineffectiveness of past attempts to incorporate practices in CME countries, such as Germany and Switzerland, in Canada's LME. These findings underline a conceptual perspective that policy learning (Raffe, 2011) requires a broader appreciation for the confluence of the environmental social, economic and political dynamics, reflecting the complexities of the adaptive process for institutions facing change.

Finally, as it stands, the absence of consistent and reliable data on apprenticeships in $\mathrm{BC}$ restricts the abilities of researchers to pursue mixed-method approaches, and hence restricts researchers' abilities to provide more research-informed insights for policy development. While the ITA has collected data, their usefulness has been undermined through changing definitions and terminology. An investment in a robust data collection and assessment system, along with a data analytics team, would not only provide a more accurate means to measure the results of policy changes, but would better guide politicians in fine-tuning the objectives of future legislative initiatives. While such quantitative data were neither reliable nor sufficiently available for this thesis, steps taken recently by the federal government 
offer the opportunity to undertake an analytical comparison between the coordinated union model of the JATC or Australia's Group Training Organization model with other types of apprenticeship programs. Such opportunities will come from recent initiatives to combine data from the Canada Revenue Agency (CRA) with existing Statistics Canada data collected within the Registered Apprenticeship Information System (RAIS) and the Postsecondary Student Information System (PSIS).

As such, through this new combination of data sets that have recently been created under the new Education and Labour Market Longitudinal Platform (ELMLP) ${ }^{36}$, it will be possible for researchers to differentiate between unionized and nonunionized apprentices, given that the former will declare union dues on their income tax returns (Statistics Canada, 2019). However, for BC to benefit from this powerful new tool it will require the commitment to an effective data analytics strategy. Such a commitment to data analytics, including cohort longitudinal studies and long-term, consistent record-keeping on all registered apprentices in $\mathrm{BC}$ would provide the necessary means to objectively measure the effectiveness of the current system. An investment by the provincial government in such a robust data analytics system and team of researchers would provide a positive and significant improvement to the ITA, and the basis for more informed decisions regarding any future reforms to apprenticeships, as well as the means to objectively assess the

36 The integration of various data sets across different federal departments, including CRA, has been a recent initiative. Delays in implementation were due to concerns about data sharing across departments, and concerns about potential violations of Canada's Privacy Act. 
results of such reforms compared with previous results, thereby also providing valuable feedback to policy makers and stakeholders alike. 


\section{Appendices}

Appendix 1: Interview questions

Q1 - What position did you occupy during the time that the specific changes were introduced to BC's apprenticeship system, and what was the timeframe that it covered?

Q2 - Who were the stakeholders that were included in the governance system during your period of involvement?

Q3 - Can you please discuss the governance system of the apprenticeship system, and think about the following:

(a) - Who were the principle stakeholders in the apprenticeship system, and what was their role? Who was included and who was excluded? Why?

(b) - What kinds of discussions were held, and who were the main participants? Was this constructive? Why or why not?

(c) - What was the role of the bureaucracy of the ITA (or ITAC) and what were the outcomes in the governance of the system? 
Q4 - Which stakeholders were involved in the governance of the system, and where did the balance of power lie? Were some stakeholders more influential than others? Why?

Q5 - What was the nature of the relationship between the ITA (or ITAC) and the government?

Q6 - What do you think the government was trying to achieve and in your view, what were the government's reasons for implementing the reforms? What was your view about the government's goals and reasons? To what extent did the government achieve its goals? Can you please explain why you think that?

Q7 - Do you believe that the stakeholders shared a common understanding and interpretation of the government's intentions and guidelines? If yes, what were the factors that resulted in these shared understandings? If not, what do you think contributed to differences in understanding and interpretation?

Q8 - When the government announced changes (or new legislation) that would impact the ITA (or ITAC), what was the nature of the consultation process on the objectives and guidelines to achieve such objectives?

Q9 - Describe the process by which the Board approved changes to the training requirements and/or qualifications of a trade? 
Q10 - What kind of consideration was given to the interests of the trades workers in decisions made by the governance system pertaining to changes in qualification requirements? Can you please explain why you think that was the case?

Q11 - Is there anything further that you would like to bring up that might be pertinent to my research? 
Appendix 2: Colour-coded spreadsheet integrating themes with analysis

\begin{tabular}{|c|c|c|c|c|c|c|c|c|c|c|}
\hline 4 & A & B & C & E & $\mathrm{F}$ & $\mathrm{H}$ & I & K & L & $\mathrm{N}$ \\
\hline 1 & Themes & GP & GP & $\mathrm{ICl}$ & $\mathrm{ICl}$ & $\mathrm{FF}$ & $\mathrm{FF}$ & $\mathrm{T} \& \mathrm{C}$ & $\mathrm{T} \& \mathrm{C}$ & economy \\
\hline 2 & nterviewees & NDP & Lib & NDP & Lib & NDP & Lib & NDP & Lib & linkages \\
\hline 3 & Pol01 & SR & $n / a$ & $C C R$ & $n / a$ & $\mathrm{Al}$ & $\mathrm{n} / \mathrm{a}$ & IA & $\mathrm{n} / \mathrm{a}$ & contribution \\
\hline 4 & Pol02 & SR & $\mathrm{PD}$ & UO & $\mathrm{n} / \mathrm{a}$ & SI & $n / a$ & VSR & VSR & legacy \\
\hline 5 & Pol03 & DMP & PD & CCR & $\overline{C C R}$ & $\mathrm{n} / \mathrm{a}$ & $n / a$ & VSR & VSR & impact of PLAs \\
\hline 6 & Pol04 & $\mathrm{PD}$ & DMP & $\mathrm{n} / \mathrm{a}$ & CCR & $\mathrm{n} / \mathrm{a}$ & $n / a$ & $n / a$ & IA & protectionism \\
\hline 7 & Gov01 & $\overline{P D}$ & $\mathrm{n} / \mathrm{a}$ & UO & MAE & $\mathrm{Al}$ & $n / a$ & DAD & $\mathrm{n} / \mathrm{a}$ & $\mathrm{n} / \mathrm{a}$ \\
\hline 8 & Gov02 & $\mathrm{n} / \mathrm{a}$ & SR & $\mathrm{n} / \mathrm{a}$ & CCR & $\mathrm{n} / \mathrm{a}$ & SI & $n / a$ & $\overline{D A D}$ & work force \\
\hline 9 & Pra01 & DMP & $\mathrm{SR}$ & MAE & $\mathrm{CCR}$ & $n / a$ & SI & IA & DAD & $\mathrm{n} / \mathrm{a}$ \\
\hline 10 & Pra02 & $\mathrm{PD}$ & PD & MAE & $C C R$ & $n / a$ & $\overline{\mathrm{Al}}$ & $n / a$ & VSR & work force \\
\hline 11 & Pra03 & DMP & $\mathrm{PD}$ & UO & UO & $\mathrm{n} / \mathrm{a}$ & $n / a$ & $n / a$ & VSR & black market \\
\hline 12 & Pra04 & DMP & $\mathrm{PD}$ & $n / a$ & MAE & $n / a$ & SI & $n / a$ & VSR & work force \\
\hline 13 & Gov03 & DMP & SR & MAE & MAE & $\mathrm{Al}$ & $\mathrm{Al}$ & DAD & DAD & work force \\
\hline 14 & Pra05 & DMP & $\mathrm{SR}$ & MAE & $\mathrm{CCR}$ & $\mathrm{Al}$ & $\mathrm{Al}$ & DAD & IA & black market \\
\hline 15 & Pra06 & DMP & PD & CCR & UO & $\mathrm{n} / \mathrm{a}$ & $\mathrm{n} / \mathrm{a}$ & VSR & IA & black market \\
\hline 16 & Pra07 & DMP & SR & MAE & CCR & $\mathrm{n} / \mathrm{a}$ & $\mathrm{n} / \mathrm{a}$ & DAD & DAD & deregulation \\
\hline 17 & Pra08 & DMP & $\mathrm{PD}$ & $\mathrm{n} / \mathrm{a}$ & $\mathrm{CCR}$ & $n / a$ & $\mathrm{n} / \mathrm{a}$ & DAD & DAD & $\mathrm{n} / \mathrm{a}$ \\
\hline 18 & Gov04 & $\mathrm{n} / \mathrm{a}$ & SR & $\mathrm{n} / \mathrm{a}$ & CCR & $\mathrm{n} / \mathrm{a}$ & $\overline{\mathrm{Al}}$ & DAD & DAD & regulations \\
\hline 19 & Gov05 & DMP & DMP & $\mathrm{n} / \mathrm{a}$ & MAE & $n / a$ & $\mathrm{Al}$ & DAD & DAD & $n / a$ \\
\hline 20 & Gov06 & DMP & $S R$ & $n / a$ & CCR & $n / a$ & $n / a$ & DAD & DAD & growth \\
\hline 21 & Gov07 & $\mathrm{n} / \mathrm{a}$ & DMP & $n / a$ & CCR & $n / a$ & $\mathrm{n} / \mathrm{a}$ & DAD & DAD & $\mathrm{n} / \mathrm{a}$ \\
\hline 22 & 1-Bill 37 & $\mathrm{n} / \mathrm{a}$ & $n / a$ & $n / a$ & $\mathrm{n} / \mathrm{a}$ & $n / a$ & $n / a$ & IA & $\mathrm{n} / \mathrm{a}$ & work force \\
\hline 23 & 2-FWSD ACt & $\mathrm{n} / \mathrm{a}$ & $\mathrm{n} / \mathrm{a}$ & $\mathrm{n} / \mathrm{a}$ & $\mathrm{n} / \mathrm{a}$ & $\mathrm{n} / \mathrm{a}$ & $n / a$ & IA & $\mathrm{n} / \mathrm{a}$ & skill develop \\
\hline 24 & 3-Abigail & $\mathrm{n} / \mathrm{a}$ & $\mathrm{n} / \mathrm{a}$ & CCR & $\mathrm{n} / \mathrm{a}$ & $\mathrm{Al}$ & $\mathrm{n} / \mathrm{a}$ & DAD & $\mathrm{n} / \mathrm{a}$ & $\mathrm{n} / \mathrm{a}$ \\
\hline 25 & 4-Bill 43 & $S R$ & $\mathrm{n} / \mathrm{a}$ & MAE & $\mathrm{n} / \mathrm{a}$ & SI & $\mathrm{n} / \mathrm{a}$ & VSR & $\mathrm{n} / \mathrm{a}$ & skill develop \\
\hline 26 & 5-ML Report & $\mathrm{n} / \mathrm{a}$ & $\mathrm{n} / \mathrm{a}$ & MAE & $\mathrm{n} / \mathrm{a}$ & $\mathrm{Al}$ & $\mathrm{n} / \mathrm{a}$ & VSR & $\mathrm{n} / \mathrm{a}$ & work force \\
\hline 27 & 6-ITAC ACt & $\mathrm{n} / \mathrm{a}$ & $\mathrm{n} / \mathrm{a}$ & MAE & $\mathrm{n} / \mathrm{a}$ & SI & $n / a$ & VSR & $\mathrm{n} / \mathrm{a}$ & skill develop \\
\hline 28 & 7-Johncox & $n / a$ & SR & $\mathrm{n} / \mathrm{a}$ & UO & $\mathrm{n} / \mathrm{a}$ & ROI & $\mathrm{n} / \mathrm{a}$ & VSR & labour costs \\
\hline 29 & 8-Bill 22 & $\mathrm{n} / \mathrm{a}$ & $\mathrm{n} / \mathrm{a}$ & $\mathrm{n} / \mathrm{a}$ & $\mathrm{n} / \mathrm{a}$ & $n / a$ & $\mathrm{n} / \mathrm{a}$ & $n / a$ & $\mathrm{n} / \mathrm{a}$ & deregulation \\
\hline 30 & 9-Unlocking & DMP & $\mathrm{n} / \mathrm{a}$ & MAE & $\mathrm{n} / \mathrm{a}$ & $\mathrm{Al}$ & $n / a$ & $\mathrm{DAD}$ & $\mathrm{n} / \mathrm{a}$ & work force \\
\hline 31 & 10-Coalitior & DMP & $\mathrm{n} / \mathrm{a}$ & MAE & $\mathrm{n} / \mathrm{a}$ & $\mathrm{Al}$ & $\mathrm{n} / \mathrm{a}$ & DAD & $\mathrm{n} / \mathrm{a}$ & employers \\
\hline 32 & 11-Bill 11 & $\mathrm{n} / \mathrm{a}$ & $\mathrm{n} / \mathrm{a}$ & $\mathrm{n} / \mathrm{a}$ & $\mathrm{n} / \mathrm{a}$ & $n / a$ & $n / a$ & $n / a$ & DAD & work force \\
\hline 33 & 12-Min $\mathrm{AE}$ & $\mathrm{n} / \mathrm{a}$ & $S R$ & $\mathrm{n} / \mathrm{a}$ & CCR & $n / a$ & $\mathrm{Al}$ & DAD & VSR & employers \\
\hline 34 & 13-BCGEU & $\mathrm{n} / \mathrm{a}$ & PD & $\mathrm{n} / \mathrm{a}$ & UO & $n / a$ & $\mathrm{Al}$ & $n / a$ & VSR & opportunities \\
\hline 35 & 14-Barrett & $\mathrm{n} / \mathrm{a}$ & DMP & $\mathrm{n} / \mathrm{a}$ & $\mathrm{CCR}$ & $n / a$ & $n / a$ & $n / a$ & VSR & construction \\
\hline 36 & 15-Bill 34 & $\mathrm{n} / \mathrm{a}$ & DMP & $\mathrm{n} / \mathrm{a}$ & MAE & $n / a$ & SI & $n / a$ & VSR & work force \\
\hline 37 & 16-Harris & SR & SR & $\mathrm{n} / \mathrm{a}$ & $\mathrm{n} / \mathrm{a}$ & $\mathrm{n} / \mathrm{a}$ & $\mathrm{n} / \mathrm{a}$ & $n / a$ & $\mathrm{n} / \mathrm{a}$ & $n / a$ \\
\hline 38 & 17-ITA Act & $\mathrm{n} / \mathrm{a}$ & $\overline{P D}$ & $\mathrm{n} / \mathrm{a}$ & $\mathrm{n} / \mathrm{a}$ & $\mathrm{n} / \mathrm{a}$ & $\mathrm{n} / \mathrm{a}$ & $n / a$ & $\mathrm{n} / \mathrm{a}$ & work force \\
\hline 39 & 18-Mtg Collin & $\mathrm{n} / \mathrm{a}$ & $\mathrm{n} / \mathrm{a}$ & $\mathrm{n} / \mathrm{a}$ & MAE & $\mathrm{n} / \mathrm{a}$ & $\mathrm{ROI}$ & $n / a$ & $\mathrm{n} / \mathrm{a}$ & training \\
\hline 40 & 19-BCCA NZ & $\mathrm{n} / \mathrm{a}$ & - & $\mathrm{n} / \mathrm{a}$ & MAE & $n / a$ & ROI & $n / a$ & $\overline{D A D}$ & $\mathrm{n} / \mathrm{a}$ \\
\hline 41 & 20-Doyle AG & $\mathrm{n} / \mathrm{a}$ & DMP & $\mathrm{n} / \mathrm{a}$ & UO & $n / a$ & $\mathrm{Al}$ & $\mathrm{n} / \mathrm{a}$ & VSR & $\mathrm{n} / \mathrm{a}$ \\
\hline 42 & 21-Hislop & $\mathrm{n} / \mathrm{a}$ & $n / a$ & $\mathrm{n} / \mathrm{a}$ & MAE & $n / a$ & $\mathrm{n} / \mathrm{a}$ & $\mathrm{n} / \mathrm{a}$ & IA & skill develop \\
\hline 43 & 22-BC Fed & $\mathrm{n} / \mathrm{a}$ & PD & $\mathrm{n} / \mathrm{a}$ & CCR & $n / a$ & $n / a$ & $n / a$ & VSR & training \\
\hline 44 & 23-McDon & DMP & DMP & $n / a$ & MAE & $\mathrm{n} / \mathrm{a}$ & ROI & $n / a$ & $\mathrm{n} / \mathrm{a}$ & work force \\
\hline
\end{tabular}

The four principal themes that were established and used in the pairs of columns in

this spread sheet matrix, along with their associated descriptors, codes and colours, 
are as follows:

Governance Process - Power Distribution (PD), Decision Making Process (DMP), Stakeholder Representation (SR)

Institutional Change Issues - Mandate, Authority \& Effectiveness (MAE), Unexpected Outcomes (UO), Changes in Collaboration \& Relations (CCR) Funding Frictions - Allocation Issues (AI), Student Impacts (SI), Return on Investment (ROI)

Training, Certification and Regulatory Implications - Delivery Approach Disagreements (DAD), Value of Standards \& Requirements (VSR), Impact on Apprentice (IA)

Green - situation improved

Grey - situation remain unchanged

Orange - situation worsened

Blue - possible anomaly

The color-coded spreadsheet above is the summation of the data organization, coding and interpretation discussed in Chapter 4. Each row is linked to the data sources depicted in Column A, with Row 3 through to Row 21 being the interviews, and Row 22 through to Row 44 being the documents. Each of the interviewees is assigned one of three lables (Pol, Gov or Pra) to preserve their anonymity, with a corresponding number to separate them within each group. These are the abbreviated forms for Politician, Governor or Practitioner respectively. Within the 
text, these lables are provided additional description to improve the contextual understanding of time and/or political affiliation (i.e. Politician 02 NDP , Governor 01 ITAC, etc.). For instance Four pairs of columns are used for each of the themes, within which a separate column is linked to when the New Democratic Party (NDP) formed the provincial government, and when the Liberals formed the provincial government. Column $\mathrm{N}$ provides an overall indicator of the dominant theme expressed by the data source pertaining to the economy.

The codes used in each cell provided unique descriptors relating to the four principal themes, whereas the colour provided a visual depiction of whether the situation relating to the particular theme worsened, remained unchanged or improved during the period in which the two different parties formed the provincial government. If none of the descriptors could be related to the interviewee or document, then "n/a" was assigned to the cell without any colour. A cell that was rendered blue was used to indentify a potential anomaly. 


\begin{tabular}{|c|c|c|c|}
\hline Date & Event & Description & Sponsor \\
\hline $\begin{array}{l}23 \mathrm{Mar} \\
1935\end{array}$ & Royal Assent & $\begin{array}{c}\text { An Act Respecting the } \\
\text { Training of } \\
\text { Apprentices }\end{array}$ & $\begin{array}{l}\text { Department of } \\
\text { Labour }\end{array}$ \\
\hline 1936 & & $\begin{array}{l}\text { Trades School } \\
\text { Regulation Act }\end{array}$ & $\begin{array}{l}\text { Department of } \\
\text { Education }\end{array}$ \\
\hline 1955 & $\begin{array}{l}\text { Replacement of } \\
1935 \text { Act }\end{array}$ & $\begin{array}{l}\text { Apprenticeship \& } \\
\text { Tradesmen's } \\
\text { Qualification Act }\end{array}$ & $\begin{array}{l}\text { Department of } \\
\text { Labour }\end{array}$ \\
\hline 1956 & $\begin{array}{c}\text { Establish } \\
\text { Vocational } \\
\text { Curriculum } \\
\text { Development Div }\end{array}$ & $\begin{array}{l}\text { Reports to the } \\
\text { Technical Branch of } \\
\text { Department of } \\
\text { Education }\end{array}$ & $\begin{array}{l}\text { Department of } \\
\text { Education }\end{array}$ \\
\hline Dec 1962 & $\begin{array}{l}\text { Report released } \\
\text { promoting PSE }\end{array}$ & $\begin{array}{l}\text { Higher Education in } \mathrm{BC} \\
\text { \& a plan for the Future }\end{array}$ & $\begin{array}{l}\text { John B. Macdonald, } \\
\text { UBC }\end{array}$ \\
\hline 1963 & $\begin{array}{l}\text { Amendment to } \\
\text { allow for regional } \\
\text { colleges in } \mathrm{BC}\end{array}$ & Public Schools Act & $\begin{array}{l}\text { Department of } \\
\text { Education }\end{array}$ \\
\hline Feb 1967 & $\begin{array}{l}\text { Annual Report } \\
\text { released }\end{array}$ & $\begin{array}{l}\text { Annual Report for the } \\
\text { Year ended 31 Dec } \\
1966\end{array}$ & $\begin{array}{l}\text { Department of } \\
\text { Labour }\end{array}$ \\
\hline $\begin{array}{c}05 \mathrm{Feb} \\
1971\end{array}$ & $\begin{array}{l}\text { BC's Annual } \\
\text { Budget }\end{array}$ & $\begin{array}{l}\text { Significant funding } \\
\text { increase for new } \\
\text { colleges }\end{array}$ & $\begin{array}{l}\text { Premier Bill Bennett } \\
\text { (also Finance } \\
\text { Minister) }\end{array}$ \\
\hline $\begin{array}{l}11 \mathrm{Dec} \\
1975\end{array}$ & BC's 31 & SOCREDs win majority & Premier Bill Bennett \\
\hline $14 \mathrm{Jul} 1976$ & $\begin{array}{l}\text { Appointment of } \\
\text { Royal Commission }\end{array}$ & $\begin{array}{c}\text { Commission on } \\
\text { Vocational, Technical \& } \\
\text { Trades Training }\end{array}$ & $\begin{array}{c}\text { Patrick McGeer, Min } \\
\text { of Education \& Allan } \\
\text { Williams, Min of } \\
\text { Labour }\end{array}$ \\
\hline $\begin{array}{c}31 \text { Jan } \\
1977\end{array}$ & $\begin{array}{c}\text { Royal Commission } \\
\text { Official Report } \\
\text { Submitted }\end{array}$ & $\begin{array}{l}\text { Recommend creation } \\
\text { of Occupational } \\
\text { Training Council }\end{array}$ & $"$ \\
\hline $\begin{array}{c}02 \text { Aug } \\
1977\end{array}$ & $1^{\text {st }}$ Reading Bill 82 & $\begin{array}{l}\text { Colleges \& Provincial } \\
\text { Institutes Act }\end{array}$ & $\begin{array}{c}\text { Patrick McGeer, Min } \\
\text { of Education, Science } \\
\text { \& Technology - } \\
\text { SOCRED }\end{array}$ \\
\hline $\begin{array}{c}06 \text { Sep } \\
1977\end{array}$ & $2^{\text {nd }}$ Reading Bill 82 & “ & " \\
\hline $\begin{array}{c}13 \mathrm{Sep} \\
1977\end{array}$ & 3rd Reading Bill 82 & " & " \\
\hline
\end{tabular}




\begin{tabular}{|c|c|c|c|}
\hline $\begin{array}{c}27 \text { Sep } \\
1977\end{array}$ & $\begin{array}{l}\text { Royal Assent Bill } \\
82\end{array}$ & “ & “ \\
\hline $\begin{array}{l}\text { 02 Aug } \\
1977\end{array}$ & $1^{\text {st }}$ Reading Bill 76 & $\begin{array}{c}\text { Apprenticeship \& } \\
\text { Training Development } \\
\text { Act }\end{array}$ & $\begin{array}{l}\text { Allan Williams, Min } \\
\text { of Labour - SOCREDs }\end{array}$ \\
\hline $\begin{array}{l}06 \text { Sep } \\
1977\end{array}$ & $2^{\text {nd }}$ Reading Bill 76 & $"$ & “ \\
\hline $\begin{array}{c}\text { 07 Sep } \\
1977\end{array}$ & 3rd Reading Bill 76 & “ & “ \\
\hline $\begin{array}{c}27 \text { Sep } \\
1977\end{array}$ & $\begin{array}{l}\text { Royal Assent Bill } \\
76\end{array}$ & “ & “ \\
\hline $\begin{array}{c}10 \text { May } \\
1979\end{array}$ & BC's 32nd Election & SOCREDs win majority & Premier Bill Bennett \\
\hline Jun 1979 & $\begin{array}{l}\text { 1st Report of the } \\
\text { Task Force }\end{array}$ & $\begin{array}{l}\text { Pre-employment \& } \\
\text { Pre-apprenticeship } \\
\text { Training Programs in } \\
\text { BC }\end{array}$ & $\begin{array}{l}\text { Min of Education, } \\
\text { Science \& } \\
\text { Technology, \& Min of } \\
\text { Labour - SOCRED }\end{array}$ \\
\hline $\begin{array}{l}10 \text { Aug } \\
1979\end{array}$ & $\begin{array}{l}2^{\text {nd }} \& \text { Final Report } \\
\text { of the Task Force }\end{array}$ & 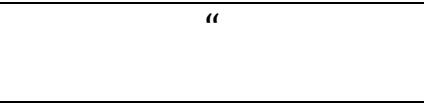 & 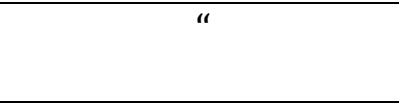 \\
\hline $\begin{array}{c}13 \mathrm{Dec} \\
1982\end{array}$ & TRAC Announced & $\begin{array}{c}\text { New Approach to } \\
\text { Vocational Training }\end{array}$ & $\begin{array}{l}\text { Bill Vander Zalm, Min } \\
\text { of Education - } \\
\text { SOCREDs }\end{array}$ \\
\hline $\begin{array}{l}05 \text { May } \\
1983\end{array}$ & BC's 33rd Election & SOCREDs win majority & Premier Bill Bennett \\
\hline Nov 1984 & $\begin{array}{l}\text { PAB Official } \\
\text { Report }\end{array}$ & $\begin{array}{l}\text { The Future of } \\
\text { Apprenticeship }\end{array}$ & $\begin{array}{l}\text { Robert McClelland, } \\
\text { Min of Labour - } \\
\text { SOCREDs }\end{array}$ \\
\hline $\begin{array}{l}22 \text { Oct } \\
1986\end{array}$ & BC's 34 $4^{\text {th }}$ Election & SOCREDs win majority & $\begin{array}{l}\text { Prem Bill Vander } \\
\text { Zalm }\end{array}$ \\
\hline $\begin{array}{l}17 \text { Aug } \\
1989\end{array}$ & $\begin{array}{l}\text { Task Force } \\
\text { announced }\end{array}$ & $\begin{array}{c}\text { Task Force on } \\
\text { Employment \& } \\
\text { Training }\end{array}$ & $\begin{array}{l}\text { Stan Hagen, Min of } \\
\text { AE \& Job Training, } \\
\text { SOCREDs }\end{array}$ \\
\hline Dec 1991 & $\begin{array}{c}\text { Task Force Report } \\
\text { submitted }\end{array}$ & “ & $\begin{array}{c}\text { Tom Perry, Min of } \\
\text { AE, Trng \& Tech, NDP }\end{array}$ \\
\hline $\begin{array}{l}17 \text { Oct } \\
1991\end{array}$ & BC's 35th Election & NDP win majority & $\begin{array}{l}\text { Premier Mike } \\
\text { Harcourt }\end{array}$ \\
\hline $\begin{array}{l}10 \text { May } \\
1994\end{array}$ & $1^{\text {st }}$ Reading Bill 37 & $\begin{array}{l}\text { Skills Development \& } \\
\text { Fair Wage Act }\end{array}$ & $\begin{array}{l}\text { Dan Miller, Min of } \\
\text { Skills, Training \& } \\
\text { Labour - NDP }\end{array}$ \\
\hline $\begin{array}{l}19 \text { May } \\
1994\end{array}$ & $2^{\text {nd }}$ Reading Bill 37 & “ & “ \\
\hline $\begin{array}{c}01 \text { Jun } \\
1994 \\
\end{array}$ & Committee Bill 37 & “ & “ \\
\hline $\begin{array}{c}10 \text { Jun } \\
1994\end{array}$ & $\begin{array}{l}\text { Royal Assent Bill } \\
37\end{array}$ & “ & “ \\
\hline
\end{tabular}




\begin{tabular}{|c|c|c|c|}
\hline $\begin{array}{l}28 \text { May } \\
1996\end{array}$ & BC's 36 th Election & NDP win majority & Premier Glen Clark \\
\hline Apr 1997 & $\begin{array}{l}\text { Thought Paper on } \\
\text { skilled work force } \\
\text { in BC }\end{array}$ & $\begin{array}{c}\text { Apprenticeship: A } \\
\text { Construction Industry } \\
\text { Perspective }\end{array}$ & $\begin{array}{l}\text { BC Construction } \\
\text { Association Task } \\
\text { Force }\end{array}$ \\
\hline $\begin{array}{c}23 \text { Jun } \\
1997\end{array}$ & $1^{\text {st }}$ Reading Bill 43 & $\begin{array}{l}\text { Industry Training \& } \\
\text { Apprenticeship Act }\end{array}$ & $\begin{array}{c}\text { John Cashore, Min of } \\
\text { Labour \& Paul } \\
\text { Ramsey, Min EST - } \\
\text { NDP } \\
\end{array}$ \\
\hline $\begin{array}{l}25 \text { Jun } \\
1997\end{array}$ & Official Report & $\begin{array}{c}\text { Revitalizing } \\
\text { Apprenticeship: A } \\
\text { Strategic Framework } \\
\text { for BC's Training } \\
\text { System }\end{array}$ & Ministry of Labour \\
\hline $16 \mathrm{Jul} 1997$ & Official Report & $\begin{array}{l}\text { Skills, Training \& } \\
\text { Education \& the BC } \\
\text { Labour Market }\end{array}$ & $\begin{array}{c}\text { Ministry of } \\
\text { Education, Skills \& } \\
\text { Training }\end{array}$ \\
\hline $23 \mathrm{Jul} 1997$ & $2^{\text {nd }}$ Reading Bill 43 & $\begin{array}{l}\text { Industry Training \& } \\
\text { Apprenticeship Act }\end{array}$ & (2) \\
\hline $25 \mathrm{Jul} 1997$ & Committee $\mathrm{B}$ & 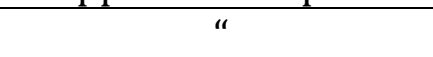 & “ \\
\hline $30 \mathrm{Jul} 1997$ & $\begin{array}{l}\text { Royal Assent Bill } \\
43\end{array}$ & “ & “ \\
\hline $\begin{array}{c}29 \text { Jan } \\
2001\end{array}$ & $\begin{array}{l}\text { Thought Paper } \\
\text { questioning the } \\
\text { need for } \\
\text { compulsory trades }\end{array}$ & $\begin{array}{c}\text { Compulsory } \\
\text { Certification in } \\
\text { Selected Trades: } \\
\text { Where to from here in } \\
\text { BC? }\end{array}$ & $\begin{array}{l}\text { Gary Johncox on } \\
\text { behalf of Business } \\
\text { Council of BC \& } \\
\text { Coalition of BC } \\
\text { Businesses } \\
\end{array}$ \\
\hline $\begin{array}{l}16 \text { May } \\
2001\end{array}$ & BC's 37th Election & Liberals win majority & $\begin{array}{l}\text { Prem Gordon } \\
\text { Campbell }\end{array}$ \\
\hline $\begin{array}{c}16 \text { Aug } \\
2001\end{array}$ & $1^{\text {st }}$ Reading Bill 22 & $\begin{array}{l}\text { Skills Development \& } \\
\text { Fair Repeal Wage Act }\end{array}$ & $\begin{array}{c}\text { Graham Bruce, Min } \\
\text { Skills Devel \& Labour } \\
\text { - Liberals }\end{array}$ \\
\hline $\begin{array}{l}20 \text { Aug } \\
2001\end{array}$ & $2^{\text {nd }}$ Reading Bill 22 & " & 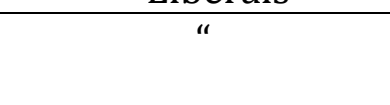 \\
\hline $\begin{array}{l}21 \mathrm{Aug} \\
2001\end{array}$ & Committee Bill 22 & “ & “ \\
\hline $\begin{array}{l}27 \text { Aug } \\
2001\end{array}$ & $\begin{array}{c}\text { Royal Assent Bill } \\
22\end{array}$ & “ & “ \\
\hline $\begin{array}{l}\text { 04 Sep } \\
2001\end{array}$ & $\begin{array}{l}\text { Thought Paper on } \\
\text { Improving ITAC }\end{array}$ & $\begin{array}{l}\text { Unlocking ITAC: A New } \\
\text { Vision and New Model }\end{array}$ & $\begin{array}{l}\text { Kerry Jothen, CEO of } \\
\text { ITAC }\end{array}$ \\
\hline Sep 2001 & $\begin{array}{c}\text { Thought Paper on } \\
\text { concerns with } \\
\text { ITAC }\end{array}$ & $\begin{array}{c}\text { The ITAC - What is its } \\
\text { Future? }\end{array}$ & $\begin{array}{l}\text { Coalition of BC } \\
\text { Businesses }\end{array}$ \\
\hline $\begin{array}{l}14 \mathrm{Mar} \\
2002\end{array}$ & $1^{\text {st }}$ Reading Bill 11 & Miscellaneous Statutes & $\begin{array}{l}\text { Geoff Plant, Attorney } \\
\text { General - Liberals }\end{array}$ \\
\hline
\end{tabular}




\begin{tabular}{|c|c|c|c|}
\hline & & Amendment Act, ${ }^{37}$ & \\
\hline $\begin{array}{l}29 \mathrm{Apr} \\
2002\end{array}$ & $2^{\text {nd }}$ Reading Bill 11 & " & “ \\
\hline $\begin{array}{l}30 \mathrm{Apr} \\
2002\end{array}$ & Committee Bill 11 & “ & “ \\
\hline $\begin{array}{l}30 \mathrm{Apr} \\
2002\end{array}$ & $\begin{array}{l}\text { Royal Assent Bill } \\
11\end{array}$ & “ & “ \\
\hline Dec 2002 & Official Report & $\begin{array}{c}\text { A New Model for } \\
\text { Industry Training in BC }\end{array}$ & $\begin{array}{l}\text { Ministry of Advanced } \\
\text { Education }\end{array}$ \\
\hline $\begin{array}{l}31 \mathrm{Jan} \\
2003\end{array}$ & $\begin{array}{l}\text { Response to Min } \\
\text { AE Official Report }\end{array}$ & $\begin{array}{l}\text { A Response by the } \\
\text { BCGEU to the New } \\
\text { Model }\end{array}$ & $\begin{array}{l}\text { BC Gov't \& Service } \\
\text { Employees' Union }\end{array}$ \\
\hline $\begin{array}{l}13 \mathrm{Feb} \\
2003\end{array}$ & $\begin{array}{l}\text { Response to Min } \\
\text { AE Official Report }\end{array}$ & $\begin{array}{l}\text { A Response by the } \\
\text { BCBTC to the New } \\
\text { Model }\end{array}$ & $\begin{array}{c}\text { BC Building \& } \\
\text { Construction Trades } \\
\text { Council }\end{array}$ \\
\hline $\begin{array}{l}30 \mathrm{Apr} \\
2003\end{array}$ & $1^{\text {st }}$ Reading Bill 34 & $\begin{array}{c}\text { Industry Training } \\
\text { Authority Act }\end{array}$ & $\begin{array}{l}\text { Shirley Bond, Min of } \\
\text { AE, Liberals }\end{array}$ \\
\hline $\begin{array}{l}05 \text { May } \\
2003\end{array}$ & $2^{\text {nd }}$ Reading Bill 34 & “ & “ \\
\hline $\begin{array}{l}13 \text { May } \\
2003\end{array}$ & Committee Bill 34 & “ & “ \\
\hline $\begin{array}{l}29 \text { May } \\
2003\end{array}$ & $\begin{array}{l}\text { Royal Assent Bill } \\
34\end{array}$ & “ & “ \\
\hline $\begin{array}{l}17 \text { May } \\
2005\end{array}$ & BC's 38 ${ }^{\text {th }}$ Election & Liberals win majority & $\begin{array}{l}\text { Prem Gordon } \\
\text { Campbell }\end{array}$ \\
\hline
\end{tabular}

37 This legislation amended the 1997 Industry Training \& Apprenticeship Act, providing for a oneperson transitional Board to wind up ITAC's activities. The Ministry of Advanced Education took on the administrative functions of the apprenticeship while awaiting a replacement for ITAC (which was the Industry Training Authority, which came into being on 29 May 2003 via Royal Assent of Bill 34). 
Appendix 4: Former Premiers of BC (1986 - 2011)

\begin{tabular}{|c|c|c|c|}
\hline Start Date & End Date & Premier's Name & Party \\
\hline 05 Jun 2001 & 14 Mar 2011 & Gordon Campbell & Liberals \\
\hline 24 Feb 2000 & 05 Jun 2001 & Ujjal Dosanjh & NDP \\
\hline 25 Aug 1999 & 24 Feb 2000 & Dan Miller & “ \\
\hline 22 Feb 1996 & 25 Aug 1999 & Glen Clark ${ }^{39}$ & “ \\
\hline 05 Nov 1991 & 22 Feb 1996 & Mike Harcourt 40 & " \\
\hline 02 Apr 1991 & 05 Nov 1991 & Rita Johnston & SOCREDs \\
\hline 06 Aug 1986 & 02 Apr 1991 & Bill Vander Zalm ${ }^{41}$ & " \\
\hline
\end{tabular}

${ }^{38}$ Elected on 16 May 2001 as part of BC's $37^{\text {th }}$ provincial election, and his Liberal party won a majority with 77 of 79 seats in the BC Legislature. The NDP formed the opposition with 2 seats. He was re-elected on 17 May 2005 as part of BC's $38^{\text {th }}$ provincial election, and his Liberal party won a majority with 46 of 79 seats in the BC Legislature. The NDP formed the opposition with 33 seats. He was re-elected a third time on 12 May 2009 as part of BC's $39^{\text {th }}$ provincial election, and his Liberal party won a majority with 49 of 84 seats in the BC Legislature. The NDP formed the opposition with 35 seats. He resigned as Premier on 14 Mar 2011, and was succeeded by Christy Clark, who won the leadership campaign for the Liberal party of BC on $26 \mathrm{Feb} 2011$.

${ }^{39}$ Elected on 28 May 1996 as part of BC's $36^{\text {th }}$ provincial election, and his NDP party won a majority with 39 of 75 seats in the BC Legislature. The Liberals formed the opposition with 33 seats. He resigned as Premier on 25 Aug 1999 as a result of the "Casinogate" scandal, and was succeeded by Dan Miller, as the interim leader.

${ }^{40}$ Elected on 17 Oct 1991 as part of BC's 35th provincial election, and his NDP party won a majority with 51 of 75 seats in the BC Legislature. The Liberals formed the opposition with 17 seats. He resigned as Premier on 22 Feb 1996 as a result of the "Bingogate" scandal, and was succeeded by Glen Clark, as the interim leader and who later won the leadership campaign for the NDP of BC in the spring of 1996.

${ }^{41}$ He replaced SOCRED Premier Bill Barrett, who retired from politics in 1986, after winning the leadership convention in Jul 1986. He subsequently called an election, and won on 22 Oct 1986 as part of BC's $34^{\text {th }}$ provincial election, and his SOCRED party won a majority with 47 of 69 seats in the BC Legislature. The NDP formed the opposition with 22 seats. He resigned as Premier on $02 \mathrm{Apr}$ 1991 as a result of a conflict of interest scandal related to the sale of his Fantasy Gardens, and was succeeded by Rita Johnston (the $1^{\text {st }}$ female Premier of BC) as the interim leader. She subsequently who won the leadership of the SOCRED party of BC in July 1991, but lost in the provincial election on 17 Oct 1991. 


\begin{tabular}{|c|c|c|c|c|}
\hline Start Date & End Date & Ministry & Name & Party \\
\hline 10 Jun 2009 & 25 Oct 2010 & $\begin{array}{l}\text { AE \& Labour } \\
\text { Market } \\
\text { Development }\end{array}$ & Moira Stilwell & Liberals \\
\hline 23 Jun 2008 & 10 Jun 2009 & $"$ & Murray Coell & " \\
\hline 16 Jun 2005 & 23 Jun 2008 & $\begin{array}{l}\text { Advanced } \\
\text { Education }\end{array}$ & " & $"$ \\
\hline 15 Dec 2004 & 16 Jun 2005 & $"$ & Ida Chong & $"$ \\
\hline 05 Jun 2001 & 15 Dec 2004 & “ & Shirley Bond & “ \\
\hline 01 Nov 2000 & 05 Jun 2001 & $\begin{array}{c}\text { AE, Training \& } \\
\text { Technology }\end{array}$ & Cathy McGregor & NDP \\
\hline 29 Feb 2000 & 01 Nov 2000 & $"$ & $\begin{array}{c}\text { Graeme } \\
\text { Bowbrick }\end{array}$ & $"$ \\
\hline 18 Feb 1998 & 24 Feb 2000 & $"$ & Andrew Petter & $"$ \\
\hline 06 Jan 1997 & 18 Feb 1998 & $\begin{array}{c}\text { Education, Skills \& } \\
\text { Training }\end{array}$ & Paul Ramsey & " \\
\hline 12 Dec 1996 & 06 Jan 1997 & $"$ & Joy MacPhail & $"$ \\
\hline 17 Jun 1996 & 12 Dec 1996 & " & Moe Sihota & " \\
\hline 28 Feb 1996 & 17 Jun 1996 & $"$ & Paul Ramsey & " \\
\hline 15 Sep 1993 & 28 Feb 1996 & $\begin{array}{l}\text { Ministry was } \\
\text { deactivated }{ }^{42}\end{array}$ & Dan Miller & $"$ \\
\hline 05 Nov 1991 & 15 Sep 1993 & $\begin{array}{l}\text { AE, Training \& } \\
\text { Technology }\end{array}$ & Tom Perry & " \\
\hline 29 May 1991 & 05 Nov 1991 & $"$ & Peter Dueck & SOCREDs \\
\hline 01 Nov 1989 & 05 May 1991 & " & Bill Strachan & “ \\
\hline 10 Dec 1986 & O1 Nov 1989 & AE \& Job Training & Stan Hagen & $"$ \\
\hline
\end{tabular}

42 Ministry of Advanced Education, Training and Technology disestablished by OIC 1210/93. 


\begin{tabular}{|c|c|c|c|c|}
\hline Start Date & End Date & Ministry & Name & Party \\
\hline 10 Jun 2009 & 25 Oct 2010 & " & Coell Murray & Liberals \\
\hline 23 Jun 2008 & 10 Jun 2009 & $\begin{array}{c}\text { Labour \& Citizens' } \\
\text { Services }\end{array}$ & Iain Black & " \\
\hline 15 Aug 2006 & 23 Jun 2008 & “ & Olga Ilich & “ \\
\hline 16 Jun 2005 & 15 Aug 2006 & " & Michael de Jong & “ \\
\hline 05 Jun 2001 & 16 Jun 2005 & $\begin{array}{l}\text { Skills Development } \\
\text { \& Labour }\end{array}$ & Bruce Graham & “ \\
\hline 01 Nov 2000 & 05 Jun 2001 & Labour & Joan Smallwood & NDP \\
\hline $29 \mathrm{Feb} 2000$ & 01 Nov 2000 & $"$ & Joy MacPhail & $"$ \\
\hline 21 Jul 1999 & $24 \mathrm{Feb} 2000$ & “ & Joan Smallwood & “ \\
\hline 18 Feb 1998 & $21 \mathrm{Jul} 1999$ & “ & Dale Lovick & “ \\
\hline 06 Jan 1997 & 18 Feb 1998 & “ & John Cashore & “ \\
\hline 12 Dec 1996 & 06 Jan 1997 & “ & Joy MacPhail & “ \\
\hline 17 Jun 1996 & $12 \operatorname{Dec} 1996$ & “ & Moe Sihota & “ \\
\hline 28 Feb 1996 & 17 Jun 1996 & “ & Penny Priddy & “ \\
\hline 15 Sep 1993 & 22 Feb 1996 & $\begin{array}{l}\text { Skills, Training \& } \\
\text { Labour }\end{array}$ & Dan Miller & “ \\
\hline 05 Nov 1991 & 15 Sep 1993 & $\begin{array}{c}\text { Labour \& } \\
\text { Consumer Services } \\
\end{array}$ & Moe Sihota & “ \\
\hline 13 Dec 1990 & 05 Nov 1991 & " & James Rabbitt & SOCREDs \\
\hline 01 Nov 1989 & $13 \operatorname{Dec} 1990$ & “ & Johan Jacobsen & " \\
\hline 06 Nov 1986 & 01 Nov 1989 & " & Lyall Hanson & $\bar{~}$ \\
\hline
\end{tabular}




\section{Appendix 7: Apprenticeship Outcomes on the BC Economy}

The historical review of the VET system in BC that was provided in Chapter 2 illustrated the evolution of the PSE institutions and the transfer of the majority of apprenticeship education and training delivery to the public colleges. With this transfer, along with the disruption that arose over the increased pre-apprenticeship training delivery by the colleges came increased government interest in terms of reviews and reports, as well as intervention through new initiatives. The intrinsic logic behind the various legislative reforms to BC's VET system and apprenticeships were commonly justified in terms of the benefits to the economy through the provision of skilled trades workers to meet the needs of different industries, as well in terms of the employability, particularly for youth preparing for their transition into the work force. Premier Clark's (2014) plan entitled B.C.'s Skills for Jobs Blueprint: Re-engineering Education and Training, was not much different in its intrinsic logic from previous governments, including the NDP and Liberals during the period of 1993 -2004. In the case of Premier Clark, her focus was on the construction trades in particular, as BC was actively preparing for a potential boom in the liquid natural gas (LNG) industry, which would require pipelines in additional to processing plants.

The tax cuts, deregulation and privatization initiatives introduced by the new Liberal government in 2001 impacted many different areas including VET and apprenticeships, yet the only area that showed noteworthy private investment and 
job growth was in the residential construction industry, and this was also concentrated in the heavily populated lower mainland and greater Victoria areas (Lee, 2004). In and around the same time, construction accounted for about 10 per cent of employment in $\mathrm{BC}$, while one in six people in the $\mathrm{BC}$ work force were employed as trades workers (Hallin, 2001). This growth would also begin to improve through major infrastructure projects in advance of the 2010 Vancouver Winter Olympics, such as the upgrading of the Sea to Sky Highway from Vancouver to Whistler. In fact, the Vancouver Regional Construction Association (2011) identified the construction industry as one of the largest employers in the lower mainland region, and the source of significant economic activity. Thus, despite efforts to improve the economy across the various sectors and throughout the province, jobs in construction were concentrated in the lower mainland and Vancouver Island, corresponding to where the large share of BC's population resides and corresponds with the concentration of the residential construction sector (Hallin, 2006).

Comparing the results between the NDP and Liberal governments in terms of both private capital investment in BC illustrates the contrast in outcomes. Private capital investment in construction was predominantly higher, in terms of the per cent of BC's GDP, during the NDP's tenure than the Liberal's despite the Liberal government's strategy to deregulate the trades, introduce CBT and to lower corporate and capital taxes (Lee, 2004). The exception was in the residential sector, which saw noticeable growth (Hallin, 2006). Although major infrastructure 
programs for the 2010 Winter Olympics would begin to impact this after 2004, the divergence between machinery and equipment (despite the elimination of sales tax on these items by the Liberals) and construction between 2001 and 2004 highlights the fact the private spending in construction was largely in the residential sector, as heavy equipment is associated with major projects such as widening highways (Lee, 2004; Sashaw, 2011).

However, one area in which there is a clear change that coincides with the change in government in 2001 is the sudden, positive reversal in the demand for trades workers within the construction industry in $\mathrm{BC}$, which again, is largely attributed to the boom in the residential sector in the lower mainland and greater Victoria areas of the province, which was becoming evident in late 2003 (Hallin, 2006). Even though the large companies decreased their support of apprenticeship programs, they expressed concerns about a shortage of skilled labour. Recognizing this imbalance in the availability of indentured positions for apprentices and a withdrawal from supporting the VET system that creates skilled workers, the Ministry undertook initiatives to motivate greater employer engagement in the apprenticeship programs (Ministry of Labour, 1997).

The residential construction industry contributed to the small and medium sized employers, as is common given the nature of the industry. The downside of small and medium sized companies, is that they are less inclined to formally sponsor an apprentice, due to the higher wages an apprentice could earn, particularly as the 
apprentice progressed to higher levels of VET and experience. For instance, a new apprentice typically earns about 50 per cent of a Journeyperson's wage, whereas a level-three apprentice (about three-quarters of the way through an apprenticeship) could expect up to 75 per cent of the wages of a Journeyperson. Furthermore, apprentices negatively impact profit margins, through less efficient use of materials and loss through mistakes that have to be corrected (Doyle, 2008).

The other disinclination for these small and medium sized companies was the risk that once the apprentice achieved his or her Journeyperson CQ they could move on and work for themselves in their own new business, or work for another company. In both cases this meant a loss on their investment in the apprentice's training, as well as potential competition. Consequently, despite the fact that small and medium sized business are more numerous and provide greater potential to indenture apprentices, they tend not to unless they are unionized (J. Barrett, 2003) ${ }^{43}$. This is an area that deserves greater policy attention by way of how best to support such companies so that more of them sponsor apprentices (Labour, 2013), perhaps through a model similar to the Joint Apprenticeship Training Committee, in which the risks can be shared amongst a pool of small to medium sized companies. In brief, JATCs are based on collective agreements between a union and multiple employers in which funds (based on hours of work) are directed into a training trust fund. These funds enable the JATC to pay staff, operate training centres and coordinate

\footnotetext{
43 In the 2003 timeframe, over 1400 of the roughly 13,200 construction companies were unionized. While the majority of construction companies in BC were small (five or less employees), those that were unionized had signed collective agreements. Collective agreements serve as the foundation for creating a demand for indenturing new apprentices through the JACT model.
} 
apprenticeship training to meet projected requirements for additional skilled workers (MacLeod, 2009). This is discussed in greater detail in the next section of Chapter 6.

Figure 4 shows the distribution of construction companies in BC circa 2006 by company size, thereby highlighting the fact small companies account for nearly twothirds of the demand for trades workers in the construction industry in particular. Consequently, small companies account for significant potential to indenture new apprentices (Hallin, 2006).

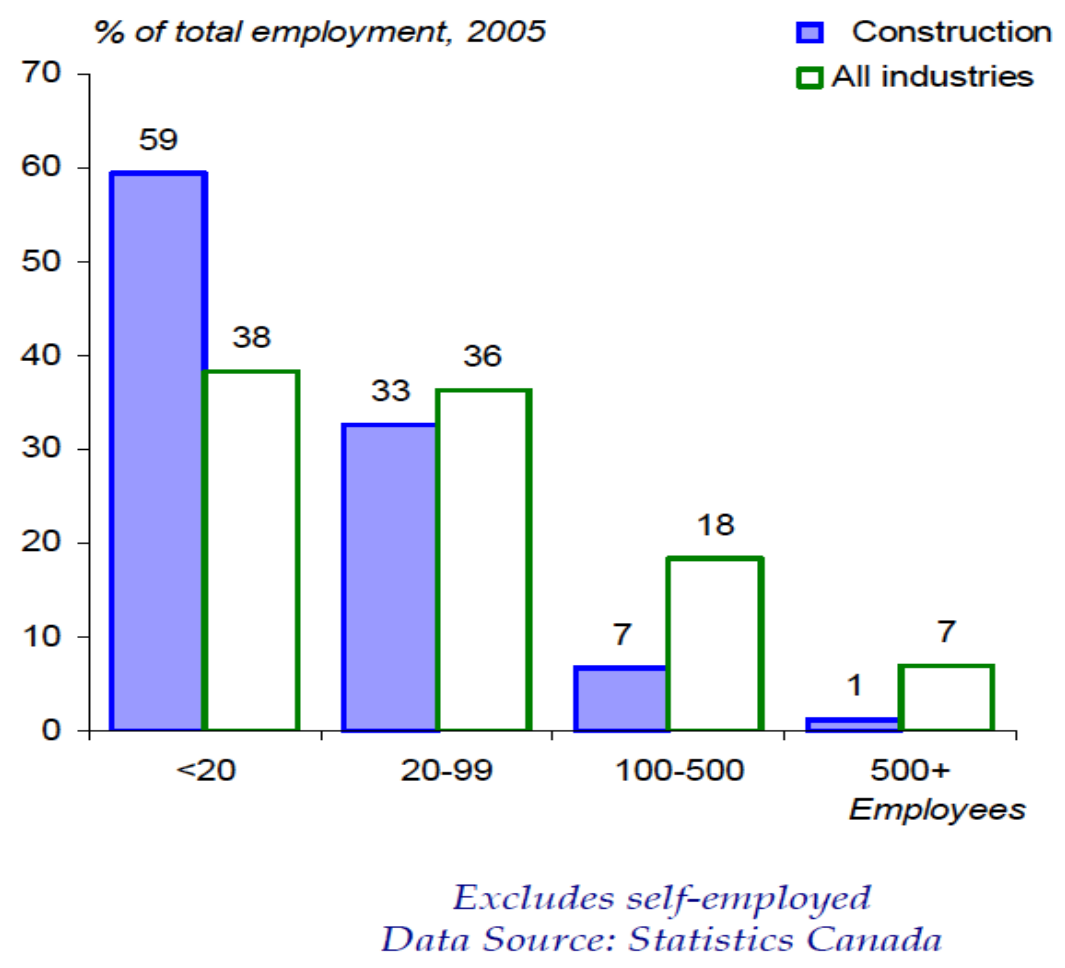

Figure 4: Distribution of BC construction companies by size Source: BC's Construction Industry Since 1990 (Hallin, 2006) 
However, if the cost can be reduced through the availability of cheaper workers who were productive at what they did, that is attractive to an employer. The elimination of the compulsory trades and the introduction of CBT created the conditions for the VET system to produce semi-skilled workers who were certified within components of their trade (BCGEU, 2003; Hyslop, 2012). The sectionalizing of the carpentry trade, which was already a voluntary trade, into sub-trades with the specific skills needed by the residential construction industry (for which wood was a primary building material), created a VET system that provided industry with a semi-skilled workforce that met their specific needs at a cheaper cost (J. Barrett, 2003). The training was paid for by the student (tuition), the province (public training facilities), and the federal government (grants). Two new sub-trades in carpentry were introduced in 2003 and were entitled the residential construction framing technician (specializing in framing the walls, floors, ceiling and roofs) and the construction formwork technician (specializing in installing temporary forms for pouring concrete foundations and structures (BC Hansard, 2005, Vol. 27, No. 7; Prism Economics and Analysis, 2017).

By breaking up the carpentry trade into these sub-trades, the semi-skilled worker could not command the wages of a fully qualified Journeyperson carpenter. Furthermore, given the high demand for their semi-skilled labour, they were less inclined to stop working to go back and complete the other modules of the carpentry trade that would allow them to get their CQ and the inter-provincially recognized Red Seal endorsement, as was explained by an employer practitioner: 
So you could go out on the job site, and when there were doors that needed to be framed, you were employed doing that as opposed to being a fully qualified carpenter that hung doors, you'd be a door framer, or a porch builder, or whatever. And so there was a strong move towards breaking up the trades (Practitioner 02).

Furthermore, even if the apprentice elected to seek additional competencies within the carpentry trade, they were unlikely to be rewarded with higher wages (like a level-two or level-three apprentice), since the construction companies now high an abundant supply of semi-skilled workers (Prism Economics and Analysis, 2017), and would hire them instead as was explained by interviewee who was on the Board of Directors and another who was a practitioner:

Taking the word 'apprenticeship' out of that crown agency [the ITA] really changed the whole direction. It was no longer about the individual, it was about the industry. And under Campbell and the folks that he had that were advising him and some of his Ministers, it was "just give them enough training so that they can be performing this task" (Governor 04 ITA).

Our sense of that, in the early days, was that those that were put forward by groups that wanted to narrow a skillset so that they could reduce the compensation that went with that skillset. And there were a number of examples like that (Practitioner 02).

This can be seen in Figure 5, obtained from the Registered Apprenticeship Information System (RAIS) collected by Statistics Canada, that shows the significant rise in new apprentices in the construction related trades (Prism Economic and Analysis, 2017). 


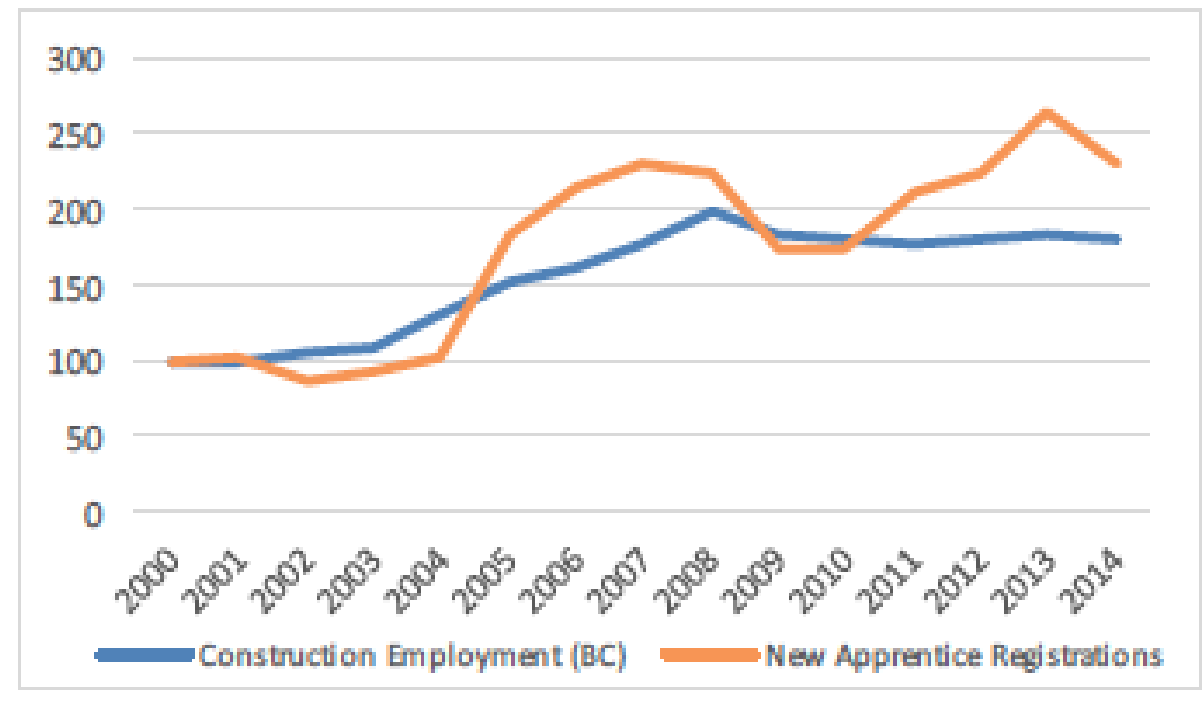

Figure 5: New apprentice registrations versus employment (BC construction) Index: Actual number is 20 times figure (i.e. $100=2000$ individuals)

Source: BC's (Not So) Great Apprenticeship Training Experiment - A Decade Reconsidered (Prism Economics and Analysis, 2017)

The unfortunate result for the semi-skilled carpenters was that they were limited to work in their sub-trade, and limited to working only within BC. As such the career prospects were poor. Furthermore, many of these semi-skilled workers were hired as sub-contractors rather than actual employees. As a result, they had little or no benefits; they were paid when they worked, often in cash, and had no employment security if they were hurt in the workplace (Governor 04 ITA and Practitioner 05), as highlighted by a couple practitioners:

A lot of the other trades were pretty much put out of business. For them, it went from piece work to cash for piece work...And I could walk you around bars outside of large developments on a Friday afternoon, and the big, fancy four-wheel drives, with the backseats full of thousands of dollars of cash being handed out...it's quite common to see (Practitioner 03). 
When there's no regulations the underground economy starts becoming an issue, and honest employers eventually throw in the towel when they continuously lose contract bids because they can't compete against people who don't pay CPP [Canada Pension Plan] or their WCB [Workers' Compensation Board] premiums, then they start doing the same thing.... So that side of the industry [residential construction] was still ruthless (Practitioner 06).

Thus, while the residential construction industry boomed, primarily in the lower mainland and greater Victoria areas of $\mathrm{BC}$, and the building companies made solid profits, the semi-skilled carpenters (amongst other trades) were challenged to find a solid career in these sub-trades. Furthermore, despite a rise in new apprentices that was registered by the ITA, the CQ completion rates stagnated, and the overall percentage of completions of apprenticeships in the carpentry trade went down (McDonald, 2014; Prism Economics and Analysis, 2017). This reflected the broader trend following the establishment of the ITA in 2003 in which completions in BC declined by four per cent, while the net result across Canada was a one per cent increase (compared with the previous three-year period), as in Figure 644:

\footnotetext{
${ }^{44}$ As previously stated in Chapter 2, apprenticeship data drawn from BC during this timeframe, or aggregated at the national level, must be used with caution due to the inherent errors resulting from inconsistencies in the use of terms, definitions and interpretations. As such, Figure 12 is meant to be illustrative only in terms of comparing the trends as an additional means to demonstrate that changes has occurred in and around the time that the ITA was created.
} 
post 2003

Figure 6: Apprenticeship completion rates (2000 - 2003 and 2004 - 2014)

Source: BC's (Not So) Great Apprenticeship Training Experiment: A Decade Reconsidered (Prism Economic and Analysis, 2017)

The other outcome was that despite an initial rise in interest for entry into these new carpentry sub-trades, the numbers began to decline around 2009 to the point where the courses were eventually dropped by 2013 , and the carpentry trade had gone full circle back to a full apprenticeship culminating with a CQ and Red Seal endorsement (Prism Economic and Analysis, 2017).

In terms of how apprenticeship outcomes affected the BC economy, it is noteworthy that the residential construction industry had been largely unregulated prior to the research period of interest. This changed in 1998 as a result of recommendations that were put forward by the Barrett Commission (1998) as a result of an extensive inquiry into the "leaky condo" crisis that had impacted thousands of home owners in $\mathrm{BC}$ as a results of a number of practices that had occurred in residential construction industry over the previous couple decades. The core of the Commission's finding were unequivocal: 
Pride in producing safe, quality housing has given way, much too often, to the hiring of unskilled labour; cutting corners at various stages of the building process; cutthroat competition; an underground cash economy; and too many occurrences of unreported, unethical practices. This situation is not the fault of the workers; rather, it is the developer or builder who is responsible for the skills of the people on site. The effect of pressured work schedules; lack of regard for skills and training; and a desire to keep wages low; has led to a downgrading of the caliber of work. This situation reflects badly on the entire industry (D. Barrett, 1998, Ch. 2, Sect. VII).

While the Commission put forward 82 separate recommendations, the core of the recommendations was the need to regulate the residential sector as is seen in three key recommendations below. The findings and recommendations were adopted by the municipality of Vancouver (where the majority of the problems had occurred), and the enforcement of these three recommendations was mandated to the ITAC, which then established a team of inspectors authorized to conduct random worksite inspections (Practitioner 05).

Recommendation \#22: That the residential construction industry be regulated under public authority through a Regulatory and Licensing arm of the Homeowner Protection Office (D. Barrett, 1998, Ch. 2, Sect. IV).

Recommendation \#34: Immediate and definite steps be taken to ensure that all compulsory trades required by law to be on site in a residential project, be enforced (D. Barrett, 1998, Ch. 2, Sect. VII).

Recommendation \#36: That any developer, builder, general contractor, or sub-trade, who employ compulsory trades to work on a residential construction site, must file a report listing the names and trade qualifications of all certified and apprentice trades on the job, and that this list form part of the necessary documentation to be provided to future strata councils and homeowners (D. Barrett, 1998, Ch. 2, Sect. VII). 
It didn't take long for certain elements of the construction industry to take notice of the effect of these new regulations, and to undertake efforts to influence the recently elected Liberal majority government (in May 2001) to consider legislative countermeasures as argued in a thought paper that was published in September, 2001by the Coalition of BC Businesses:

In the interest of worker safety, consumer protection and quality of training, ITAC has taken on the questionable role of a regulatory agency...given that other mechanisms, like WCB [Workers' Compensation Board], government inspectors...already safeguard against these concerns, one must question whether ITAC should mix a regulatory regime with its training mandate (Coalition of $\mathrm{BC}$ Businesses, 2001).

With the elimination of compulsory trades, as well as the downsizing of the staff of the newly created ITA in 2003, which eliminated the inspection branch (BC Hansard, 2003, Vol. 15, No. 2), the door was re-opened to practices that put the interests of the residential industry companies / employers ahead of the interests of the apprentices. While the ITA was recognized for its increase in new apprentices as a measure of success for the legislative reforms that had led to these changes (BC Hansard, 2005), the Auditor General of BC thought otherwise following the audit of the ITA in 2008:

One of the ITA's main responsibilities is to ensure a quality trades training system, which means making sure that apprentices receive current, relevant training...We found that the ITA's quality assurance practices are not sufficient to ensure the quality of trades program development and delivery (Doyle, 2008). 
This review is germane to one of the tensions experienced by apprenticeships as it pertains to the different perspectives on the VET curriculum, the training delivery methods and the value of the associated qualifications awarded to trades workers. The economic considerations of the employers in terms of cost savings (salaries and training costs) and labour disruptions (apprentices returning for their next phase of VET) were central to efforts by the ICBA, and supported by the Liberals, that continued to weaken the social settlement. Furthermore, the measures by which the ITA's success were evaluated were called into question when Premier Clark commissioned a comprehensive review in 2014 to assess its performance since it was established in 2003. One finding was that the ITA not only failed to incorporate an effective data analytics protocol to accurately measure progress with key indicators such as apprenticeship completion rates and Red Seal endorsements (McDonald, 2014). Rather, it focused on misleading results to claim success, such as the increase in new apprentices (despite stagnation in completion rates) and counting the rise in certificates issued (upon completion of CBT modules) rather than on Journeyperson CQs to claim success:

Successful completion of each level results in a credential. The goal of the initiative was accomplished; increasing the number of credentials issued nearly tenfold, from 116 to 971 credentialed Professional Cooks. However, while this increased the number of credentialed cooks available for job openings and doubled the number of registered apprentices, it did not change the actual proportion of apprentices reaching Red Seal completion, which remained at approximately 25\% (McDonald, 2014). 


\section{Appendix 8: The Value of Coordination Mechanisms - Examining the Joint}

\section{Apprenticeship Training Committee (JATC) Model}

The Canadian Apprenticeship Forum (2014)conducted a series of surveys with apprentices and employers, along with an analysis of data from the Registered Apprenticeship Information System (RAIS). A key point that was reinforced in the report was that mentoring, combined with training plans, were important practices towards successful retention in apprenticeship programs and completion of the Journeyperson certificate of qualification (CQ).

The regular monitoring of the training helps to ensure that gaps are identified and addressed. Targeted assignments linked to learning objectives, evaluation forms, journals, records of meeting, log books and bi-weekly meetings were tools used to provide structure...(Canadian Apprenticeship Forum, 2014).

This stands in contrast with the situation on and after the establishment of the Industry Training Authority (ITA) in 2003. The ITA staff were substantially reduced (compare with the Industry Training and Apprenticeship Commission), thereby eliminating the regional field mentors across the province and significantly reducing administrative support to the registered apprentices.

This situation of sub-optimal support for individual apprentices in British Columbia (BC) is worsened by the broader conditions that reflect the Liberal Market Economy (LME) typology and the stakeholder tensions associated with the predominant education logic as identified by Schuetze (2003) who explains: 
There also are structural reasons: the lack of investment in coordinated school-work pathways and the lack of employer interest in and commitment to employee training. Recent attempts by some provincial governments to link schools more closely to the workplace by prescribing work experience as part of the school curriculum and by promoting cooperative education and school apprenticeships have so far yielded only modest results.

Similar findings were published by Sharpe and Gibson (2005a) shortly after the period studied, which explained in greater detail the weaknesses in the coordination and support provided by the government in Canada (and in Anglo-Saxon countries), including in the all-important transitions into apprenticeships;

The disconnect between secondary education and the apprenticeship system is strongly reflected in the education system's academic bias, reinforcing the negative image of apprenticeship as a second-best option to university or college education (Sharpe \& Gibson, 2005a).

Conversely, when concerted efforts are made to develop coordination mechanisms, particularly between the employers, the training delivery agencies (TDAs), and the individual apprentices, completion rates improve. The union-based JATC model provides an example of such a coordinated approach, as was briefly mentioned in Chapter 2 (see Figure 7 which outlines completion rates for different types of apprentices). In this case, the mechanism that fosters the coordination is that of the collective agreement, the negotiated contract between a given union and its network of signatory employers. Within the terms of such collective agreements, is a funding formula for training programs which is the basis for supporting the JATC arrangement. It also provides the basis for commitments by employers to indenture an agreed upon number of apprentices based on anticipated work in the future. As 
such, the JATC is able to anticipate the number of new apprentices who can be indentured in a given trade, and can adjust the size of the cohort accordingly to ensure each individual has a guaranteed initial work placement upon completion of any designated pre-apprenticeship training or immediately upon selection if they already possess the necessary basic experience.

The JATC model is further enriched by a screening process for selecting potential apprentices, and a mentorship program that guides each of them through the successive levels of training and associated work assignments, providing support where necessary (MacLeod, 2009). For instance, if additional tutoring is required to get through a particularly challenging phase of their classroom vocational education and training (VET), it would typically be provided. Similarly, the work assignments would also be monitored to ensure each apprentice was rotated through different aspects of onsite work assignments to provide a broad base of exposure and experience. Employers would also contribute to the feedback process to identify areas of weaknesses or strengths, while feedback would be provided from the apprentices in regards to their assessment of the work experience they receive. The coordination mechanism would continue throughout each phase of the apprenticeship until completion of the CQ and the Red Seal endorsement. The outcome would be seen as a win-win-win for the JATC in that the apprentice has completed their apprenticeship, the union has gained another qualified Journeyperson, and the employers would have another well-rounded and qualified tradesperson to assign to their projects. 
While it would be misleading to promote the JATC as the ideal model for improving apprenticeship results, it does demonstrate how coordination is possible within an LME and a predominant education logic environment such as Canada. The main point is that the apprentice is the focus of the coordination, rather than being viewed as a commodity. This was emphasized in the McDonald report when reviewing the ITA and apprenticeship programs in BC; namely that "Despite various differences in views on many issues, we heard consistently that the key ingredients to high apprentice completion rates are screening, tracking and personal support" (McDonald, 2014). The report also provided a snapshot of the difference in completion rates in BC between the JATC model and that of apprentices going through a regular apprenticeships as shown in Figure 745. Of note, the "Union Orgs" represented approximately 12 per cent of all the ITA registered apprentices, while the "ICBA" were related to smaller (three per cent) cohort of apprentices involved in the Christian Labour Association of Canada (McDonald, 2014).

45 Although the data collected in BC must be used with caution and for illustrative purposes only, the data used for this chart is based on common terms and definitions, rendering it more reliable for comparing completion rates amongst the three categories provided. 


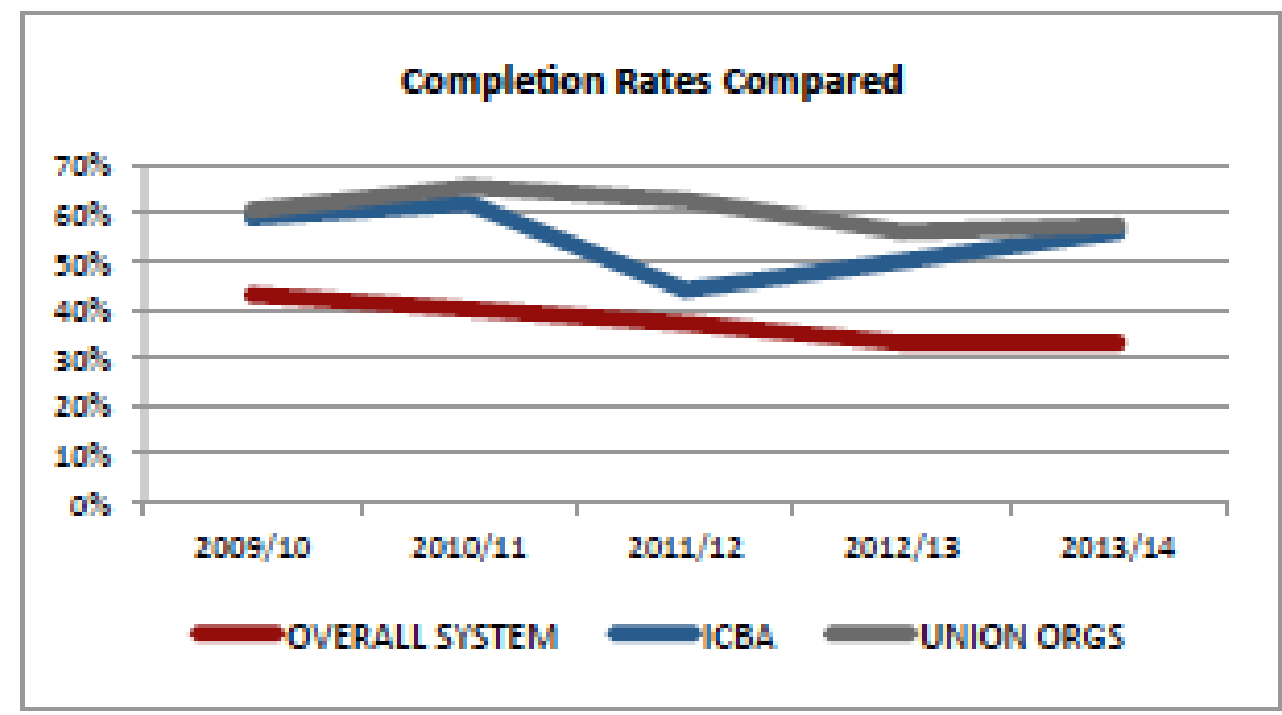

\section{Figure 7: Comparison of completion rates}

Source: The Industry Training Authority and Trades Training in BC: Recalibrating for High Performance (McDonald, 2014).

So, there are several key factors that are implicated in the success of apprenticeship programs in BC's LME that have been identified, yet the implementation repeatedly fell short of achieving government objectives. Given that apprenticeships are typified by an employment logic tendency with an active interest by employers in these programs, both during the apprenticeship phase as well as in increasing the pool of qualified Journeypersons graduating out of apprenticeship programs, the role of employers is crucial to the success of these programs. While the LME environment in $\mathrm{BC}$ creates significant pressures on employers to reduce costs so as to remain competitive, it is not unusual that they would seek to have training costs and risks transferred elsewhere (to the government, other employers and to the students who pay for their tuition expenses). Furthermore, despite the disproportionate number of small and medium-sized employers who provide jobs 
within BC's construction industry, these same market conditions create business risks that lead to dissuasion (rather than enticement) for such employers to invest in apprenticeship programs and to indenture apprentices (Busemeyer \& Vossiek, 2016).

However, the generic JATC model represents an example of how such extant business risks can be reasonably reduced through collaboration and distribution of such risks across several employers and stakeholders, rather than being imposed on employers individually. Such collaboration, and the associated investment into the careful selection, training and mentoring of quality apprentices provide the means for positive outcomes for the employers, apprentices and other stakeholders (such as the trade unions for the JATC model). Furthermore, such a collaborative approach would enable the apprenticeship ecosystem to benefit from a greater pool of employer sponsors, namely the small and medium sized employers, if the model sufficiently reduced the risk and costs to these employers. Given the interest by various $\mathrm{BC}$ governments of different political ideologies to improve the VET system, attract more British Columbians into apprenticeships, and to increase the skilled workforce in the province, the government would have a strong basis for providing the necessary support to attract these employers to enter into such collaborative arrangements.

Thus despite the predominant pressures that can be conceptually attributed to the extant educational logic tendency and the LME environment, government-led 
initiatives to adopt such a model of collaboration and coordination of the apprenticeship programs in $\mathrm{BC}$ could potentially reduce the gap in the stakeholder tensions that can be seen as differences between intrinsic and institutional logics, and reverse the trend in the social settlement amongst the primary stakeholders towards one of convergence. 


\section{References}

Al-Yateem, N. (2012). The effect of interview recording on quality of data obtained: a methodological reflection. Nurse Researcher, 19(4), 31-35.

Barbash, J. (1968). Union Interests in Apprenticeship and Other Training Forms. Journal of Human Resources, 3(No. 1), 63-85.

Barrett, D. (1998). The Renewal of Trust in Residential Construction - Commission of Inquiry into the Quality of Condominium Construction in British Columbia. Victoria, BC: Queen's Printer.

Barrett, J. (2003). A Response by the British Columbia and Yukon Territory Building and Construction Trades Council to the Discussion Paper: A New Model For Industry Training In $B C$. Retrieved from Burnaby, British Columbia: BC Building Trades Council.

Bates, R. H. (1998). Analytic narratives. Princeton, NJ: Princeton University Press.

BC Hansard. (1971). Budget Speech. Victoria, British Columbia: Queen's Printer.

BC Hansard. (1994). Bill 37 - Skills Development and Fair Wage Act. Victoria, British Columbia: Queen's Printer.

BC Hansard. (1997). Bill 43 - Industry Training \& Apprenticeship Act. Victoria, British Columbia: Queen's Printer.

BC Hansard. (2001). Bill 22 - Skills Development and Fair Wage Repeal Act. Victoria, British Columbia: Queen's Printer.

BC Hansard. (2003). Bill 34 - Industry Training Authority Act. Victoria, British Columbia: Queen's Printer. 
BC Hansard. (2005). Throne Speech Debate. Victoria, British Columbia: Queen's Printer.

BC Hydro. (2016). Apprenticeships. Retrieved from https://app.bchydro.com/careers/students_grads/apprenticeships.html

BC Ministry of Finance. (2004). Budget and Fiscal Plan 2004/5 - 2006/7. Victoria, BC: Queens Printer.

BCFED. (2012). Apprenticeship \& Skills Training - Report to Convention. 55th Federation Convention - Vancouver. Retrieved from https://bcfed.ca/sites/default/files/SUMMARY\%200F\%20PROCEEDINGS\% 202012.pdf

BCGEU. (2003). A response by the British Columbia Government and Service Employees' Union to the discussion paper - A New Model for Industry Training in British Columbia. Retrieved from http://www.bcgeu.ca/sites/default/files/bcgeu_itacbriefjan031.pdf

Bond, S. (2015). 2015/16 Mandate Letter to ITA Chair. Victoria, BC: Office of the Minister JTST Jobs, Tourism, Skills and Training. Retrieved from http://www.itabc.ca/sites/default/files/docs/about-ita/letter-ofexpectation/Mandate Letter 2015-16.pdf.

Bosch, G., \& Charest, J. (2008). Vocational training and the labour market in liberal and coordinated economies. Industrial Relations Journal, 39(5), 428-447.

Bourke, B. (2013). Our jobs aren't being stolen...The BC government is selling them. Retrieved from http://www.bcbuildingtrades.org/Temporaryforeignworkersaren'tstealingo urjobs

Bowen, G. A. (2009). Document analysis as a qualitative research method. Qualitative Research Journal, 9(2).

Bowles, S., \& Gintis, H. (2011). Schooling in Capitalist America - Educational Reform and the Contradictions of Economic Life. Chicago: Haymarket Books. 
British Columbia Construction Association. (1997). APPRENTICESHIP: A CONSTRUCTION INDUSTRY PERSPECTIVE. Retrieved from Victoria, BC: BC Archives.

Brockmann, M., Clarke, L., \& Winch, C. (2011). Knowledge, Skills and Competence in the European Labour Market: What's in a vocational qualification? London, UK: Routledge.

Brown, J., Donald Thomas and Robert Crocker. (2010). Motivation to Enter Apprenticeship - 2007 National Apprenticeship Survey. Ottawa, Ontario: Human Resources and Skills Development Canada.

Brunello, G. (2009). The Effect of Economic Downturns on Apprenticeships and Initial Workplace Training: A Review of the Evidence. Retrieved from http://ftp.iza.org/dp4326.pdf

Brydon, R., \& Dachis, B. (2013). Access Denied: The Effect of Apprenticeship Restrictions in Skilled Trades. Ottawa, ON: C.D. Howe Institute.

Buchanan, J., et al. (2016). Beyond mentoring: social support structures for young Australian carpentry apprentices. Retrieved from https://www.ncver.edu.au/publications/publications/all-publications/2865

Buchanan, J., Schofield, K., Briggs, C., Considine, G., Hager, P., Hawke, G., . . Ryan, S. (2001). Beyond Flexibility: Skills and Work in the Future. Retrieved from http://www.bvet.nsw.gov.au

Busemeyer, M. R., \& Vossiek, J. (2016). Global Convergence or Path Dependency? Skill Formation Regimes in the Globalized Economy. In K. A. G. B. L. A. V. Mundy (Ed.), The Handbook of Global Education Policy (pp. 169-185): John Wiley \& Sons, Ltd.

Cadieux, B. (2010). Factors Influencing Completion of Apprenticeship - 2007 National Apprenticeship Survey. Ottawa, Ontario: Queens Printer. 
Canadian Apprenticeship Forum. (2004). Accessing and Completing Apprenticeship Training in Canada: Perceptions of Barriers. Retrieved from http://caffca.org/reports/page/7/

Canadian Apprenticeship Forum. (2007). Apprenticeship Labour Market Outcomes in Canada since 2000: An Assessment of the Resources for Research. Retrieved from http://caf-fca.org/reports/page/6/

Canadian Apprenticeship Forum. (2011). Investigating Apprenticeship Completion in Canada: Reasons for Non-Completion and Suggested Initiatives for Improving Completion. Retrieved from http://caf-fca.org/reports/

Canadian Apprenticeship Forum. (2012). Apprenticeship Analysis: Registration and Completion in 2010. Retrieved from http://caf-fca.org/reports/page/4/

Canadian Apprenticeship Forum. (2013). Apprenticeship Analysis - Youth Perceptions of Careers in the Skilled Trades. Retrieved from http://caffca.org/reports/page/2/

Canadian Apprenticeship Forum. (2014). Supporting Apprentice Success: Apprenticeship Data, Trends and Observations. Retrieved from http://caffca.org/reports/

Canadian Apprenticeship Forum. (2016a). Apprentice Mobility in Canada. Retrieved from http://caf-fca.org/reports/

Canadian Apprenticeship Forum. (2016b). Apprenticeship 101. Retrieved from http://caf-fca.org/apprenticeship-in-canada/apprenticeship-101/

CCDA. (2014). 2014 Annual Review. Ottawa, Ontario: Human Resources and Skills Development Canada.

Clark, C. (2014). B.C.'s Skills for Jobs Blueprint: Re-engineering Education and Training [Press release]. Retrieved from https://www.workbc.ca/TrainingEducation/B-C-s-Skills-for-Jobs-Blueprint/Learn-about-Blueprint.aspx 
Coalition of BC Businesses. (2001). The Industry Training and Apprenticeship Commission - What is its Future? Retrieved from http://www.coalitionbcbusiness.ca/pdf/Itac\%20paper.pdf

Conference Board of Canada. (2002). Solving the Skilled Trades Shortage - A Feasibility Report Examining the Barriers and Solutions to Youth Participation in the Skilled Trades in Canada and Proposing the Development of Pilot Projects to Increase the Supply of Youth nto the Skilled Trades. Ottawa, Ontario: Human Resources and Skills Development Canada.

Cowin, B. (2012). Apprenticeship And Pre-Apprenticeship Training. Made In B.C. - A History of Postsecondary Education in British Columbia, 5. New Westminster, BC: Douglas College.

Cowin, J. R. (2017). PUBLIC POLICY AND THE STRUCTURAL DEVELOPMENT

OF POSTSECONDARY EDUCATION IN BRITISH COLUMBIA, CANADA, 1960 - 2015. (PhD). Vancouver, BC: University of British Columbia.

Creswell, J. W., \& Creswell, J. D. (2018). Research Design - Qualitative, Quantitative, and Mixed Methods Approaches (5th ed.). Thousand Oaks, CA: SAGE Publications Inc.

Crocker, R. (2014). Apprenticeship Completion, Certification and Outcomes. Ottawa, ON: Queens Printer.

Crocker, R., \& al., e. (2010). National Apprenticeship Survey 2007 - Profile of Participants. Ottawa, ON: Human Resources and Skills Development Canada.

Crocker, R., Trent Craddock, Marjorie Marcil, and John Paraskevopoulos. (2010). National Apprenticeship Survey 2007 - Profile of Participants. Ottawa, ON: Human Resources and Skills Development Canada.

Culpepper, P. D. (2001). Employers, Public Policy, and the Politics of Decentralized Cooperation in Germany and France. In P. A. Hall, and David Soskice (Ed.), Varieties of Capitalism - The Institutional Foundations of Comparative Advantage (pp. 251-271). Oxford, UK: Oxford University Press. 
Dawson, J. (2010). Thick Description. In A. J. Mills, G. Durepos, \& E. Wiebe (Eds.), Encyclopedia of Case Study Research. doi:10.4135/9781412957397.n347

Deissinger, T., \& Gremm, D. (2017). The Status of VET in Canada: Evidence from Literature and Qualitative Research. In F. Marhuenda-Fluixá (Ed.), Vocational Education beyond Skill Formation - Vet between Civic, Industrial and Market Tensions (Vol. 15, pp. 293-317). Bern, Switzerland: Peter Lang AG.

DiCicco-Bloom, B., \& Crabtree, B. F. (2006). The qualitative research interview. Medical Education, 40(4), 314-321.

Dolby, N., and Greg Dimitriadis. (2004). Learning to Labor in New Times. New York, NY: RoutledgeFalmer.

Doyle, J. (2008). A Major Renovation: Trades Training in British Columbia. Victoria, British Columbia: Queens Printer.

Ecclestone, K., Gert Biesta, and Martin Hughes. (2010). Transitions in the lifecourse The role of identity, agency and structure. In K. Ecclestone, Gert Biesta, and Martin Hughes (Ed.), Transitions and Learning Through the Lifecourse (pp. 115). New York, NY: Routledge.

Estevez-Abe, M., Iversen, T., \& Soskice, D. (2001). Social Protection and the Formation of Skills: A Reinterpretation of the Welfare State. In P. A. Hall, and David Soskice (Ed.), Varieties of Capitalism - The Institutional Foundations of Comparative Advantage (pp. 145-183). Oxford, United Kingdom: Oxford University Press.

Ferguson, M. (2017). Report 5 - Temporary Foreign Worker Program - Employment and Social Development Canada. Retrieved from http://www.oagbvg.gc.ca/internet/English/parl_oag_201705_05_e_42227.html

Finegold, D. (1999). Creating self-sustaining, high-skill ecosystems. Oxford Review of Economic Policy, 15(1), 60-81. 
Fisher, D., KjellRubenson, Jones, G., \& Shanahan, T. (2008). The political economy of post-secondary education: a comparison of British Columbia, Ontario and Quebec. Higher Education, 57, 549-566.

George, A. L., \& Bennett, A. (2005). Case Studies and Theory Development in the Social Sciences. Cambridge, Massachusetts: MIT Press.

Goard, D. H. (1977). Report of the Commission on Vocational, Technical, and Trades Training in British Columbia. Victoria, BC: Queens Printer.

Goedbloed, D. L. (2014). What do they mean by skilled? A Critical Discourse Analysis of skills policies for apprenticeship in Canada and British Columbia: 1980-2010. (Doctor of Education PhD), University of British Columbia, Vancouver, BC. Retrieved from https://open.library.ubc.ca/media/download/pdf/24/1.0165969/1

Gonon, P. (2008). Innovation and the Swiss Vocational Education and Training System. Paper presented at the Situated Competence Development through Innovative Apprenticeships - The Role Of Different Stakeholders. Retrieved from http://www.oeibf.at/db/calimero/tools/proxy.php?id=12774

Green, A., Mostafa, T., \& Preston, J. (2010). The Chimera of Competitiveness: Varieties of Capitalism and the Economic Crisis. London, U.K.: University of London.

Gunderson, M. (2013). Completion Counts: Raising Apprenticeship Completion Rates in Ontario's Construction Industry. Toronto, Ontario: Ontario Construction Secretariat.

Haddow, R. (2008). How malleable are political - economic institutions? The case of labour - market decision - making in British Columbia. Canadian Public Administration, 43(4).

Hall, P. (2015). The Fate of the German Model. In B. Unger (Ed.), The German Model Seen by its Neighbours (pp. 43-62). London, UK: SE Publishing. 
Hall, P. A. (2006). Systematic process analysis: when and how to use it. European Management Review, 3(1), 24-31.

Hall, P. A. (2013). Tracing the progress of process tracing. European Political Science, 12(1), 20-30.

Hall, P. A., \& Soskice, D. (2001). An Introduction to Varieties of Capitalism (P. A. Hall, and David Soskice Ed.). Oxford, United Kingdom: Oxford University Press.

Hall, P. A., \& Thelen, K. (2009). Institutional change in varieties of capitalism. SocioEconomic Review, 7(7-34).

Hall, R. (2008). Social Research: planning, designing and conducting real-world research. South Melbourne: Palgrave Macmillon.

Hallin, L. (2001). An introduction to $B C^{\prime}$ 's economy. Victoria, British Columbia: BC Stats.

Hallin, L. (2006). BC's Construction Industry Since 1990. Victoria, British Columbia: BC Stats. Retrieved from http://www.bcstats.gov.bc.ca/Publications/AnalyticalReports.aspx.

Harris \& Company LLP. (2003). BILL 34 - INDUSTRY TRAINING AUTHORITY ACT. Retrieved from Legal News website http://www.harrisco.com/resources/legal-news/122

Heinrichs, B. (2015). Canada's Broken Compulsory Trades System. Retrieved from Calgary, Alberta:

Hurrell, K. (2010). The Impact of Compulsory Certification on Apprenticeship in Canada - 2007 National Apprenticeship Survey. Retrieved from Ottawa, Ontario: http://www.red-seal.ca/others/n.1s_r.2g.5l.1t.3.4n-eng.html

Hyslop, K. (2012, 02 July 2012). BC's Job Trainers in Trouble - As demand for skilled tradespeople grows, so does pressure on the Industry Training Authority to 
fill the gap. The Tyee, p. 7. Retrieved from

https://thetyee.ca/News/2012/07/02/JobTrainersInTrouble

Iannelli, C., \& Raffe, D. (2007). Vocational Upper-Secondary Education and the Transition from School. European Sociological Review, 23(No. 1), 49-63.

ITA. (2016). Apprenticeship Basics. Retrieved from http://www.itabc.ca/aboutapprentices/apprenticeship-basics

Johncox, G. (2001a). Compulsory Certification in Selected Trades - Where to from here in $B C$ ? Retrieved from Vancouver, British Columbia:

Johncox, G. (2001b). Compulsory Certification in Selected Trades - Where to from here in $B C$ ? Vancouver, British Columbia: Coalition of BC Businesses.

Jothen, K. (2001). Unlocking ITAC: Reforming \& Repositioning "ITAC" as BC's flagship for work-based skills planning, standards \& credentialing. Retrieved from the author.

Labour, B. F. o. (2013). Independent Review of the ITA's Role and Function Jessica McDonald, Review Leader. Vancouver, BC: British Columbia Federation of Labour.

Laporte, C., and Richard Mueller. (2010). The Persistence Behaviour of Registered Apprentices: Who Continues, Quits, or Completes Programs? Vancouver, BC: British Columbia Federation of Labour.

Laporte, C., \& Mueller, R. (2013). The completion behaviour of registered apprentices in Canada: who continues, who quits, and who completes programs? Empirical Research in Vocational Education and Training, 5(No. 1).

Lassnigg, L. (2011). The 'duality' of VET in Austria: institutional competition between school and apprenticeship. Journal of Vocational Education \& Training, 63(3), 417-438. 
Laurie, I. (2013). 'ALL THE WORLD'S A STAGE': ACTING OUT THE GOVERNMENTSUPPORTED APPRENTICESHIP PROGRAMME IN ENGLAND. (PhD), University of Southampton. Retrieved from http://eprints.soton.ac.uk/358504/

Lee, M. (2004). State of the BC Economy 2004. Ottawa, ON: Canadian Centre for Policy Alternatives.

Lehmann, W., Taylor, A., \& Wright, L. (2015). Youth apprenticeships in Canada: on their inferior status despite skilled labour shortages. Journal of Vocational Education \& Training, 66(4), 572-589.

Levy, J. S. (2008). Case Studies: Types, Designs, and Logics of Inference. Conflict Management and Peace Science, 25(No. 1), 1-18.

Lowndes, V., \& Roberts, M. (2013). Three Phases of Institutionalism Why Institutions Matter: The New Institutionalism in Political Science (pp. 18-45). New York, USA: Palgrave Macmillan.

Lyons, J., Randhawa, B., \& Paulson, N. (1991). The Development of Vocational Education in Canada. Canadian Journal of Education, 16(2), 137-150.

Macdonald, J. B. (1962). Higher Education in British Columbia and a plan for The Future. Vancouver, BC: University of British Columbia.

MacLeod, C. D. (2009). Guide to Best Practices for Joint Apprenticeship Committees in the Electrical Industry. Ottawa, ON. National Electrical Trade Council.

Mandryk, J. (2014). The Case for a Stronger Fair Wage Policy in Ontario. Retrieved from

https://www.policyalternatives.ca/sites/default/files/uploads/publications /2014/05/Fair_Wage_FINAL.pdf

McClelland, R. H. (1984). The Future of Apprenticeship. Victoria, BC: Ministry of Labour. 
McDonald, J. L. (2014). The Industry Training Authority and Trades Training in BC: Recalibrating for High Performance. Victoria, British Columbia: Queen's Printer.

McDowell, J. (2011). A shared responsibility - Apprenticeships for the 21st Century: Final Report of the Expert Panel. Retrieved from http://www.australianapprenticeships.gov.au/sites/default/files/publicatio n-documents/Apprenticeshipsforthe21stCenturyExpertPanel_0.pdf

McMartin, W. (2009, 23 Apr 2009). BC's Economy: Whose Was Best? The Tyee. Retrieved from https://thetyee.ca/Views/2009/04/23/BCEcon/

Meredith, J. (2011). Apprenticeship in Canada: where's the crisis? Journal of Vocational Education \& Training, 63(No. 3), 323-344.

Miles, M. B., Huberman, A. M., \& Saldana, J. (2014). Qualitative Data Analysis - A Methods Sourcebook (3rd Ed. ed.). Thousands Oaks, CA: SAGE Publications Inc.

Minister of Education Science and Technology, \& Minister of Labour. (1979). Second Report of the Task Force on Pre-Employment and Pre-Apprenticeship Training Programs in British Columbia. Victoria, BC: Queen's Printer.

Ministry of Advanced Education. (2002). DIscussion Paper: A New Model for Industry Training in British Columbia. Victoria, BC: Queen's Printer.

Ministry of Education. (1982). Training Access Announced [Press release]

Ministry of Education Science and Technology, \& Ministry of Labour. (1979). FIrst Report of the Task Force on Pre-Employment and Pre-Apprenticeship Training Programs in British Columbia. Victoria, BC: Queen's Printer.

Ministry of Labour. (1997). Revitalizing Apprenticeship: A Strategic Framework for $B C$ 's Apprenticeship Training System. Victoria, BC: Queen's Printer. 
O'Leary, Z. (2014). Secondary Data: Documents, Data Sets and Online Data. In J. Seaman (Ed.), The Essential Guide to Doing Your Research Project (pp. 243273). London, United Kingdom: Sage Publications Ltd.

OECD. (2018). Education at a Glance 2018 - OECD Indicators. Retrieved from http://dx.doi.org/10.1787/eag-2018-en

Oliver, D., Yu, S., \& Buchanan, J. (2018). Political Economy of Vocational Education and Training. In U. a. Gailie (Ed.), Handbook of Vocational Education and Training (pp. TBC). London: Routledge.

Orren, K., \& Skowronek, S. (1994). Beyond the Iconographyof Order: Notes for a "New Institutionalism". In L. C. D. a. C. Jillson (Ed.), The Dynamics of American Politics: Approaches and Interpretations (pp. 311-330). New York, US: Routeledge.

Peterson, L. R. (1967). Annual Report for the Year Ended December 31 1966. Victoria, BC: Queen's Printer.

Powell, J. J. W., Bernhard, N., \& Graf, L. (2012). The Emergent European Model in Skill Formation : Comparing Higher Education and Vocational Training in the Bologna and Copenhagen Processes. Sociology of Education, 85(3), 240-258.

Powell, J. J. W., \& Solga, H. (2010). Analyzing the nexus of higher education and vocational training in Europe: a comparative - institutional framework. Studies in Higher Education, 35(6), 705-721.

Prism Economic and Analysis. (2017). BC's (Not So) Great Apprenticeship Training Experiment: A Decade Reconsidered. Retrieved from http://bcfed.ca/sites/default/files/attachments/BCFED_apprenticeship_trai ning_reprint_Feb_2018_web.pdf

Raffe, D. (2008). The Concept of Transition System. Journal of Education and Work, 21(No. 4), 277-296. 
Raffe, D. (2011). National Qualifications Frameworks: What Can Be Learnt From the International Experience? Journal of Education and Work, 21(No. 4), 66-80.

Raffe, D., Croxford, L., \& Howieson, C. (1994). The Third Face of Modules: Gendered Patterns of Participation and Progression in Scottish Vocational Education. British Journal of Education \& Work, 7(3), 87-104.

Rauner, F., \& Smith, E. (2010). Introduction - Rediscovering apprenticeship. In F. Rauner, and Erica Smith (Ed.), Rediscovering Apprenticeship (pp. 1-7). Dordrecht, The Netherlands: Springer.

Rauner, F., Smith, E., Hauschildt, U., \& Zelloth, H. (2009, 17-18 Sep 2009). Innovative Apprenticeships - Promoting Successful School-to-Work Transitions. Paper presented at the INAP Conference, Turin, Italy. Retrieved from http://download.springer.com/static/pdf/679/bok\%253A978-90-4813116-7.pdf

Sashaw, K. (2011). A Tale of Two Decades - How effective policies benefit communities, support construction and create jobs. Vancouver, British Columbia: Vancouver Regional Construction Association.

Sayer, A. (1992). Method in Social Science - A Realist Approach (2nd ed.). London, UK: Routledge.

Schuetze, H. G. (2003). Alternation Education and Training in Canada. In R. Sweet, and Hans G. Schuetze (Ed.), Integrating school and workplace learning in Canada: principles and practices of alternation education and training (pp. 6692). Montreal, Quebec: McGill-Queen's University Press.

Schugurensky, D. (2004). The tango of citzenship learning and participatory democracy, 607-617. Toronto, ON: University of Toronto, Ontario Institute for Studies in Education.

Selman, G. (1995). Adult Education in Vancouver before 1914 Adult Education in Canada - Historical Essays. Toronto: Thompson Educational Publishing Inc. 
Sharpe, A., \& Gibson, J. (2005a). The Apprenticeship System in Canada: Trends and Issues. Ottawa, Ontario: Centre for the Study of Living Standards.

Sinclair, J. (2017). We Build BC - History of the BC Building Trades (C. Rose Ed.). New Westminister, British Columbia: BC Building Trades.

Skolnik, M. L. (2010). A Look Back at the Decision on Transfer Function at the Founding of Ontario's Colleges of Applied Arts and Technology. Canadian Journal of Higher Education, 40(2), 1-17.

Smith, E., and Ros Brennan Kemmis. (2013). Towards a model apprenticeship framework: A comparative analysis of national apprenticeship systems. Retrieved from http://www.ilo.org/wcmsp5/groups/public/---asia/---robangkok/---sro-new_delhi/documents/publication/wcms_234728.pdf

Stake, R. E. (1978). The Case Study Method in Social Enquiry. Educational Researcher, 17(2), 5-8.

Starman, A. (2013). The case study as a type of qualitative research. Journal of Contemporary Educational Studies(1), 28-43.

Statistics Canada. (2018). Pathways and earnings indicators for registered apprentices in Canada. Retrieved from www150.statcan.gc.ca/n1/dailyquotidien/181205/dq181205b-eng.htm

Statistics Canada. (2019). Number of apprenticeship program registrations. Retrieved from www150.statcan.gc.ca/t1/tbl1/en/cv.action?pid=3710002301\#timeframe

Statistics Canada. (2019). Supplement to Statistics Canada's Generic Privacy Impact Assessment related to the Education and Labour Market Longitudinal Platform. Retrieved from http://www.statcan.gc.ca/eng/about/pia/generic/educationlabour

Stewart, G., \& Kerr, A. (2010). A Backgrounder on Apprenticeship Training in Canada. Canadian Apprenticeship Forum, 1. 
Strand, K. (1991). BC Task Force Report on Employment and Training 1991. Victoria, BC: Ministry of Advanced Education, Training and Technology.

Streeck, W. (1997). German capitalism: Does it exist? Can it survive? In C. C. W. Streeck (Ed.), Political Economy of Modern Capitalism - Mapping Convergence and Diversity (pp. 33-54). Thousand Oaks, CA, US: SAGE Publishers Inc.

Streeck, W. (2011). Skills and Polititics: General and Specific. Max Plank Institute for the Study of Societies, 11(1), 1-32.

Swars, E. (2014). Getting Qualified for Employment - How the dual-track VET system in Switzerland matches skills development and the needs of the labor market. Paper presented at the KRIVET International Seminar, Seoul, South Korea. Retreived from http://www.voced.edu.au/content/ngv\%3A65685

Taylor, A., \& Watt-Malcom, B. (2010). Opportunities and constraints related to vocational education partnerships in Canada. Retrieved from: http://www.ccl-cca.ca/pdfs/FundedResearch/Taylor_FullReport.pdf

Technical Education Matters. (2009). The Guilds and ApprenticeshipsA Short History of Technical Education: Technical Education Matters. Retrieved from http://www.technicaleducationmatters.org/2009/05/10/book-references/.

The Coalition of BC Businesses. (2001). The Industry Training and Apprenticeship Commission - What is its Future? Vancouver, British Columbia: The Coalition of BC Businesses.

Thelen, K. (1999). Historical Institutionalism in Comparative Politics. Annual Review of Political Science, 2(No. 1), 369-404.

Thelen, K. (2004). How Institutions Evolve: The Political Economy of Skills in Germany, Britain, the United States, and Japan. Cambridge, U.K.: Cambridge University Press.

Thelen, K. (2012). Varieties of Capitalism: Trajectories of Liberalization and the New Politics of Social Solidarity. Annual Review of Political Science, 15, 137-159. 
van Vught, F. (2008). Mission Diversity and Reputation in Higher Education. Higher Education Policy, 21, 151-174.

Watt-Malcolm, B., \& Barabasch, A. (2010). Opportunities and constraints related to vocational education partnerships in Canada. Retrieved from: http://www.ccl-cca.ca/pdfs/FundedResearch/Taylor_FullReport.pdf

Wheelahan, L. (2015). The future of Australian vocational education qualifications depends on a new social settlement. Journal of Education and Work, 28 (No. 2), 126-146.

Wheelahan, L., \& Moodie, G. (2016a). Global Trends in TVET: A framework for social justice. Education International(November 2016), 85.

Wheelahan, L., \& Moodie, G. (2017). Vocational education qualifications' roles in pathways to work in liberal market economies. Journal of Vocational Education \& Training, 69(1), 10-27.

Wheelahan, L., Moodie, G., \& Buchanan, J. (2012a). Revitalising the 'vocational' in flows of learning and labour. Retrieved from https://www.ncver.edu.au/wps/portal/vetdataportal/restricted/publicatio nContent/

Wheelahan, L., Moodie, G., \& Buchanan, J. (2012b). Using the 'transition systems' literature to understand the position of VET in Australia. Paper presented at the AVETRA 15th Annual Conference, Canberra, Australia. Retrieved from http://avetra.org.au/publications/conference-archives/conference-2012papers

Willis, Paul E. (1978). Learning to Labour - How working class kids get working class jobs. Farnborough, United Kingdom: Saxon House Teakfield Ltd.

Yin, R. K. (1994). Case Study Research - Design and Methods (Second ed.). London, United Kingdom: Sage Publications. 
Young, M. (2003). Comparing Approaches to the Role of Qualifications in the Promotion of Lifelong Learning. European Journal of Education, 38(2), 199211. 